\title{
Pathogenesis of Viral Infections
}

\author{
J. HAY and M.J. BARTKOSKI, JR.
}

\section{A. Introduction}

This introductory chapter is an attempt to combine our knowledge of the general features of viral replication studied at the molecular level (usually in cell culture) with some information on the course and outcome of infection (insofar as it can be studied) in the whole animal. A comprehensive review of molecular virologic studies would be so diverse that it would be beyond the scope of this chapter and would probably be superfluous for the majority of readers. However, some remarks on the underlying principles of the immune response to viral infection and on viral pathogenesis seem to be appropriate, along with some specific comments on integration of viral DNA into cell genomes and on defective interfering particles. Paradoxically, the host's immune response to virus infection can play several roles: it can provide both short- and long-term assistance in combating the infection, but also may be at least partially responsible for development of disease symptoms.

Three types of antibody are involved in the antiviral humoral immune response. The first of these which an infecting virus may encounter is $\operatorname{IgA}$, secreted locally onto mucous surfaces of the gut and respiratory tract in response to the presence of virus at that site. Viremia, which may or may not (depending on the virus) follow from initial virus infection, leads to major production of $\mathrm{IgG}$ and $\operatorname{IgM}$, the former persisting for long periods and the latter quickly disappearing. These immunoglobulins will prevent (by neutralization) the spread of cell-released virus throughout the body via body fluids. Cell-to-cell transmission of virus, on the other hand, is probably prevented by cell-mediated responses which have been programmed to recognize viral antigens and lyse cells carrying them. This may involve T-lymphocytes and/or macrophages in a number of complex interactions whose relative importance for a given disease is not well worked out.

Contributions to the pathogenesis of a disease can be made in several ways: nephritis can result from the deposition in the kidney of antibody-antigen (virus) complexes with complement to give a cell-mediated inflammatory response, or virus which grows in lymphocytes (such as cytomegalovirus) may set up a markedly lymphoproliferative condition. These are just two examples of what is likely to be, once our knowledge of these cell-mediated responses in general is more developed, a major feature of viral pathogenesis. A further factor in the spread of virus infection is interferon, which is induced in variable amounts by different viruses and to which individual viruses are differentially susceptible. 
Virus can enter the organism by a number of routes. Infection through contact with respiratory tissues is frequent and normally gives rise to fairly localized virus multiplication and consequent local symptoms: the rhinoviruses are a good example of this category. Other viruses, which have structures that can survive the gut environment, infect and multiply in the gastrointestinal tract, and may spread to other body sites to multiply further and cause disease signs there. Genital contact and insect bites are two other important sources of virus infection.

When virus spreads in the body, it usually does so via the blood, reaching special target organs (e.g., hepatitis) or spreading less specifically (e.g., disseminated zoster). In some cases viremia may be maintained over long periods by chronic infections of the reticuloendothelial system. The skin (and mucous membranes) is a target organ for several different viruses, and multiplication of virus at sites on the body surface (via viremia) combines with the immune response to give characteristic rashes. Central nervous system infections can be set up by direct virus growth along nerves (e.g., rabies) or by virus growth in tissues adjacent to the central nervous system (e.g., in the choroid plexus).

The period between initial contact with the virus and the onset of obvious signs of disease is the incubation period, and this can be a variable length of time, depending on the virus. For most infections it is in the range of 2-3 days to 2-3 weeks, and is a direct consequence of the route of pathogenesis in the host. The incubation period is also a useful parameter to bear in mind for each virus infection, since it usually determines the treatment that is likely to be useful.

Most of what has been outlined so far has dealt with acute virus infections, characterized by virus multiplication, developing and disappearing over a relatively short period. However, several viruses can establish a persistent infection, in which virus may be shed over long periods at low levels, or latent infections, in which the virus escapes detection. In these cases the virus may be reactivated to cause an acute infection at a later date. Slow virus infections produce chronic fatal progressive illnesses over long periods, normally through degeneration of nerve tissue.

\section{Defective Interfering Particles}

Defective interfering (DI) particles can be produced by a large number of virus groups (and conceivably by all viruses) and are formed in cell culture after multiple passage, usually at high multiplicity of infection (m.o.i.) or in the infected host animal as a consequence of natural infection. These particles are defective in that they contain viral genome material with deletions, both large and small. Indeed, the genome need not code for any recognizably normal virus polypeptide, but must be able to be replicated (enzyme recognition site) and to be packaged in the virus particle (packaging sequences). DI particles cannot replicate in the absence of helper (usually standard) virus but will interfere with the normal replication of standard virus.

It was postulated by HUANG and BALTIMORE (1970) that production of DI virus was a natural means of modulating virus infections. This has been amply demonstrated both in the animal and in cell culture; it is quite feasible to prevent the onset of disease (e.g., with influenza) with DI preparations in infected animals. The 
mechanism of interference is not entirely understood; however, it probably involves direct interference at the level of virus replication as well as the immune response and interferon production. In addition to preventing acute infection, DI virus may be a major factor in the establishment of persistent infections in cases in which standard virus infection is usually acute. While the mechanism of this change is again obscure, it is significant that the cell has a role in the formation of DI virus.

\section{Integration of Viral Genomes}

Another mechanism of achieving a persistent infection in animal cells is demonstrated by several groups of viruses which are capable of integrating their genome into the genome of the host cell. The retroviruses are RNA viruses which can integrate their genetic information into germ line cells of susceptible species through a DNA intermediate. In this way, the "provirus" is passed on from generation to generation; although gene expression is usually quite severely repressed, and induction of the provirus usually quite difficult.

All the DNA viruses which replicate in the nuclei of cells, of course, share this ability to become integrated into cell DNA and this has been shown to take place during normal lytic infection. The extent of this integration detected appears to be increasing as technology develops; however, a role for integration of viral DNA in lytic infections has not been defined.

On the other hand, as a feature of cell transformation by DNA viruses, integration seems to have an important part to play: either it ensures that modification or expression of cellular genes is heritably based, or that viral genes are stably present, in the correct copy number and appropriately controlled. Generally, transformed cells which are able to cause tumors in susceptible animals carry integrated viral sequences with them into the tumor cells. One hypothesis to explain "abortively transformed" cells is that true integration was never established to give stable association of viral and cell DNA, but this has not been rigorously shown.

Another function of integrated genomes may well be in the establishment of a latent (or persistent) infection: in this case the whole genome is integrated, as opposed to cell transformation, in which only part of the viral DNA complement is required. Inherent in the latency model is a means by which the integrated genome can be activated and allowed to be replicated in the cell. Much work, it is clear, still remains to be done to explain the phenomenon. What follows this general introduction is a description of the many virus types important in human disease.

\section{B. Adenoviruses}

Adenoviruses have, in all likelihood, been the cause of outbreaks of acute respiratory disease in military recruit populations for many years, but only recently have they been diagnosed as such (DINGLE and LANGMUIR 1968). Most children have, by the end of their first year, been infected with an adenovirus, and in about onehalf of these, obvious disease is seen, normally a rather nonspecific respiratory illness (Fox et al. 1969). 


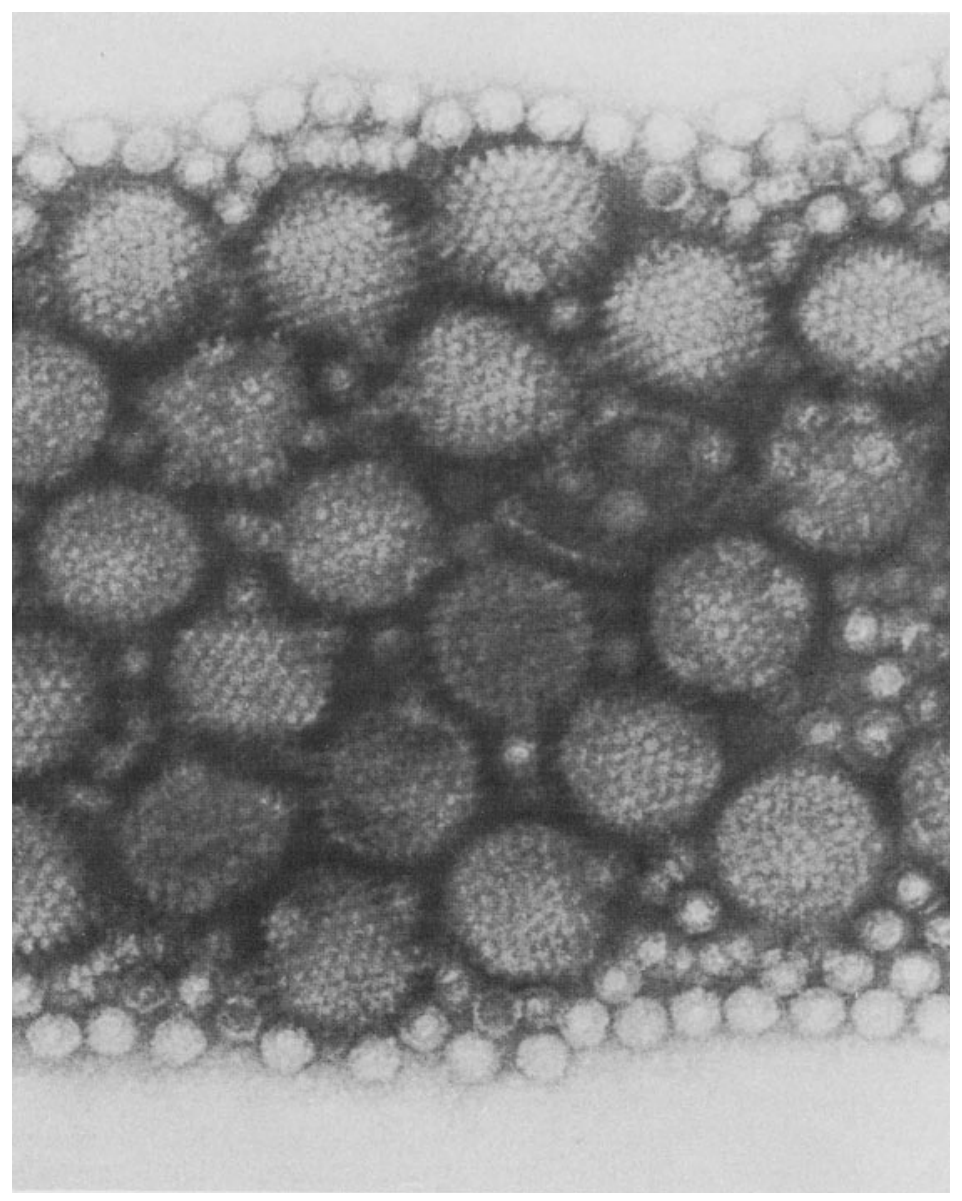

Fig. 1. Adenovirus type 18 ( $80 \mathrm{~nm}$ diameter) preparation banded on a $\mathrm{CsCl}$ density gradient. The preparation is contaminated with adeno-associated virus, a parvovirus $(20 \mathrm{~nm}$ diameter). (Courtesy of C. GARON and J.ROSE)

\section{Structure and Replication}

Adenoviruses have a unique structure, an icosahedron of 252 capsomeres, 240 hexons with 12 penton proteins (which consist of a base and a fiber) surrounding a nucleoprotein core structure and having no envelope (Fig. 1). The 240 hexon proteins have 3 identical polypeptides (molecular weight about $10^{5}$ daltons) and carry the type-specific as well as type-common antigens (MAIZEL et al. 1968; WILCOX and GINSBERG 1963). The fiber contains three polypeptides (molecular weight about 60,000 daltons), and is phosphorylated and glycosylated (ISHIBASHI and MaIZEL 1974; RUSSEL et al. 1972), while the penton base protein has four or five polypeptides of molecular weight 70,000-80,000 daltons associated noncovalently with the fiber (MAIzel et al. 1968). Three basic core proteins (V, VII, X) are complexed with DNA in the center of the particle (LAVER 1970) and several other minor polypep- 
tides can also be found associated with the virus structure (GINSBERG and YounG 1977). An endonuclease, specific for DNA, is also present in the virion.

The viral DNA is a linear double strand of molecular weight $20-25 \times 10^{6}$ daltons and the strands can be separated. The human adenoviruses contain 31 serotypes which have 5 DNA homology subgroups (A-E), (GREEN et al. 1979a). Subgroup $\mathrm{C}$ (type $1,2,5,6$ ) is the most common cause of childhood infection. Recently, it has been suggested that intermediate strains of adenovirus exist, which carry a single type of neutralizing antigen, but hemagglutinins of two different strains (HIERHOLZER et al. 1980). The DNA has an inverted terminal repetition which allows formation of single-stranded circles (GARON et al. 1972; ARRAND and ROBERTS 1979).

In subgroup $\mathrm{C}$ adenovirus, the $5^{\prime}$ terminus of the DNA is covalently bound to a protein of molecular weight 55,000 daltons (REKOSH et al. 1977; a fourth core protein). It increases infectivity of viral DNA in vitro (SHARP et al. 1976) but is not related (structurally) to any of the viral proteins recognized so far (HARTER et al. 1979).

The fiber of the virus particle attaches to the surface of a susceptible cell, but the identity of the specific recognition site is not clear (LEVINE and GINSBERG 1967). The particle passes through the plasma membrane of the host cell and then starts to disintegrate; the pentons are removed first and the capsid follows to leave the core structure. The uncoating process may be host specified (SuSSENBACH 1967). Migration to the nucleus follows, where replication is initiated by transcription from the viral DNA; whether this is carried out on naked DNA or on a still partially coated molecule is not known. The naked viral DNA is infectious at about $10^{9} \mathrm{pfu}^{\mathrm{m} \mathrm{mol}^{-1}}$ (GRAHAM and VAN DER EB 1973).

The host cell's RNA polymerase II (presumably unmodified) produces initially five distinct "early" transcriptional units, which can be synthesized in the presence of cycloheximide (NEVINS et al. 1979; Fig. 2). Each of these is produced with different kinetics with the unit for the 72,000 dalton DNA-binding protein appearing last, conceivably a reflection of that protein's controlling role in gene expression. All of the mRNAs corresponding to these early DNA regions appear to be the product of posttranscriptional splicing (BERK and SHARP 1978) and several sizes of mRNA are generated from each region. The early $1 \mathrm{~B}$ region, for example, encodes three mRNAs and three proteins, protein IX, a 15,000, and a 52,000 dalton polypeptide (HALBERT et al. 1979). The final number of early adenovirus polypeptides is still in doubt; there may be as many as seven polypeptides encoded by the transforming region (the left-hand end, 0-11 map units on the genome, see Fig. 2) alone (HALBERT et al. 1979). At about $6 \mathrm{~h}$ postinfection, DNA synthesis starts and is followed by the production of late mRNA species, all formed from a very large transcription unit reaching from 16 to 99 units on the genome, under the influence of a single promoter region (ZIF and Evans 1978; Fig. 2). While late transcription occurs, only some of the early transcription units decline in production, e.g., unit 4 (NeVINS and WINKLER 1980). These late mRNAs all have the same $5^{\prime}$ end (which is "capped") and appear to be polyadenylated before splicing (NEVINS and DARNELL 1978). The viral transcipts appear as mRNAs in the cytoplasm and at late times consist chiefly of structural polypeptides: the first of them to appear is the hexon protein, and all are made in great excess (GREEN 1970). As late transcription 

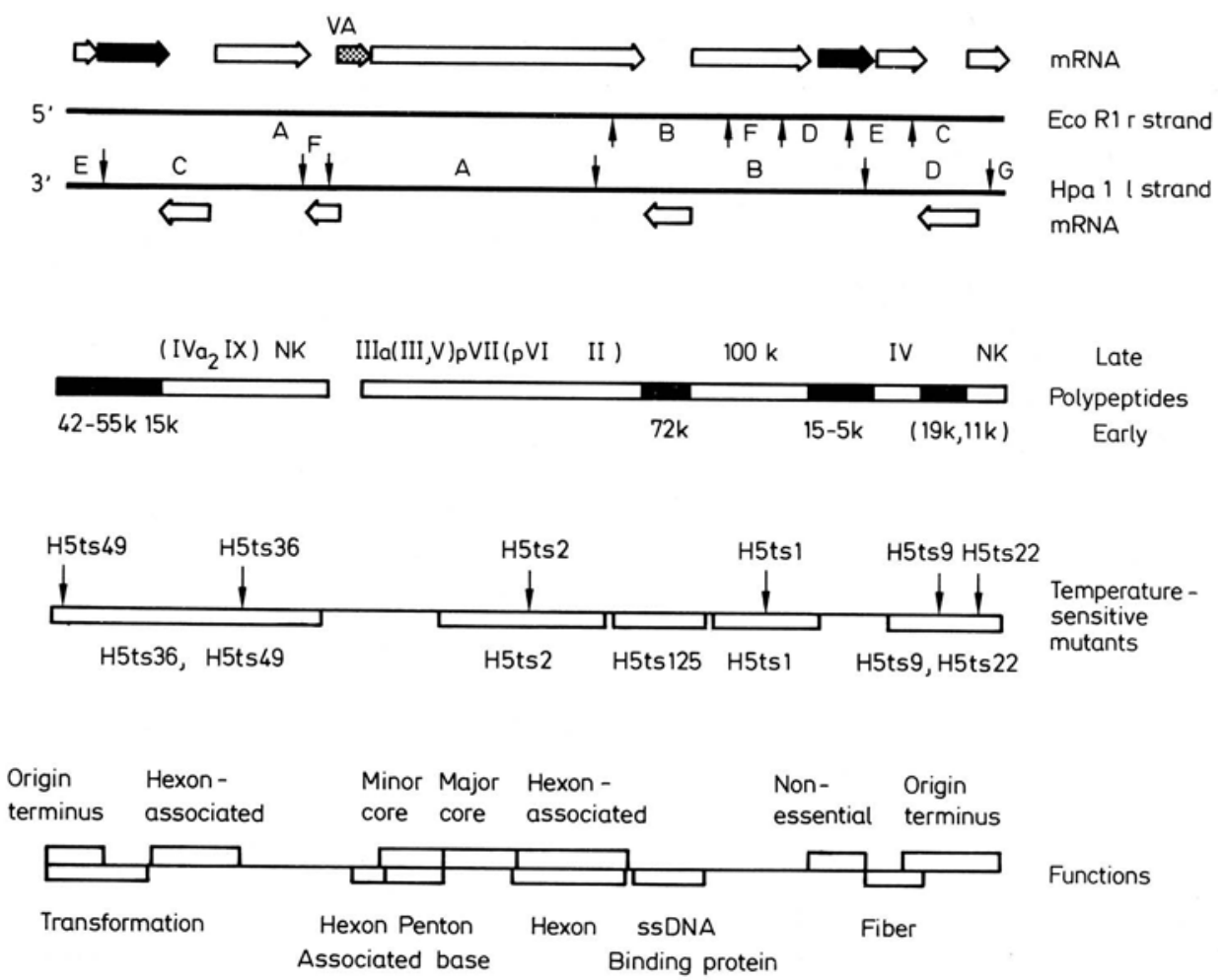

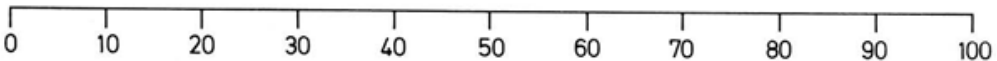

Fig. 2. The adenovirus genome is shown by horizontal lines, 0-100 units, in each part of the figure. In the map of mRNA sequences, the two lines represent the $r$ and 1 strands of Ad2 DNA; the vertical lines indicate sites of cleavage by Eco R1 and Hpa 1. The arrows above and below the genome depict the regions to which mRNA is complementary; genes for the nonmessenger RNA, VA RNA, are indicated by the stippled area. In this, and the map of polypeptides shown below, solid areas indicate early viral gene products, whereas open areas show late products. In the polypeptide map, parentheses indicate uncertainty in order. (FLINT 1977)

starts, a large increase in the amount of viral RNA produced takes place with viral DNA (or its replication) playing a major role. However, it does not seem that a DNA replicative intermediate is the target for late transcription (BRISON et al. 1979).

Viral DNA synthesis cannot start without early protein synthesis, but it is not yet clear how many early products are required: genetic studies suggest three, one of which is the 72,000 dalton DNA-binding protein (VAN DER VLIET and LEVINE 1973). It has been possible to isolate nucleoprotein complexes from adenovirus-infected cells which will elongate and terminate viral DNA synthesis, but not initiate it (WILHELm et al. 1976). Viral DNA in such complexes has been shown to be associated with several proteins which may assist in DNA synthesis in vivo. Among 
them are the viral 72,000 dalton DNA-binding protein, the cellular DNA polymerase $\alpha$ and $\gamma$ (but not $\beta$ ), a DNA ligase, and the cell's RNA polymerase II (ARENS et al. 1977). Presumably this list is incomplete since the system does not initiate, and genetic studies suggest more than one viral product is involved: as a corollary, not all of the above activities may be necessary in vivo. Initiation of DNA synthesis needs the 72,000 dalton DNA-binding protein, possibly also the 55,000 dalton terminal protein (REKOSH et al. 1977), and takes place at the terminus of one strand of the molecule. The subsequent elongation displaces a parental strand which is independently used as a template in the subsequent continuous synthesis of the second new strand (WINNAKER 1978). The inverted terminal repeat has been sequenced (STERNBERGH et al. 1977) and has clusters of GC and AT-rich regions analogous to those seen in other DNA initiation sites, but the mechanism of initiation (e.g., involvement of RNA primer, etc.) and of successful completion of adenovirus DNA molecules remains obscure.

The various components of the virus structure gather in the nucleus where a likely sequence of events is capsid proteins $\rightarrow$ capsid structures, light intermediate $(7-11 S$ DNA) $\rightarrow$ heavy intermediate (34 $S$ DNA) $\rightarrow$ young virions (36 $S$ DNA) $\rightarrow$ mature virions (34 $S$ DNA); (D'HALluIN et al. 1978). During these steps, two proteins are associated with and then leave the structure $(50,000$ and 39,000 dalton, possibly scaffolding proteins), while precursors to the core proteins V and VII are cleaved (EVERITT et al. 1977). Empty capsids have recently been shown to associate with one molecule of viral DNA in vitro (TIBBETTS and GIAM 1979). The inclusion bodies seen in adenovirus-infected cells appear to be aggregates of excess structural proteins and viral DNA, and mature adenovirions are only seen in the cytoplasm when the nuclear membrane has been breached to allow release of virus. Release from the cell presumably depends on rupture of the cytoplasmic membrane. Adenoviruses catalyze a rather slow decrease in cell functions after infection and the penton fiber protein has been characterized as responsible for these processes.

The human adenoviruses, while not as yet implicated in human oncogenesis, have the property of causing tumor formation and cell transformation in rodents and rodent cells. On the basis of oncogenicity, the following subgroups of the adenovirus serotypes can be recognized: A - highly oncogenic (high frequency of tumor formation in newborn rodents); B - weakly oncogenic (low frequency of tumor formation), and C, D, E which do not cause tumors directly, but can transform cells in tissue culture (GREEN et al. 1979a). The transforming region of the DNA is at the extreme left-hand end and probably ranges from about $8 \%$ to $4.5 \%$ of the adenovirus genome (DIJKEMA et al. 1979). Although there is much similarity among members of one group (MARKEY et al. 1979), different subgroups have different transforming sequences which may explain the old observation that different T antigens are made by the different groups (HEUBNER 1967). A number of candidate transformation proteins have been described with molecular weights in the range 10-65,000 daltons (LEwIS et al. 1976; GREEN et al. 1979) and seem to be similar in size among the virus group examined.

The mechanism (or mechanisms) for tumor formation is thus not well understood, but viral sequences do seem to persist in transformed cells. Transformed cells also frequently contain copies of viral DNA sequences other than those at the extreme left-hand end (GALLIMORE et al. 1974). 
In view of the easily demonstrable oncogenic potential of human adenoviruses, interest has been aroused in their possible involvement in human oncogenic disease. It was recently reported that "normal" human placenta and liver and various primate tissues had adenovirus DNA sequences, including the left-hand end of the adenovirus genome (JoNES et al. 1979). On the other hand, GREEN et al. (1979c) examined a large number of normal and tumoral human tissues for adenovirus DNA sequences with no apparent success. In the same study, multiple copies of the adenovirus genome were shown to be present in tonsil tissue from which it is possible to cultivate adenovirus. Restriction enzyme analysis of the DNA from tonsils showed unusual patterns which suggested that some of the viral DNA might be integrated into the cell genome. Also, since adenovirus frequently becomes latent in tonsil tissue, this finding may have a bearing on the mechanism of latency establishment by adenovirus.

In the course of adenovirus infection, incomplete or defective particles may accompany normal infectious virions; these usually retain some viral functions (e. g., cell-killing ability) but may not be infectious (MAK 1971). Some particles have a DNA genome derived from host cell DNA (TJIA et al. 1977) and others, viral DNA with deletions (MAK et al. 1979). The former type of particle probably resulted from aberrations in the final assembly process in the infected cell. Generation of at least one class of incomplete DNA molecule has been proposed to take place via DNA replication read-through past looped-out regions related to possible splicing mechanisms (MAK et al. 1979). The role of adenovirus defective particles in normal infection has not been elucidated.

Adenovirus mutants have been isolated from a number of laboratories (for review see GINSBERG and YoUNG 1977) and both complementation and recombination have been demonstrated to occur. Recombination maps for adenovirus type 5 (Ad5; Williams et al. 1974; GinsBerg and Young 1977) and adenovirus type 2 (Ad2; BÉGIN and WEBER 1975) have been constructed and give remarkably good correlation (two factor crosses) with each other $(2,5)$ and with the physical maps of the genome which have been constructed. There are 13 complementation groups of Ad2 and Ad12 (BÉGIN and WeBER 1975; SHIROKI and SHIMOJo 1974) and mutants within one complementation group seem to cluster on the recombination map. Adenovirus-SV40 hybrids can be isolated from monkey cells (normally nonpermissive for adenovirus) upon coinfection with the two viruses. Sequences of the SV40 early region can replace part of the AD2 genome and presumably supply a helper function.

Ad2-infected cells produce, in large amounts late in infection, virus-associated (VA) RNA with a major (1) and a minor (2) component (HARRIS and ROEDER 1978) which has the same 156 nucleotides as (1) plus an extra 38-40 at the $3^{\prime}$ end. These RNAs have no certain function but a recent hypothesis suggests (MURRAY and HOLLIDAY 1979) that their role may involve binding across a splice point of heterogeneous nuclear RNA to allow formation of the true message.

\section{Adenovirus Infections}

The endemic adenoviruses (group $\mathrm{C}$, types, 1, 2, 5, 6) tend to infect children to give respiratory infections; infection with types 3 and 7 , on the other hand, frequently 
leads to pharyngoconjunctival fever, which occurs in epidemics. Acute respiratory disease (ARD) in recruits is usually caused by Ad4 (or Ad7) in epidemics (DuDDING et al. 1973) and epidemic keratoconjunctivitis is frequently caused by Ad8 (GRAYSTON et al. 1964).

Transmission occurs via several routes to give characteristic disease: for example, eye infections can be acquired in swimming pools. The most frequent route of spread, however, is a fecal-oral one, to give respiratory illness. In general, illness is acute and self-limiting in terms of symptoms, but the virus may continue to be shed for long periods after symptoms have disappeared. Viremia may develop in some cases and result in the formation of a rash which can be confused with rubella (GUTEKÜNST and HEGgIE 1961). Tonsils are a source of virus in about one-half of the child population, and adenovirus is presumed to inhabit this tissue in a latent form, although no one knows exactly what the state of the virus is under these circumstances (Evans 1958). Type-specific antibody is produced upon infection, and is protective. Young children (with residual maternal antibody) seem less prone to adenovirus infections, a probable reflection of the protective power of circulating antibody.

The incubation period appears to be about 1 week, and in the rare fatal case of adenovirus infection, virus is present in essentially all body organs. An interesting correlation appeared during the New York Virus Watch program: mumps infection appeared to stimulate the production of adenovirus, conceivably by triggering the release of the latent state (Fox et al. 1969).

Vaccination against adenovirus infection has been shown to be successful, but has been limited to the military population. Inactivated monkey-cell-grown virus preparations were used initially but suffered from variable potency and contamination problems (PIERCE et al. 1968). Now a live vaccine is used, presented in a capsule whose contents are released only in the gastrointestinal tract, to give reliable immunity without respiratory tract infection. Since there is still concern about a possible role of adenovirus in tumorigenesis and since the virus is spread quite effectively through populations (STANLEY and JACKSON 1969), there are no plans at present to use the vaccine on children or the general population.

\section{Arenaviruses}

The arenaviruses are a recently characterized group of viruses which derive their name (Latin harenosus, sandy) from the electron-dense granules (host ribosomes) found in variable numbers in the virus particles (CARTER et al. 1973; FARBER and RAWLS 1975). The viruses in this group include lymphocytic choriomeningitis (LCM) virus, Lassa fever virus, and the Tacaribe group of viruses (Machupo, Junin, Tacaribe, Tamiami, Parana, Latino, Pichinde, and Atmapari). Of these viruses only Lassa fever, Machupo, Junin, and LCM are known to cause human disease; LCM virus causing a sporadic, and relatively mild meningoencephalitis, while the other three may cause a serious, highly fatal hemorrhagic fever.

The virions of the arenaviruses are pleomorphic in shape, approximately 80 $130 \mu \mathrm{m}$ in diameter (MURPHY and WHITFIELD 1975) and its outer shell is a unit membrane derived from the host cell through budding (Fig. 3). The genome con- 


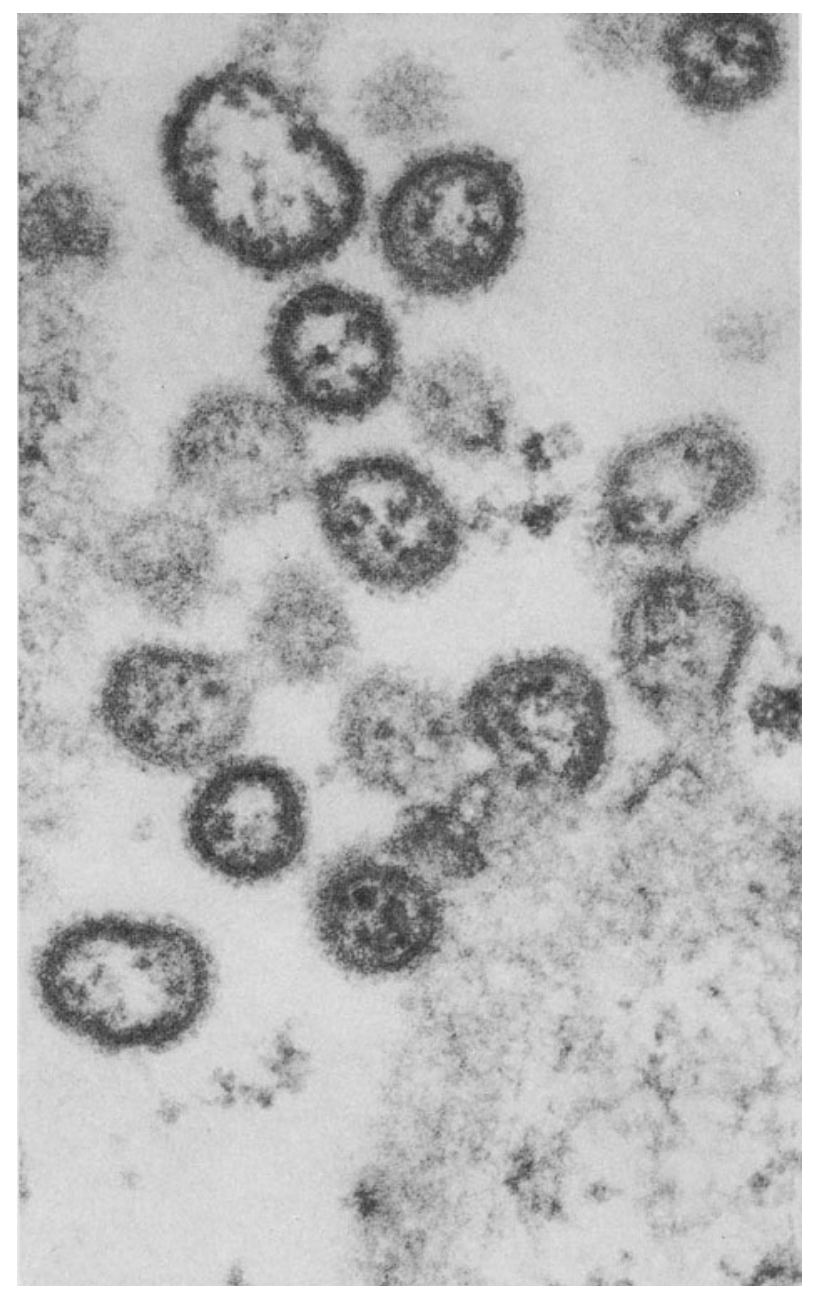

Fig. 3. Arenaviruses. Photograph shows Lassa fever virus in first cell passage after isolation from a patient in Sierra Leone. The envelope, surface projection layers, and internal ribosomes are well resolved. (Courtesy of F.A. MURPHY) $\times 121,000$

sists of two major size classes of RNA, L (molecular weight $3.2 \times 10^{6}$ daltons) and S(molecular weight $1.6 \times 10^{6}$ daltons; FABER and RAWLS 1975), as well as variable amounts of host cell RNA species (VEZZA et al. 1978). As a consequence of their segmented genome these viruses show a high frequency of genetic recombination (VezzA and Bishop 1977). There appear to be four main structural proteins, two of which are glycoproteins, probably representing components of the viral envelope (RAmos et al. 1972) and the virion is also reported to contain a RNA polymerase (CARTER et al. 1974). The replication cycle of the arenaviruses is not well defined, but high multiplicity passage of undiluted stocks of virus may lead to the production of DI particles (HUANG and BALTIMORE 1977). Studies with macrophages from 
mice infected with LCM virus demonstrated that these cells were resistant to infection with a homologous, but not a heterologous virus (MIMS and SUBRAHMANYAN 1966). A quantitative assay for these DI particles based on interference with infectious center formation by wild-type virus has been worked out (WELSH and PFAU 1972). The DI particles cannot be separated from the wild-type virus (WELSH et al. 1972) but the variability in host response to arenavirus infection may indicate an important role for these particles in normal infection (WOODWARD and SMITH 1975).

Rodents appear to be the natural host of the arenaviruses. The virus population in nature is maintained by chronic infection of the host, usually by perinatal inoculation; the result is chronic lifetime infection, with many animals showing a total lack of immunologic response. In contrast, inoculation of adult animals results in an acute (often fatal) disease with a normal immunologic response. Infection of humans (as is the case with many diseases) is accidental and the disease is acquired after coming into contact with excreta from an infected animal. Infection of humans with LCM, as with all arenaviruses, is classified as a zoonosis. The spread of LCM in most human cases is not well documented, but is throught to be through infected aersols and contact with infected rodent urine (FARMER and JANEWAY 1942; Himan et al. 1975). Person-to-person spread has not been shown except for Lassa fever (MONATH 1975). LCM infection begins with fever, chills, and myalgia which may occur after an incubation period of 5-10 days, with symptoms of meningitis usually starting 15-23 days after exposure (MANDELL et al. 1979). There is no specific treatment available but human deaths are rare.

LCM infection in mice is a classic example of a virus-induced immunopathologic disease, and for this reason its pathogenesis deserves special mention. The virus is transmitted congenitally to every mouse in an infected colony. The mice are born "normal" and remain "normal" for most of their lives. Throughout this time they have persistent viremia and viruria and nearly all cells in the animal are infected. Circulating free antibody is not detectable as the virus circulates in the bloodstream in the form of a virus-IgG complex which is infectious. Late in life these mice may show "late" disease. This late disease is due to the deposition of the antigen-antibody (virus-IgG) complexes in the glomeruli, resulting in glomerulonephritis. In the adult mice, a different response is seen. Intracerebral inoculation results in the stimulation of the immune response, causing a fatal choriomeningitis with no evidence of neuronal damage. Immune suppression of the adult mice protects against death due to the virus, even though viral growth is similar in both suppressed and nonsuppressed animals. Further work has suggested that cell-mediated rather than humoral immunity is responsible for the lesions. A similar relationship between virus and natural host may be true for many of the arenaviruses.

Lassa fever and the remaining arenaviruses which infect humans, in contrast to LCM infection, may produce a fatal hemorrhagic fever. Lassa fever is primarily a disease of West Africa (Frame et al. 1970; BuCKLEY and CASALS 1970), but has spread to other areas of the world, resulting in sporadic outbreaks (LEIFER et al. 1970). Lassa fever virus, unlike other arenaviruses, may on occasion be spread in groups such as health care workers owing to their intimate contact with infected patients. The spread in these nosocomial outbreaks may be through parenteral in- 
oculation of infected fluids, close contact, or airborne spread (MONATH 1975). The symptoms of Lassa fever range from a mild or subclinical disease to a fulminant, often fatal condition. Following an incubation period of 1-2 weeks symptoms including fever, chills, malaise, myalgia, and diarrhea begin (MONATH and CASALS 1975). By the end of the first week the symptoms worsen and mouth lesions, exudative pharyngitis, and pulmonary symptoms appear. Edema, along with a petechial rash of neck and face, may occur. In the second week of symptoms a shock syndrome may appear, characterized by loss of intracellular mass through capillary leakage, vasoconstriction, hypotension, kidney failure, and pulmonary edema; myocarditis may also be present. There are hemorrhages, but of insufficient amount to produce the shock. At this point, either the patient dies or convalescence begins. Mortality in hospitalized cases averages about $36 \%$. The diagnosis may be made serologically or by virus isolation, but this should be attempted only in a maximum containment laboratory.

Machupo and Junin viruses, the cause of Bolivian hemorrhagic fever (BHF) and Argentinian hemorrhagic fever (AHF), respectively, have similar clinical symptoms as well as being antigenically related (JOHNSON 1977). The diseases are often multisystem, involving the renal, hematopoietic, and clotting systems. Fever is high and sustained for 5-8 days. Patients often appear to be intoxicated and very sick, with fever, malaise, and myalgia (MANDELL et al. 1979; JOHNSON 1977). As the illness progresses, significant hemorrhagic as well as neurologic manifestations may be seen. Mortality averages $10 \%-20 \%$.

Infection by arenaviruses may be prevented by blocking transmission, from rodents or infected persons. Rodent control has been shown to work for both BHF and lymphocytic choriomeningitis (HINMAN et al. 1975; MACKENZIE 1965). Treatment is supportive and may be lifesaving. Vaccines are available for Junin and Machupo virus and may be of some benefit. No vaccine is available for LCM or Lassa fever (JoHNSON 1975).

\section{Coronaviruses}

The coronaviruses belong to the family Coronaviridae. The human strains of this family are morphologically similar to the infectious bronchitis virus (IBV) of chickens, mouse hepatitis virus (MHV), and transmissible gastroenteritis virus (TGE) of swine (TYRRELL et al. $1968 \mathrm{a}$ ). The term corona refers to the crown-like appearance of the particle surface projections (TYRRELL et al. $1968 \mathrm{~b}$ ). The first human strain was isolated in 1965 from a patient suffering from a cold (TYRRELL and BYNOE 1965) but the virus proved resistant to growth in common tissue culture and grew only after several passages in organ culture (TYRRELL and BYNOE 1965). The newer isolates of the virus have proved equally difficult to grow, and only two human strains, 229E and OC43 have been adapted to tissue culture (MCINTOSH 1979).

The coronaviruses are enveloped RNA viruses, approximately $80-120 \mathrm{~mm}$ in diameter, with helical nucleocapsides (Fig. 4). The genome has been shown to be composed of a single-stranded, nonsegmented, RNA of positive polarity (messenger sense) and having a molecular weight of 5-6 $610^{6}$ daltons (LAI and Stohlman 1978). A molecular weight in excess of $8 \times 10^{6}$ daltons has also been reported (LOMNICZI and KeNNEDY 1977; TANNOCK 1973; MACNAUGHTON and 


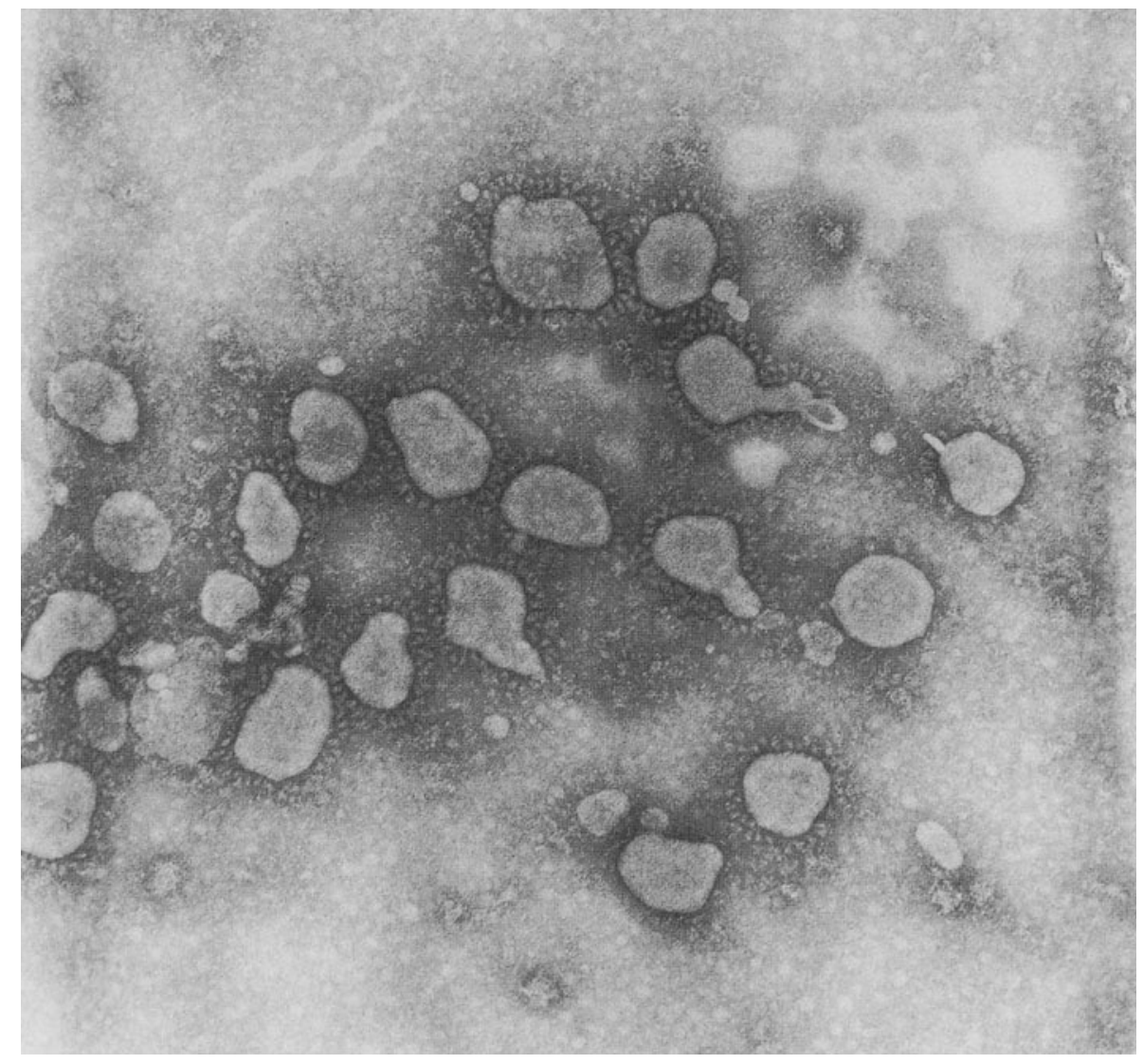

Fig. 4. Coronaviruses. Negatively stained preparation showing corona effect produced by surface projections. (KAPIKIAN, 1969) $\times 144,000$

MADGE 1977). The genomic RNA is both polyadenylated and infectious (SCHOCHETMAN et al. 1977; WeGE et al. 1978).

The structural polypeptides of the coronaviruses are made up of two envelope glycoproteins E1 and E2 and a third nucleocapsied protein $\mathrm{N}$ of molecular weight 23, 180, and 50,000 daltons respectively (STURMAN et al. 1980). El lies within the lipoprotein envelope (STURMAN 1977), E2 may be found in two forms (180 and 90,000 daltons) and the 180,000 dalton from can be cleaved into the 90,000 dalton form by trypsin (STURMAN and Holmes 1977).

During replication, as many as six different RNA species may be synthesized, five of which are subgenomic while the other is the whole genome. All six RNA species are synthesized in roughly constant proportions and are polyadenylated (STERN and KENNEDY 1980). Human coronavirus 229E replication was shown to be sensitive to actinomycin D (KENNEDY and JOHNSON-LUSSENBURG 1978) while other coronaviruses were not (MALLUCI 1965). DI particles have not been demonstrated, but one suspects that this is because the proper experiments have not been 
done. The virus matures by budding from internal cellular membranes and not from the plasma membrane (MCINTOSH 1974). It must be pointed out that all the work so far collected on the molecular biology and physical characterization of the coronaviruses has been performed on coronaviruses other than human strains.

Coronaviruses appear to be a major cause of common respiratory infection in all age groups (MonTo 1976), responsible for up to $15 \%$ of all colds (McINTOSH 1979). The coronaviruses are probably transmitted by the respiratory route (STAIR et al. 1972) as no other route of transmission has been shown, but animal coronaviruses are infectious by the fecal-oral route (STAIR et al. 1972). In the United States, periodicity, with epidemics occuring at 2-3-year intervals, has been demonstrated (MonTo 1974).

The incubation period for coronaviruses is relatively short, ranging from 2 to 4 days (BRADBURNE et al. 1967; TYRRELL et al. 1968 a) and the duration of the illness is from 6 to 7 days. Infections mainly involve the surface of the respiratory tract, meaning that IgA probably plays a direct role in protection (MoNTO 1976) and coronavirus are characterized by a high rate of reinfection (MONTO and LIM 1974). Coronaviruses have been reported isolated from the stools of patients with diarrhea, raising the possibility of the involvement of these viruses in human gastroenteritis, as is the case with some animal coronaviruses (STAIR et al. 1972). However, a definitive role for these agents in gastroenteritis has not been discovered.

\section{E. Viral Hepatitis}

Acute inflammation of the liver can be caused by a number of human viruses, such as some of the herpesviruses, coxsackievirus, mumps virus, and yellow fever virus, but viral hepatitis is usually considered to describe infections with hepatitis A virus (HAV), hepatitis B virus (HBV), or neither - the so-called non-A and non-B hepatitis.

Viral hepatitis is a major health problem worldwide, particularly in countries with poor public health and sanitation. In the United States, 60,000 cases annually are reported and this is generally accepted as a small fraction of the true occurrence (Center for Disease Control 1977). It appears to have been a recognized health problem for 2,500 years (ZUCKERMAN 1976) but its infectious nature was not taken seriously until the $1940 \mathrm{~s}$ when injection equipment was implicated in the spread of hepatitis. In the mid $1960 \mathrm{~s}$, two events took place which have laid the foundation for our current knowledge of viral hepatitis. It had been recognized that two forms of the disease existed, one with a short and the other with a long incubation period. BLUMBERG (1977) discovered "Australia antigen" in the serum of multiply transfused patients and subsequent work demonstrated that this was a serologic marker for the long-incubation hepatitis or hepatitis B; blood which was positive for Australia antigen (now known to be the surface antigen HBsAg) could transmit hepatitis B infection. The second discovery was that, as had been suspected, two distinct forms of the disease could be recognized (KRUGMAN et al. 1967) on the basis of the general clinical and immunologic picture: hepatitis A or "infectious" hepatitis and hepatitis B or "serum" hepatitis. 


\section{Hepatitis A}

The infectious agent of hepatitis A appears to be a picornavirus (BRADLEY et al. 1978), and it is excreted in large quantities into the environment from stools of infected individuals. Not all of these infected individuals will show signs of disease, however, and it may be that the majority of those shedding virus have mild or asymptomatic infection. Spread of the virus by the fecal-oral route had been demonstrated in 1945 when feces was fed to volunteers who subsequently (average of 4 weeks) developed the disease. Natural transmission appears to be via contaminated water and food (there have been several outbreaks of shellfish-related disease, but no evidence for a nonhuman host) and by close personal contact.

The primary site of infection is probably not the liver, since virus is shed well before any clinical or molecular evidence of liver damage is apparent, but the sequence of events leading to hepatocyte damage is not clear. The virus (which is stable in the intestinal environment) enters the body via the gastrointestinal tract and presumably reaches the liver through the blood. However, liver damage may result not from direct infection of liver cells but from an immune reaction to the presence of virus or viral antigens (MURPHY et al. 1978). Infections with hepatitis A tend to be mild but a small number of people (about 50/year in the United States) die of fulminant hepatitis (FrancIS and MAYNARD 1979).

The HAV is an unenveloped cubic particle of about $27 \mathrm{~nm}$ diameter with three major structural polypeptides (CONLEPIS et al. 1978). Since the genome has been shown to be single-straded RNA (apparently somewhat smaller than poliovirus RNA; SIEGL and FrosNer 1978) and the particle polypeptides similar in size to those seen in the enteroviruses, HAV has been judged to be a picornavirus. It is, like the enteroviruses, resistant to heat, acid, and organic solvents. Infected individuals have antibody to hepatitis A (there is only one serotype) and sensitive serologic tests for this now exist; as a corollary, human immune serum can be used prophylactically. No vaccine is available at present, since the virus has yet to be grown successfully in cell or tissue culture.

\section{Hepatitis B}

The onset of hepatitis B is usually associated with a long period (weeks to months) of fatigue and malaise, and the overall course of the disease is normally more severe than for hepatitis A, leading to significant mortality in older age groups (Fig. 5). HBV also causes both chronic acute and chronic persistent hepatitis. The standard route of infection is from infected serum via vaccination, transfusion, injection, drug abuse, etc., but it is becoming increasingly clear that various forms of intimate contact help to spread infection too. Infectious virus has been found in blood, semen, and saliva (ALTER et al. 1977) and, once released into the environment, it is apparently quite stable. Contact with objects contaminated by these body fluids may be sufficient, even days after the event, to cause infection.

Three factors appear to be important in the pathogenesis of HBV infection. First, the immunocompetence of the host (PRINCE et al. 1978) inversely determines the chronic status of the disease. Second, the route of infection plays an important role in establishing the infection, e.g., subcutaneous injection is particularly effi- 


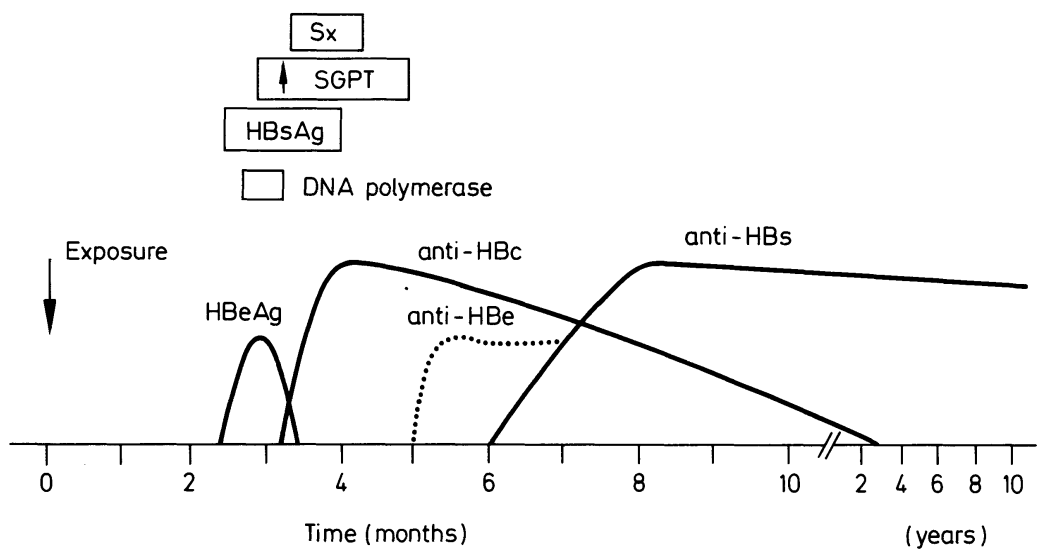

Acute viral hepatitis $A$

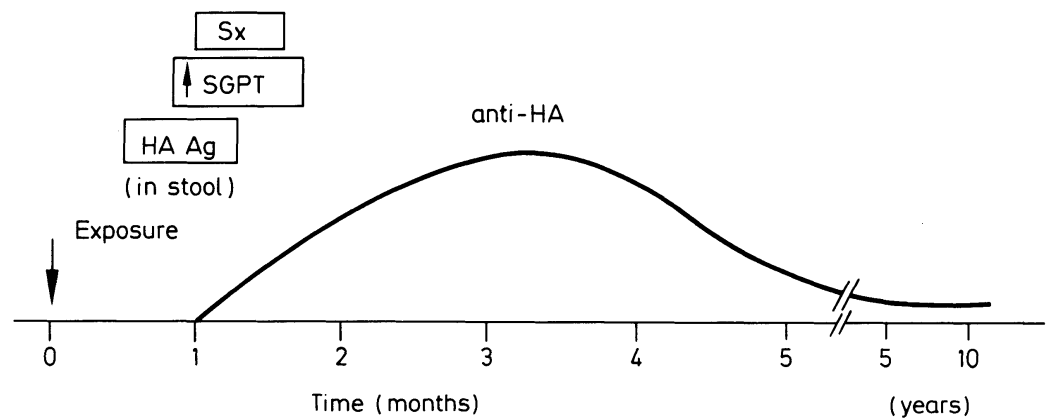

Fig. 5. Representative time course of appearance of clinical symptoms (if present), liver enzyme elevation, viral antigens, and antibodies in acute hepatitis B and A. Persons are infectious for hepatitis $\mathrm{B}$ during the period when $\mathrm{HB}_{\mathrm{s}} \mathrm{Ag}$, DNA polymerase and $\mathrm{HB}_{\mathrm{e}} \mathrm{Ag}$ are present in serum. For hepatitis A, the period of infectivity corresponds to the presence of hepatitis antigen (HA Ag) in feces. (REED and BOYER 1979)

cient (BARKER et al. 1975). Third, the source of virus is crucial: many individuals whose blood contains viral antigens are not infectious and the best test of infectivity seems to be the level of $\mathrm{HBeAg}$ (SEEFF et al. 1978).

A month or more after infection is normally required before signs of virus replication are detectable: the first of these is the presence of HBsAg in the blood, a result of replication of the virus at some unknown site or sites (KRUGMAN and GILES 1973). Normally, an additional month elapses before signs of liver damage are obvious, but there is no clear correlation between the level of infectious virus in the blood and the severity of hepatic damage. It has recently been postulated that the pathogenicity of the virus stems from the host's immune response to infected 
hepatocytes (CHISARI et al. 1978). This model proposes that both humoral and suppressor T-cell-mediated mechanisms interact with the infected cell; preponderance of the latter mechanism allows infected cells to survive owing to the lessening of the immune response, while the opposite reaction results in massive destruction of hepatocytes. In this latter case, severe acute illness develops: in the former, a chronic carrier state is the result.

The virus particle (dane particle) is $42 \mathrm{~nm}$ in diameter, infecting humans and a few other primates and is a most unusual type of virus - a woodchuck analog has recently been isolated, (SUMMERs et al. 1978) but cannot be grown at present in cell culture. The viral DNA is a partially single-stranded circle (HRUSKA et al. 1977) of molecular weight about $1.6 \times 10^{6}$ daltons and can be converted to an intact double strand (3,200 base pairs) by the DNA polymerase activity present in the virion. These circles are formed by the annealing of single-stranded cohesive ends (about 300 bases long; SATTLER and RoBINSON 1979). Recently, particles of varying antigenic subtypes have been shown to possess distinctive restriction enzyme cleavage sites (SIDDIQUI et al. 1979). One of the antigenic structures associated with the virion is the HBsAg with both group-specific and type-specific determinants, and it may also form $22 \mathrm{~nm}$ spherical or tubular particles with no nucleic acid, which occur in sera. Two other antigens are the internal virion antigen $\mathrm{HBeAg}$ and the core antigen $\mathrm{HBcAg}$, located internally to the coat of the virion (AlmeIDA et al. 1971). All these antigens occur in infected patients' sera and the $\mathrm{HBeAg}$ occurs as a small molecule distinct from the $27 \mathrm{~nm} \mathrm{HBcAg}$ or the HBsAg forms. The $\mathrm{HBeAg}$ is most frequently (when seen in conjunction with $\mathrm{HBsAg}$ ) a signal in serum of present disease and high infectivity (ELEFTHERIOU et al. 1975). The antigen is present both in Dane particles and cores, but needs to be activated (proteolysis or detergent treatment) before activity can be seen. Two core polypeptides (19,000 and 45,000 daltons) are associated with the antigenicity (TAKAHASHI et al. 1979). A recent study, in which a primary liver carcinoma cell line (from a patient with hepatitis B infection) producing small amounts of HBsAg was examined, indicates that the whole HBV genome is present in an integrated form in these cells and that all sequences are transcribed (MARION et al. 1980), although only the HBsAg appeared to be produced in a detectable form. The suspicion that a link exists between HBV and liver carcinoma (SzMUNESS 1978) may be strengthened by this observation. Dane particles have a complex antigenic structure with groupspecific (a) and type-specific determinants (d,y,w,r), so that the complete description of particle might be HBsAg/adr, for example. The particle is a double-shelled structure and the outer coat (where resides the HBsAg) has two polypeptides (P1 and P2); both are probably the same polypeptide, P2 being a glycoprotein. Other polypeptides up to about 100,000 daltons have also been described in surface antigen preparations (SHI and GERIN 1977). Several successful attempts have been made recently to clone sequences from HBV DNA into bacterial vectors. It has been possible to obtain expression of the HBcAg in Escherichia coli such that the product is immunologically active in rabbits, establishing the feasibility, at least, of vaccine production from viral antigen synthesis in prokaryotic cells (PASEK et al. 1979). The cloned product has molecular weight 21,000 daltons, close to that found in vivo. Preliminary data suggest that the HBsAg may also be effectively produced in a somewhat modified system (PASEK et al. 1979). 


\section{F. Herpesviruses}

There are five human herpesviruses, herpes simplex types 1 and 2, cytomegalovirus, varicella zoster virus, and Epstein-Barr virus. All cause widespread infections, with occasionally quite serious consequences and all have the property of remaining latent in the infected host, sometimes for the lifetime of that host. A variety of stimuli can resurrect the virus from its latent state (in which it is normally undetectable) to give recurrent infections which may be quite frequent (in the case of herpes simplex, for example) and either localized or more generalized. There is also evidence that members of this group are involved in oncogenesis.

\section{Herpes Simplex Viruses 1 and 2}

Herpes simplex viruses (HSV) exist as two genotypes distinguisable by routes of transmission and sites of infection. HSV-2 is spread by genital contact and tends to infect sites below the waist, usually the genitalia, while HSV-1 is spread by other means (e.g., oral contact) and is normally found above the waist. The correlations with site of occurence are not absolute, however. Infection with both genotypes is widespread, HSV-1 being acquired in childhood, HSV-2 somewhat later; HSV-1 infections are also more prevalent than HSV-2 although the latter infection often represents serious problems (social and otherwise) for the people involved. Both infections are characterized by latent states and more or less frequent recurrences.

Based on electron microscopic data, the herpes virion has four major structural components: core, capsid, tegument, and envelope (O'CALLAGHAN and RANDALL 1976). The core has a cylindrical protein structure around which the DNA is wound as a toroid (FurLONG et al. 1972) and the whole is encased in the capsid, a 162 capsomer icosahedron (WILDY 1967, Fig. 6). Between capsid and envelope is the amorphous tegument layer (RoIzMAN et al. 1975) and the envelope, in the electron microscope, is indistinguishable from the cell's nuclear membrane. There may be as many as 30 polypeptides in the particle, and RoIzMAN et al. (1975) have summarized the probable location of many of them in the four components recognized. The major virus glycoproteins are found on the envelope, are derived from four unique polypeptides (SPEAR 1976), and appear to be necessary for successful infection and for the cell fusion reaction typical of some HSV strains. Sulfation may accompany glycosylation and several virion proteins appear to be phosphorylated (GIBSON and RoIZMAN 1974). Two polyamines, spermine and spermidine, are associated with the nucleocapsid and the envelope, respectively (GIBSON and RoIzMAN 1971).

Both HSV-1 and HSV-2 DNA have a molecular weight of about $100 \times 10^{6}$ daltons and have a linear double-stranded configuration with $67 \%$ and $69 \%$ guanosine plus cytosine content, respectively (KIEFF et al. 1971). The linear duplex is susceptible to alkali fragmentation, probably owing both to nicks and to ribonucleotides present in the DNA; whether alkali treatment yields random single strands or defined pieces of viral DNA is still a matter for controversy (FRENKEL and ROIZMAN 1972; WILKIE 1973). The genome has a terminal redundancy which allows formation of double-stranded circles after, for example, $\lambda$ exonuclease digestion (GrAFSTROM et al. 1974). The most interesting feature of HSV DNA, how- 


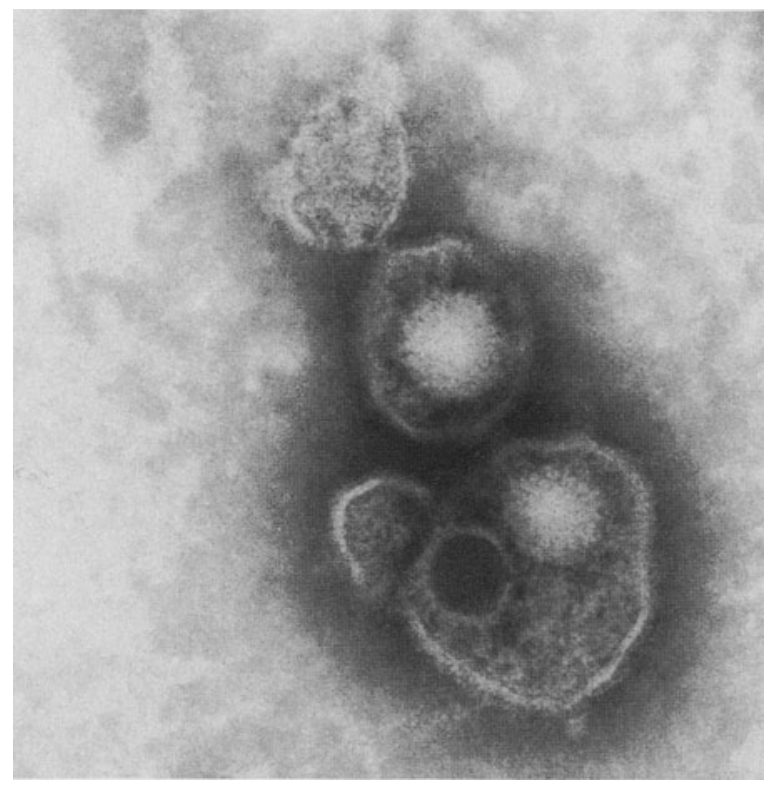

Fig. 6. Herpes simplex virus (capsid diameter $100 \mathrm{~nm}$ ). Shown is a full enveloped particle (center) (Courtesy of D. H. WATSON)

ever, is the existence of two sets of internally inverted repeat sequences, duplicating sequences in the termini of the duplex (Fig. 7), postulated by SHELDRICK and BERTHELOT 1974). A consequence of this structure is that intramolecular rearrangement may occur to generate four forms of the HSV genome (Fig. 7). That these four forms exist in infected cells and in virons (in more or less equal proportion) was demonstrated by restriction enzyme cleavage and by partial denaturation mapping (Hayward et al. 1975; Delius and Clements 1976). Whether all four forms are functional is not yet clear and it is suspected that not all are (RoIzMAN 1979). There are several other insertions, deletions, redundancies, etc., whose importance is ill defined. Other herpesviruses have different structures. Cytomegalovirus (CMV) looks like HSV-1 and HSV-2, except that it is larger, while Epstein-Barr virus (EBV) is radically different (Fig. 7). Varicella zoster virus (VZV) DNA appears to be the smallest of this group and to have one internal inverted region (STRAUS et al. 1981).

The herpesvirus particle enters the cell either by pinocytosis or by membrane fusion and moves to the cell nucleus to become an active transcription substrate, presumably as some uncoated entity: some association of input DNA with the cellular nuclear proteins has been suggested (WAGNER and SUMMERS 1978). Infection leads to disruption of all polysomes, cell RNA synthesis inhibition, and degradation of cell mRNA (WAGNER and RoIzMAN 1969 b; NiSHOKA and SilvERSTEIN 1977). Viral message on cytoplasmic polysomes (about 10-33 S) seems to be derived from larger precursor RNAs (WAGNER and RoIzMAN 1969a) and to account for esentially all genome sequences late in infection. Early RNA is largely representative of about $40 \%$ of coding sequences, with, probably, less abundant RNA spe- 


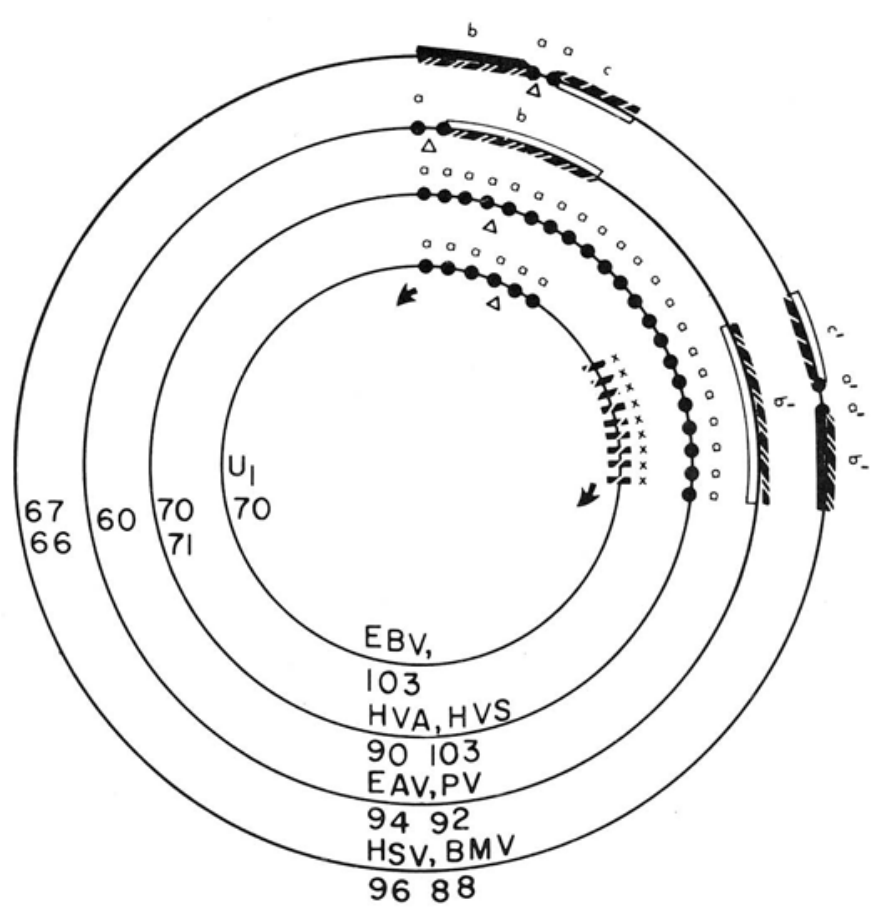

Fig. 7. Comparison of the structures of several known herpesvirus DNAs shown in a circular arrangement. The triangles denote the positions of the termini of the linear molecules. The full circles, shown out of proportion to their true size, represent the a sequences. The full, open, and striated segments of the circular representations are meant to indicate the terminal sequences that are inverted internally. The numbers below each circle give the molecular weights of the DNAs in millions. The numbers on the left indicate the approximate molecular weights of the unique sequences of $L$ components $\left(U_{L}\right)$. EBV Epstein-Barr virus; HVA Herpesvirus ateles; HVS Herpesvirus saimiri; EAV equine abortion virus; PV pseudorabies virus; HSV herpes simplex virus; BMV bovine mamillitis virus. (RoIzMAN 1979)

cies accounting for up to another 40\% (SwANSTROM and WAGNER 1974; KozAK and RoIZMAN 1974). Evidence for restricted cytoplasmic sequences being dependent on processing from more extensive transcription in the nucleus has been presented, but is not generally agreed upon (CLEMENTS and HAY 1977). A subset of early RNA is immediate early RNA, which is produced in the absence of viral protein synthesis and has been mapped physically to restricted regions of the genome (CLEMENTs et al. 1977). Thus, at least three levels of control seem to operate: first, "on-off" control; second, abundance control; and third, control by specific nuclear retention of certain sequences. mRNA is capped (BARTKOSKI and RoIZMAN 1976), can be polyadenylated, and is produced by the cell's RNA polymerase II (ALWINE et al. 1974). Recently, some limited splicing has been demonstrated (R. J. WATSON, personal communication 1980).

There may be well over 100 polypeptides in infected cells (H.S. MARSDEN and L. HAAR, personal communication 1980) of which perhaps 30 are structural. HoNESS and RoIzMAN (1974) have divided the synthesis of viral polypeptides into three main groups, $\alpha, \beta, \gamma$, regulated by an interlocking cascade scheme: $\alpha$ polypeptides 


Component
Sequence arrangement
Hybridization of $\alpha$ RNA
Origin of defective DNA
Markers and functions
Polypeptide number
Fractional distance

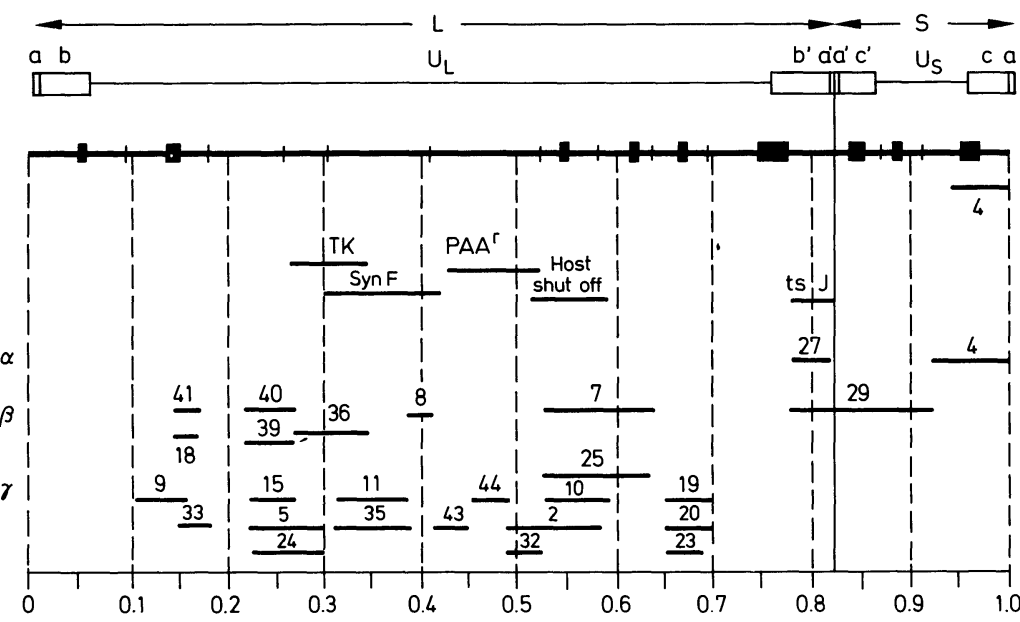

Fig. 8. Location of templates specifying HSV markers, functions, and polypeptides determined from an analysis of HSV-1 $\times$ HSV-2 recombinants. $U_{L}$ and $U_{S}$ are the long and short unique regions of the DNA; TK is thymidine kinase; $\mathrm{PAA}^{\mathrm{r}}$ is the resistance locus for phosphonoacetate; Syn is a locus for syncytium formation; $\mathrm{F}$ and $\mathrm{J}$ are temperature-sensitive mutants of HSV-1. (MORSE et al. 1978)

are made first (from immediate early or $\alpha$ mRNA) and regulate the switch to later modes of synthesis (PRESTON 1979); $\gamma$ polypeptides represent structural polypeptides and their synthesis is not (qualitatively) dependent on viral DNA synthesis, although a class of proteins which seems to be progeny DNA-dependent has been described (Powell et al. 1975); $\beta$ polypeptides include enzymes, DNA-binding proteins, etc.

Several enzyme activities have been shown to be induced by herpes simplex virus infection, and some of them have been shown to be virus coded. Pyrimidine deoxynucleoside kinase (DuBBS and KIT 1964), DNA polymerase, and alkaline deoxyribonuclease (KEIR and GOLD 1963) have all been mapped physically on the genome, and other induced activities include ribonucleotide reductase, deoxythymidylate kinase (part of the pyrimidine deoxynucleoside kinase activity), RNase $\mathrm{H}$, nucleoside phosphotransferase, uridine, and choline kinases, protein kinase, and deoxynucleoside triphosphatase. No evidence for altered or new RNA polymerase II activity has been forthcoming, although it has been looked for.

Much effort has recently gone into physical and functional mapping of viral polypeptides, and Fig. 8 shows the data of MorSE et al. (1978) more or less identical with that of MARSDEN et al. (1978) and PRESTON et al. (1978). Viral DNA synthesis, judged by the number of viral mutants deficient in that function, is likely to be dependent on several viral activities, one of which is a DNA polymerase activity (PURIFOY and Powell 1977), although cell functions are also implicated (YANAGI et al. 1978). It takes place in the nucleus, by a mechanism which is currently uncertain, although RoIzMAN (1979) has proposed a plausible model. Viral structural polypeptides can migrate from the cytoplasm to form capsids in the nucleus; these can become associated with viral DNA and enter the cytoplasm, acquiring a nu- 
clear membrane-derived envelope on the way. The virus leaves the cell either by budding or via channels in the membranes of infected cells.

Like most other animal viruses, herpesvirus accumulates DI particles when virus stocks are passaged in tissue culture or in the animal. Tandem repeats of DNA from herpes simplex, either from short, S regions (FRENKEL et al. 1976) or from the middle of long, L regions (CUIFO and HAYWARD 1980) form molecules of about whole genome size and their bouyant densities may be higher or the same as wild-type virus. Defective molecules derived from L also have a short (200 base pairs) region derived from the right-hand end of $S$. The existence of initiation sites for DNA synthesis in both $\mathrm{L}$ and $\mathrm{S}$ is suggested by these data.

\section{Herpes Simplex Virus Infections}

Infection with HSV often leads to a productive lytic cycle, but can also result in transformation of cells in culture in a persistent infection in vitro or in latency in vivo. Latent infections with HSV occur as a result of a primary infection and virus can be reactivated from its latent state to give recurrent lytic phases of viral multiplication. Later HSV-1 infections in humans were traced to the trigeminal ganglion by the nerve section experiments of CARTER and KILBOURNE, 1952. Using the mouse model, STEVENS and COOK (1971) found that infection of the footpad resulted in acute sensory ganglion infection; in surviving animals, latent infections had been established, but no direct demonstration of virus or viral products was apparent. However, explantation and in vitro cultivation leads to production of infectious virus and, in addition to mouse ganglia, herpes simplex virus has been thus recovered from rabbit trigeminal ganglia (STEVENS 1972) and human trigeminal ganglia (HSV-1; BARINGER and SwOVELAND 1973) and sacral ganglia (HSV-2; BARINGER 1975). Recent evidence suggests that a particular HSV-1 strain infects each individual and that, after replication, this virus may become latent at more than one ganglionic site (LONSDALE et al. 1979). It is not known how virus is transported neurally, but an intra-axonal mechanism has been proposed (LAVAIL and LAVAIL 1972). Which cell type harbors the latent virus has not been agreed upon; on the one hand the neuron itself has been suggested (CoOK et al. 1974), and on the other the satellite cells (A MCLENNAN and G. DARBY, personal communication 1980). Similarly, whether the latency represents a tiny amount of viral replication (essentially undetectable) in a few cells or a total lack of viral multiplication (e.g., viral DNA integrated into the cell genome and quite nonfunctional) is not yet clear. In the mouse, antiviral IgG seems to be of importance in preventing reactivation, but cellular immunity may also play a role (NAHMIAS and RoIZMAN 1973). Some human ganglia also harbor defective viral genomes and these may play a role in other disease processes, currently not understood (BROWN et al. 1979).

Several herpes viruses can cause tumors after direct inoculation in a host; herpes simplex virus does not appear to do this with any great frequency, although HSV-2 may have a function in the formation of cervical carcinoma. Seroepidemiologic surveys (ADAM et al. 1974) were supported by the findings that cervical carcinoma tissue harbors HSV-2 sequences (FrENKEL et al. 1972) and although a series of negative findings were subsequently reported (PAGANO 1975), very recent 
data lends support to the original experiments (R. EGLIN and G. B. ClemenTs, personal communication 1981).

Both "biochemical" and "morphological" transformation have been described with herpes simplex virus, the prerequisite, in both cases, being virus which is unable to replicate properly, (e.g., UV-inactivated, temperature-sensitive $(t s) \mathrm{mu}$ tant, DNA fragment). Biochemical transformation involves the sequestration of viral thymidine kinase (TK) gene sequences in an expressible form in cells and was originally described for LTK $^{-}$cells by MUNYON et al. (1971). Other regions (not just the TK gene) of the viral DNA are co-transferred and this system should be generally useful in the (selectable) transfer of genes to a mammalian cell. The TK genes have been mapped to a region of the HSV-1 and HSV-2 genome around 0,300 fractional length; biochemically transformed cells are not oncogenic.

Morphological transformation was first carried out by DUFF and RAPP (1971) in hamster cells, and both HSV-1 and HSV-2-transformed cells were oncogenic in newborn hamsters. An analogous rat system was described by MACNAB (1974) using $t s$ mutants. Fragments of viral DNA can be used to transform cells morphologically and, using this assay, the transforming regions of HSV-1 and HSV-2 have been located. A number of polypeptides seen in normal infections with HSV have been detected in transformed cells, and some specific tumor-related antigens are also cataloged (AURELIAN et al. 1975) but no HSV "T antigen" is obvious at present.

The characteristic pattern of herpes simplex virus infection is, as we have already mentioned, a primary infection followed by recurrences at the body surface served by a specific nerve. Primary episodes can be varied, and induce infection of the oral (HSV-1 mainly) and genital (HSV-2 mainly) regions, herpetic keratitis, skin herpes, respiratory herpes, and herpes encephalitis. Neonatal herpes infections occur usually via passage through an infected birth canal. All of these are likely to result in recurrent infections of the same general area as the primary infection by transmission of the virus from latently infected ganglia to the surface of the body served by the corresponding nerve endings. Respiratory herpes does not usually recur and encephalitis is most often a fatal primary infection. There is no known animal vector and transmission takes place through direct contact, e.g., oral contact for oral herpes and genital contact for genital herpes. Primary infections are usually inapparent, but in special cases, like severe undernourishment, the disease may be severe. In these cases, virus replicates at the site of infection to give viremia which allows further multiplication in certain organs, resulting in a second wave of viremia and yet further organ involvement (BECKER et al. 1968; in the neonate this often affects the brain. Commonly, viremia is unusual and the replication at the initial site (or in local lymph tissue) would seem to be the major source of virus necessary to establish the infection. Both humoral antibody responses and involvement of cell-mediated mechanisms are common responses to primary infections (Nahmias and RoIzman 1973; Nahmias et al. 1976).

Recurrent infections tend to be less severe than primary ones but there have been reports of encephalitis presenting as a recurrent infection (CRAIG and NAHMIAS 1973). Recurrences tend to occur in the presence of humoral antibodies and of functioning cell-mediated responses, while both nonspecific and specific mechanisms are capable of halting cell-to-cell spread of virus (LODMELL et al. 1973). 


\section{Cytomegalovirus}

Cytomegalovirus (CMV) infections are ubiquitous and are acquired during the childhood years generally, although acquisition is often asymptomatic. Congenital infections are serious in many cases and are considered to the major problems associated with this virus infection. Primary infection can be followed by bouts of virus shedding (recurrence) although circulating antibody levels are high.

The virus is a typical herpesvirus when viewed in the electron microscope, but the particle contains a DNA molecule (double-stranded, linear) which is much larger $\left(150 \times 10^{6}\right.$ daltons) than all the other human herpesviruses. Defective virus contains much smaller DNA, some of which has a molecular weight of about $100 \times 10^{6}$ daltons (DeMarchi et al. 1978; StINSKI et al. 1979). The genome-sized molecule is internally arranged in a fashion analogous to that of HSV, with long and short unique regions bounded by inverted repeat sequences. The particle has about 35 recognizable polypeptides, some modified (STINSKI 1977), not all of which may necessarily be virus specified.

One of the difficulties in analysis of events after infection of cells with CMV is that all DNA, RNA, and protein synthesis can be stimulated (FURUKAWA et al. 1975), although cell DNA synthesis stimulation is not seen in cells actively replicating CMV (DEMARCHI and KAPLAN 1977). An early and a late phase of protein synthesis are discernable, and the late proteins seem to correlate with structural polypeptides (STINSKI 1978). Early proteins (at least ten) are made in the absence of viral DNA synthesis (and in nonpermissive cells) but late proteins need progeny viral DNA. CMV induces cellular RNA polymerases I, II, and III (TANAKA et al. 1978) and its own DNA polymerase activity (HUANG 1976), although no thymidine kinase seems to be virus specified. Several $t s$ mutants of CMV have been isolated and their properties suggest that at least four complementation groups are involved in viral DNA synthesis, which, in turn, is not needed for cell DNA synthesis stimulation (YAMANISHI and RAPP 1979).

Inactivated CMV can induce oncogenic transformation of hamster embryo fibroblasts (ALBRECHT and RAPP 1973) and in human fibroblasts a persistent infection can be set up in vitro (GEDER et al. 1976; MOCARSKI and STINSKI 1979), but what factor or factors control restriction is uncertain. Interestingly, a fraction of the persistently infected cells mentioned previously become transformed after passage and can cause tumors in mice.

Extensive secretion of CMV in body fluids over long periods in the absence of symptoms and in the presence of circulating antibody is common, and the virus is spread through populations with ease. This is particularly true in groups which live in close proximity to one another, e.g., in nursing homes or boarding schools. Congenital infection (to give cytomegalovirus inclusion disease, CID) is more common following primary natural infection (STERN and TUCKER 1973). The reason for this, presumably, is that viremia is more likely in a primary infection and thus spread to other organs (including the placenta) is favored. However, it is clear that such events do not always have a serious outcome, although CID has a $1 \%$ live birth frequency with $10 \%$ serious sequelae (STARR et al. 1970). Primary infection in the young adult can lead to an infectious mononucleosis type of illness whose pathogenesis may be an immunologic interaction. Similar to that suggested for Epstein- 
Barr virus (SHELDON et al. 1973) and hepatitis due to CMV is also found. CMV can be contracted via blood transfusion or organ transplant, but the source of infection in these cases is still vague. The immune response to CMV is long-lasting in most cases, but the roles of humoral versus cell-mediated antibody have not been fully assessed.

\section{Varicella Zoster Virus}

Varicella zoster virus (VZV) is the agent of two common diseases, one generally of childhood, chickenpox, and the other generally of older people, zoster. The second is a classical herpes recurrent infection resulting from an initial primary infection (the chickenpox). The virus is particularly infectious in populations (in school classrooms, for example) and children may acquire chickenpox from recurrent zoster lesions. Paradoxically, VZV has been extraordinarily difficult to grow in cell culture systems, which explains why the molecular biology of the virus is still in such a primitive state.

The virus particle is typical of herpes viruses and is easily distinguished from smallpox virus in the electron microscope (rash from both infections can be confused). The viral DNA (about $47 \%$ guanine plus cytosine, linear double-stranded) is the smallest of the human herpesviruses, around $80 \times 10^{6}$ daltons, and has been shown to be infectious, as have the other human herpesviruses (DumAs et al. 1980; STRAUS et al. 1981). The DNA exists in two forms differentiated by the orientation of a unique set of sequences $\left(5.8 \times 10^{6}\right.$ daltons $)$, bounded by invertible repeat regions (each $3.5 \times 10^{6}$ daltons; STRAUS et al. 1981). DNA from both chickenpox and from zoster isolates appear to have some sequence differences, but are equally infectious in vitro. Analysis of viral DNA from separate virus isolates (from both zoster and chickenpox) show clear variations in restriction enzyme digest patterns and imply that "molecular epidemiology" may be feasible (S. E.STRAUS and J. HAY, unpublished work 1981). The events which characterize the infectious cycle have not been defined for VZV, although a DNA polymerase activity as well as a thymidine kinase activity and a deoxyribonuclease activity (CHENG et al. 1979) have been reported. The virus specificity of these enzymes is presumably the reason for the ability of antiviral agents such as acycloguanosine to modify VZV infections. Under special circumstances, both varicella and zoster may be life-threatening. Leukemia and other malignancies may lead to disseminated varicella in children, and Hodgkin's disease reactivates zoster at rates higher than in normal patients.

In the normal host with operative immune mechanisms, one attack of varicella is not likely to be followed by a second and the incubation period of the disease is about 2 weeks. The virus probably enters the body via the oropharynx, upper respiratory tract or, rarely, the skin. Multiplication in situ leads to a spread of infection followed by several cycles of further multiplication. The ensuing viremia allows dissemination and skin lesions start to appear. These are contained by humoral as well as cell-mediated responses.

An aftermath of varicella is the persistence of VZV in the body. It has been proposed that the virus sequesters itself in sensory ganglia, and there is evidence to support that contention (ESIRI and ToMLINSON 1972). Overt infection is triggered 
by some unusual circumstance and virus appears at the nerve endings in characteristic vesicles. One attack of zoster is normal and more than two very rare (JUELJENSEN and MACCALLUM 1972). It is tempting to equate the latency and reactivation of herpes simplex with that of zoster, but at present, this is not wholly justified. Quite often the virus replication seems to be more widespread than simply in those cells close to sensory nerve endings and dissemination of the virus (with serious consequences) is a recognized difficulty with reactivity in patients with Hodgkin's disease.

\section{Epstein-Barr Virus}

Epstein-Barr virus (EBV) is the fifth member of the herpesvirus group. Infection with the virus is worldwide in distribution, usually causing a subclinical infection in early childhood. When infection occurs in late adolescence or early adulthood the result is normally heterophile-positive infectious mononucleosis (HENLE et al. 1968; NiEDERMAN et al. 1968). The virus was first identified in cultured lymphoblasts from Burkitt's lymphoma (EPSTEIN et al. 1964), and has since been implicated as the causal agent of both this lymphoma and nasopharyngeal carcinoma.

EBV has the characteristic morphology of the herpesvirus group (Fig. 6). The virions are approximately $100-150 \mathrm{~nm}$ in diameter and consist of an icosahedral mucleocapsid surrounded by a lipid envelope. The DNA of EBV is linear, approximately $1 \times 10^{8}$ daltons in molecular weight $\left(1.7 \times 10^{5}\right.$ base pairs; PRITCHETT et al. 1975; HAYWARD and KIEFF 1977). The bouyant density of the DNA is $1.718 \mathrm{~g} / \mathrm{cm}^{2}$, indicating a guanosine plus cytosine content of $57 \%-58 \%$ (PRITCHETT et al. 1975). At both ends of the DNA are a series (1-12) of tandem repeats of a 500 base pair sequence and both ends of the DNA contain sequences which are direct repetitions of each other (GIVEN and KIEFF 1978, 1979). In addition, internally there are 1-12 reiterations of a 3,200 base pair sequence of relatively high guanine plus cytosine content (RYMO and ForSBLUM 1978; GIVEN and KIEFF 1979; HAYWARD et al. 1980). These repeats are arranged in an adjacent tandem array with all copies in the same orientation (HAYWARD et al. 1980). Thus, the arrangement of terminal and internal repeats indicates that EBV DNA, like other mammalian herpesviruses, is divisible into a large (L) segment and a smaller (S) segment (HAYWARD et al. 1980), although the arrangement of these repetitive sequences within the EBV S segment is different from all other herpesvirus genomes so far described (HAYWARD et al. 1980). An interesting observation relating to the possible function of the internal repeats is that the DNA of EBV strains that transform cord blood lymphocytes have 8-12 copies of the repeat, while nontransforming strains have only 3-4 (HAYWARD et al. 1980).

The host range of EBV is very limited. In vitro cultivation has been shown only in B-lymphocytes, possibly because they alone have proper receptors for the virus (JONDAL and KLEIN 1973). That the restriction for growth of EBV is at an early event (adsorption, penetration, or uncoating) is shown in experiments in which microinjection of EBV DNA into normally nonpermissive cells allowed for transcription of some viral products (GRAESSMAN et al. 1980). As if this restricted host range were not enough of a problem for experimentalists, only a minority of the cells in these "producer" lines actually produces virus (RoIZMAN and KIEFF 1974). It is believed that the natural target cells in vivo for primary infection by EBV are 
epithelial cells of the ororhinopharynx (DE THÉ 1979; LEMON et al. 1977), and makes some sense of the association of EBV with nasopharyngeal carcinoma, an epithelial tumor.

Several antigens have been detected in EBV-infected cells and used as markers for infection of cell lines: EBNA, EBV-specific nuclear antigen; EA, early antigen (the production of these two antigens is not prevented by blocking DNA synthesis (HeNle et al. 1970; Gergely et al. 1971); VCA, viral capsid antigen, and MA, membrane antigen.

Compared with the herpes simplex viruses, little is known of the regulation of events during infection. The virus-specific RNA is adenylated (HAYWARD and KIEFF 1976) and appears to be processed differently in permissive and nonpermissive (restringent) infections (HAYWARD and KIEFF 1976; ORELlANA and KIEFF 1977). In restringent infection about $16 \%-30 \%$ of the DNA is represented by RNA of which only $5 \%-7 \%$ is adenylated and found on polyribosomes, while in the permissive system $45 \%$ of the DNA is represented by RNA; all of these sequences associate with polyribosomes (HAYWARD and KIEFF 1976; ORELlana and KIEFF 1977; THOMAS-Powell et al. 1979). Whether this selective polyadenylation is related to the restriction is unknown. An analysis of the EBV-specific RNA in Burkitt's lymphoma tissue indicated adenylated RNA homologous to $3 \%-6 \%$ of the EBV DNA (DAMBAUGH et al. 1979). EBV has also been shown to code for its own DNA polymerase (AllaNDEEN and BERTINo 1978; DATTA et al. 1980), nuclease (ClOUGH 1979), and to be sensitive to phosphonoacetic acid, properties shared with other herpesviruses; no general agreement exists as to the induction of a virusspecific thymidine kinase.

The major route of transmission of infectious mononucleosis in young adults is through intimate oral contact (HoAGLAND 1955; SAWYER et al. 1971; EvANS and NIEDERMAN 1977) and the incubation period is 4-7 weeks (HoAGLAND 1964; EVANS 1960). Virus shedding occurs during acute illness and from weeks to months after onset (EVANS and NiEDERMAN 1977). After invasion of the nasopharynx, the virus enters the blood stream; here B-lymphocytes are infected and proliferate, leading to immune stimulation and proliferation of T-cells, the atypical cells characteristic of the disease (PurTILO 1976). The proliferation of B-cells is thought to be held in check by a T-cell-cytotoxic response and by antibody production (PEARSON and ORR 1976). Recovery from illness results in disappearance of these atypical lymphocytes and presence of both humoral and cell-mediated immune functions specific for EBV (SCHOOLEY and DoLIN 1979). The virus, however, is not eliminated from the host; thus EBV is similar to other members of the herpesvirus group in its ability to remain "latent." The immune responses are thought to play a role both in Burkitt's lymphoma and in fatal infectious mononucleosis (PURTILO et al. 1977).

The characteristic clinical picture consists of fever, pharyngitis, and cervical lymphadenopathy, accompanied by splenomegaly and/or hepatomegaly. Abnormalities in liver function are a regular occurrence (EVANS and NIEDERMAN 1977; SCHOOLEY and DoLIN 1979); serious complications (e.g., fatal infectious mononucleosis) are rare (BAR et al. 1974; PURTILO et al. 1977). The vast majority of the cases resolve spontaneously in 2-3 weeks and the prostration associated with the illness is usually gradual in its course. The disease results in the production of circulating antibodies against viral antigens as well as unrelated antigens; these latter antibod- 


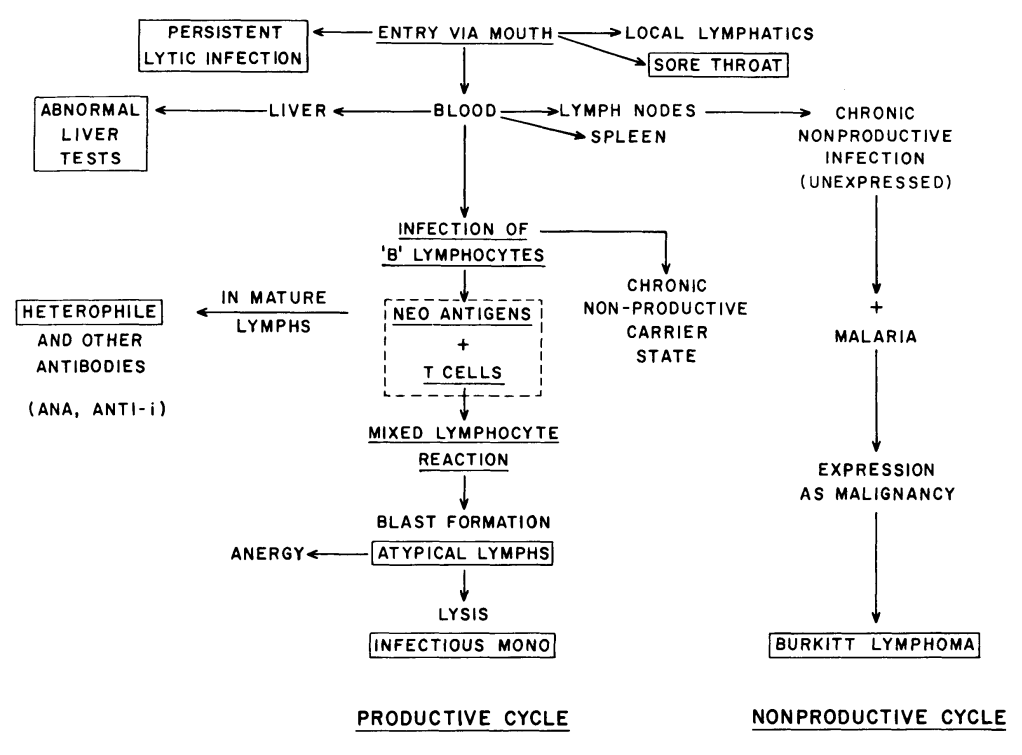

Fig. 9. Hypothetical pathogenesis of EBV infection. (Evans and NiEDERMAN 1977)

ies being the heterophile antibodies. Diagnosis is based on the typical clinical picture with fever, sore throat, and lymphadenopathy in addition to heterophile antibodies. In heterophile-negative cases, antibodies to EBV must be demonstrated. A flow diagram of our current understanding of EBV pathogeneiss is presented in Fig. 9.

EBV has been associated with two malignant human tumors, the African type Burkitt's lymphoma (BL) and nasopharyngeal carcinoma (NPC) of a particular type encountered in people of Southern Chinese extraction (FENNER and WHITE 1976; EPSTEIN and ACHONG 1977). The association between EBV and BL is based upon the regular presence of viral products in tumor cells and a specific EBV immune profile of the patients. The tumor tissue of Burkitt's lymphoma consists of B-lymphocytes of a single clone (WRIGHT 1972; Fialkow et al. 1973), which are infected with EBV. Tumor tissue usually contains multiple copies of the EBV genome (Zur Hausen et al. 1970; NonOYAMA and PAgANo 1973) and the EBV DNA in this tumor tissue is found in the form of a closed circular episome (KASCHKADIERICH et al. 1976; LINDAHL et al. 1976); whether any viral DNA is actually integrated into the host genome is not known (DAMBAUGH et al. 1979).

There are many different kinds of epidemiologic data linking EBV to African BL. The data suggest an etiologic role for the virus and imply that endemic malaria in these areas may be a cofactor. For example, patients with BL were shown to have higher levels of antibodies against a variety of EBV antigens (EA, VCA, MA) than unaffected patients in the same area (DE THÉ 1979). A simple relationship of EBV to BL is difficult to understand since EBV is widespread, while BL has a very limited geographic distribution (BURKITT and WrIGHT 1966). Nevertheless, the data from the best prospective study to date (DE THÉ et al. 1978) suggest a strong association of BL and EBV, particularly in cases characterized by EBV DNA in 
tumor cells, and high VCA titers. The risk of developing BL was estimated to be 30 times greater in children with high VCA titers and these titers may reflect the severity of the original primary infection, owing either to dose or host response. It is known that with other oncogenic viruses oncogenic potential is enhanced when the virus is given to newborn infants (Gross 1970), and such may be the case with EBV (DE THÉ 1977). The data supporting a relationship of EBV to NPC is similar to that for BL. Patients with NPC have high VCA titers (HENLE et al. 1970) and DNA has been demonstrated in biopsy material (ZUR HAUSEN et al. 1970). Of particular interest has been the observation that the tumor cells in NPC are epithelial (WoLF et al. 1973) as opposed to lymphoid as in BL. As with BL, NPC is remarkably restricted in distribution though EBV is widespread, suggesting that genetic and/or environmental factors are also involved in tumor induction.

\section{G. Orthomyxoviruses}

Three types of influenza virus have been described; A, B, and C. Every 2-3 years major outbreaks of influenza A occur with high attack rates $(40 \%)$ in the 5-14 year age group, declining progressively with age; conversely, the mortality rate increases with age. Total excess deaths in the United States per 100,000 attributable to pneumonia following influenza infection in recent outbreaks has been less than 10 , but this still represents a significant number of avoidable deaths. Influenza B, on the other hand, causes disease with a lower attack rate and less mortality than influenza A, major outbreaks generally appearing only every 4-7 years. Influenza $\mathrm{C}$, with poorly defined epidemiology, is a relatively minor problem for children.

\section{Influenza $A$ and $B$ Viruses}

Influenza A virus isolated from successive outbreaks demonstrates two types of variation. "Antigenic shift" occurs when a strain of virus appears which is either not, or only remotely, related antigenically to the virus of the preceding outbreak. This occurred in 1947, with the emergence of the $A_{1} / \mathrm{Fm} / 1 / 47$ prototype (FRANCIS et al. 1947) and again in 1957 when $A_{2} / J a p a n / 305 / 57$ appeared (MEYER et al. 1957). Between these bouts of distinct change in the virus isolates a more subtle "antigenic drift" is evident which results from small changes in virus polypeptides and is driven, presumably, by the rising levels of antibody present in the population as infections with a given subtype become more widespread. Antigenic shift releases a virus strain for which little or no immune protection exists in the population, and is a major factor in the relative severity of outbreaks every 10-15 years. An attractive theory for the development of new antigenically shifted virus is that recombination between certain animal and human influenza viruses can occur in which virulence for the human population is combined with an antigenic component of the animal virus in a new virus subtype (KILBOURNE 1968; LAVER and WEBSTER 1973). Influenza B was first associated (retrospectively) with an outbreak in 1936 (FRANCIS 1940) and, while it seems to drift antigenically, no large shifts have been evident.

The basic architecture of the particle is shown in Fig. 10 in which nucleoprotein is surrounded by a lipid membrane, coated on the inside by a matrix protein and 


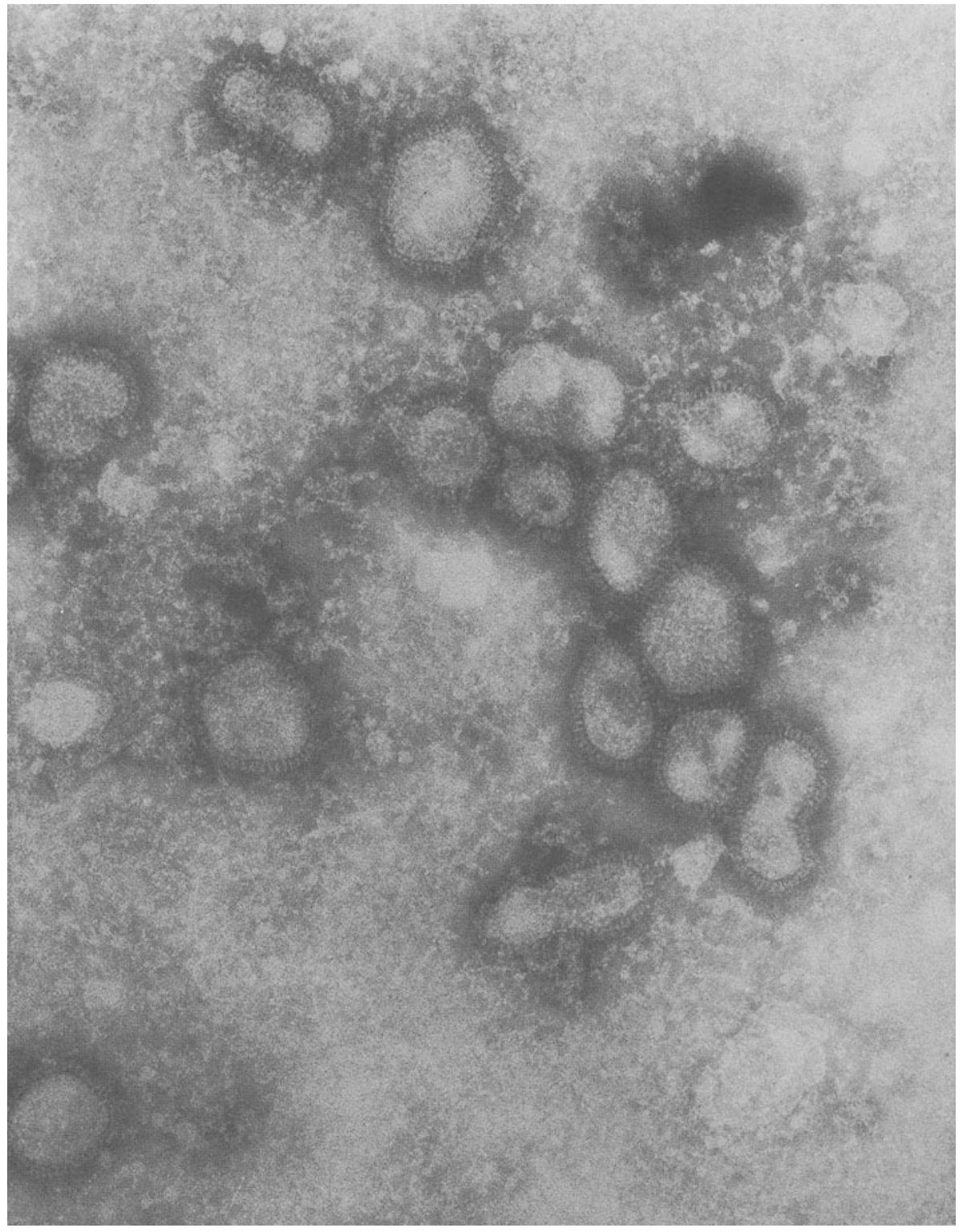

Fig. 10. Electron micrograph of influenza A virions. (MADELEY 1972) $\times 200,000$

externally by spikes of neuraminidase (NA) and hemagglutinin (HA), both glycoproteins. The whole virion is about $100 \mathrm{~nm}$ in diameter. The NA recognizes neuraminic acid on cell surface mucoproteins, converting mucous to a thin liquid and exposing cell surface receptors, while HA allows recognition and attachment to the mucoproteins. The genome RNA (negative polarity) is present in several segments: for influenza A and B there are eight segments, varying in total molecular weight 


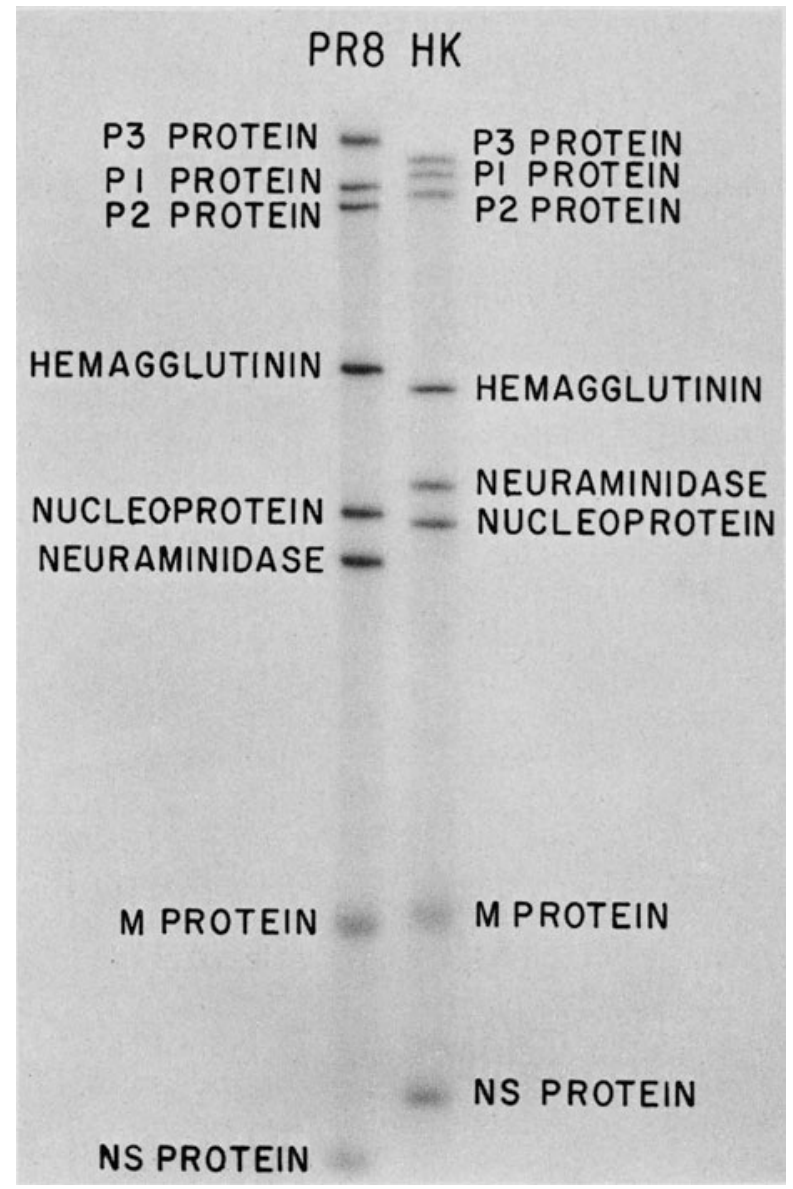

Fig. 11. Map of influenza virus genome. Polyacrylamide gel of the RNAs of A/PR/8/34 and $\mathrm{A} / \mathrm{HK} / 8 / 68$ viruses (PR8 and $\mathrm{HK}$ viruses) showing identification of the eight genes with respect to their gene products. (PALESE et al. 1978)

from 5 to $7 \times 10^{6}$ daltons, while influenza $\mathrm{C}$ seems to have half that number (PAlese and Schulman 1976; Pons 1976; McGeOch et al. 1976). This property of the RNA allows "recombinants" (products of the reassortment of the RNA segments) to be isolated and the generation of specific recombinants along with the use of $t s$ mutants and in vitro polypeptide synthesis have allowed the assignment of each RNA segment to production of a specific virus polypeptide (PALESE et al. 1978; Fig. 11).

Virus is able to enter susceptible cells either by vacuolation of virus or by the uptake of nucleoproteins directly following fusion of particles with the cell plasma membrane. As with all negative-strand viruses, the first step in intracellular replication is the production of RNA complementary to virion RNA, to form functional mRNAs. Production of $\mathrm{mRNA}$ is under the control of the particle-associated RNA polymerase activity and seems to be associated with proteins P1 and P3 
(PAlese et al. 1974; Ritchey and PAlese 1977). Each mRNA is employed as a template for new virion RNA synthesis and requires $\mathrm{P} 2$ and the nucleoprotein (NP). The precise mode of interaction of the RNA and polypeptide components in the infected cell is not clear, but evidence suggests that there is a coordinated packaging mechanism which results in the formation of particles with a single copy of each segment of RNA (LAVER and DOWNIE 1976). Virulence factor for influenza have not been assigned to specific polypeptides but a potential $t s$ live vaccine candidate has defects in proteins P3 and in NP (PALESE and RITCHEY 1977) which appear to be directly connected to attenuation of the virus in humans.

The primary step in uncoating influenza virus appears to be the removal of the outer envelope which releases the nucleoprotein active in primary transcription. The eight segments of influenza virus genome RNA are transcribed into new virion RNA individually (PoNS and RocHOVANSKY 1979). Initial transcription of the influenza genome is catalyzed by the particle-associated RNA polymerase which in vitro produces polyadenylated incomplete transcripts which seem identical to in vivo message (MCGEOCH and KITRON 1975). Two classes of RNA complementary to genome RNA (cRNA) appear in vivo, mRNA (capped) which is the smaller, is located on polysomes and is made at different times from the other cRNA class, the putative precursor of new virion RNA (SKEHEL and HAY 1978). The control of virus protein production would seem to be at the level of control of transcription into mRNA species (SKEHEL and HAY 1978). An RNA polymerase activity can be isolated from infected cells, which contains NP and P polypeptides (CALIGUIRI and Compans 1974) and which probably is analogous to the virion activity.

The production of new virion RNA needs functional protein systhesis in the infected cell (HAY et al. 1977) and continuous nucleoplasmic RNA synthesis for transcription to occur (SPOONER and BARRY 1977). The influenza viruses are unique in their need for active DNA transcription without, apparently, the formation of viral DNA; this seems to relate to the role of host message in transferring a cap structure to influenza mRNA.

The eight RNA fragments of both influenza A and B have been assigned to the production of the individual proteins of influenza: the two surface glycoproteins HA and NA; the two internal NP and M (matrix) proteins; NS (nonstructure) proteins of unknown function; and three P proteins involved, probably, in the synthesis of virus-specific RNA (RACANIELlo and PALESE 1979). HA can be divided into two parts, coded by the same gene: HA1 which binds to cell receptors and HA2 which is involved in insertion of HA into the membrane of the particle. Recently, it has been suggested that certain segments of RNA may code for two functional mRNA molecules (LAMB and CHOPPIN 1979). Antigenic shift, as we have seen, usually means that a new type of HA has appeared (perhaps accompanied by a new type of NA). About 16 different types of HA can be distinguished antigenically in virus isolated from human and other animals (LAVER and WEBSTER 1979). Recently the HA gene has been cloned in the plasmid pBR 322, and the sequence data suggest that there are major changes in amino acid sequence among "shifted" strains (Jou et al. 1980), probably so major that the different subtypes would have to have existed already. Drift, on the other hand, looks like a series of single base changes in the RNA (GERHART and WEBSTER 1978) affecting, probably, HA1. It is still not clear, however, which feature or features of the biology of influenza viruses make 
them prone to such frequent antigenic variation, a situation not seen with other animal RNA viruses.

The precursor to the viral envelope is a patch of cell plasma membrane which has been modified externally by the addition of spikes of HA and NA, and internally with a coating of M protein. Meanwhile, the ribonucleoprotein (RNP) which has formed in the cytoplasm migrates to these altered membrane patches and the particle is formed by budding at that point. Final release may be aided by neuraminidase activity. Influenza A maturation is blocked in HeLa cells, probably owing to a defect in a late event involving the cell membrane in maturation of the virus (CAliguiri and Holmes 1979).

\section{Influenza C Virus}

Influenza $\mathrm{C}$ differs from $\mathrm{A}$ and $\mathrm{B}$ in a number of respects. It has a different neuraminidase (KENDALL 1975) and a different carbohydrate composition in the structural glycoproteins as well as some host range pecularities; on the other hand it does have a segmented genome (between six and nine pieces is the current estimate, (PETRI et al. 1979; Compans et al. 1977). As we have seen, influenza A and B need host nuclear functions for replication and recent evidence (PETRI et al. 1979) suggests that the same is true for influenza $\mathrm{C}$, perhaps emphasizing the close similarity between $\mathrm{C}$ and the other two types.

It is over 25 years since the classic description by VoN MAGNUS (1954) of influenza particles with low infectivity and the capacity to interfere with normal infection and normal HA activity. Only recently have the physical and clinical properties of DI influenza particles come under serious scrutiny. DI particles have altered morphology and polypeptide composition compared with wild-type virus (LENARD and COMPANS 1975) and recent evidence suggests that general features of their genetic makeup are smaller quantities of the larger RNA segments and the presence of new small RNA segments. However, the entire complement of genome RNA is present, unlike most other DI systems. There is evidence that at least some (and perhaps all) of the new small RNAs are derived from part of other genome segments (NAYAK et al. 1978; NAKAJIMA et al. 1979).

\section{Influenza Infections}

Infection in humans probably occurs when air containing droplets of infected respiratory secretions is inhaled into the upper respiratory tract; the general spread can then be either upward, if mucociliary action prevails, or downward, if mucosal secretions swamp the action (Mims 1976; SwEET and SMITH 1980). The virus seems to be localized to the respiratory tract during the infectious cycle, and secretions from these tissues may have as many as $10^{6}$ infectious particles $/ \mathrm{ml}$. Peak virus production starts 1-2 days after infection and carries on for the next 2-3 days, although symptoms of the disease (fever, malaise, respiratory problems) may persist for longer (STUART-HARRIS 1965). The most feared complication is pneumonia, about one-fifth of which is directly viral while the majority of cases are related to bacterial infections. This increased susceptibility to bacterial infection is felt to be 
due to hindered disposal of inhaled bacteria caused by mechanical damage of the respiratory epithelium after virus infection (STUART-HARRIS 1979).

A program of annual vaccination of those considered to be at special risk from infections of the lower respiratory tract has been in force for several years. The killed vaccine preparations are available as whole virus or subunit (for children) and are usually polyvalent for the strains of influenza expected to be incubating in any one year (for 1979-1980 it was A/Brazil/78; A/Texas/77; B/Hong Kong/72). Most of the side effects of vaccination are akin to a mild dose of influenza, but rare complications such as immediate allergic responses or the Guillian-Barré syndrome may also occur. Vaccination seems to be of real benefit to the recipient, affording a high level of protection. In the U.S.S.R., a live vaccine has been in use for some time with results similar to those obtained with killed material. Potential advantages of live vaccine are better production of local immunity and use of smaller doses.

\section{H. Human Papillomavirus}

The human papillomavirus (HPV), commonly called the human wart virus, belongs to the papovavirus group. More common members of this group include SV40 of monkeys, polyomavirus of mice, and Shope papillomavirus of rabbits. Human papilloma virus is the only authentic human tumor virus, producing a transmissible benign neoplastic disease (warts).

The virus is an unenveloped, icosahedral particle, approximately $45-55 \mathrm{~nm}$ in diameter (Fig. 12). The DNA is in the form of a superhelical, closed, circular structure of approximately $5 \times 10^{6}$ daltons molecular weight. Essentially nothing is known of the replication strategy of the virus as it has never been reproducibly grown in tissue culture. Reports of growth of the virus in tissue culture (EISINGER et al. 1975) have appeared, but have not been corroborated. Until recently it was believed that only one type of human wart virus existed (GoLDSCHMIDT and KLIGMAN 1958). Recent experiments in which viral DNA was purified from virus particles extracted from wart tissue has indicated the existence of several genetically different strains. In these experiments, viral DNA was cleaved with restriction endonucleases. What emerged in the examination of 30 isolates were 3 strains (HPV1-3) which were closely related, and HPV-4, different from the others in both base composition and antigenicity (GISSMAN and ZUR HAUSEN 1976; GissmaN et al. 1977). These data indicated that HPV-4 predominated in warts with rather low particle production and HPV-1-3) in warts with high particle production. HPV-1 was found in more than $60 \%$ of the warts. A result of particular interest in these studies was that DNA from HPV-1 or HPV-4 failed to hybridize to DNA from different types of warts, indicating the existence of further types of papilloma viruses.

The pathogenesis of human warts is poorly understood. Human transmission experiments indicate an incubation period of 1-20 months. The location of the virus during the incubation is unknown. Warts are classified into major categories depending on their location or appearance: verruca vulgaris (common warts), verruca plana (flat warts), plantar warts, condyloma acuminatum (venereal warts), and filiform warts. Human warts seem to be the consequence of an infection of a single basal cell. Thus, each wart is probably a clonal descendent of a single in- 


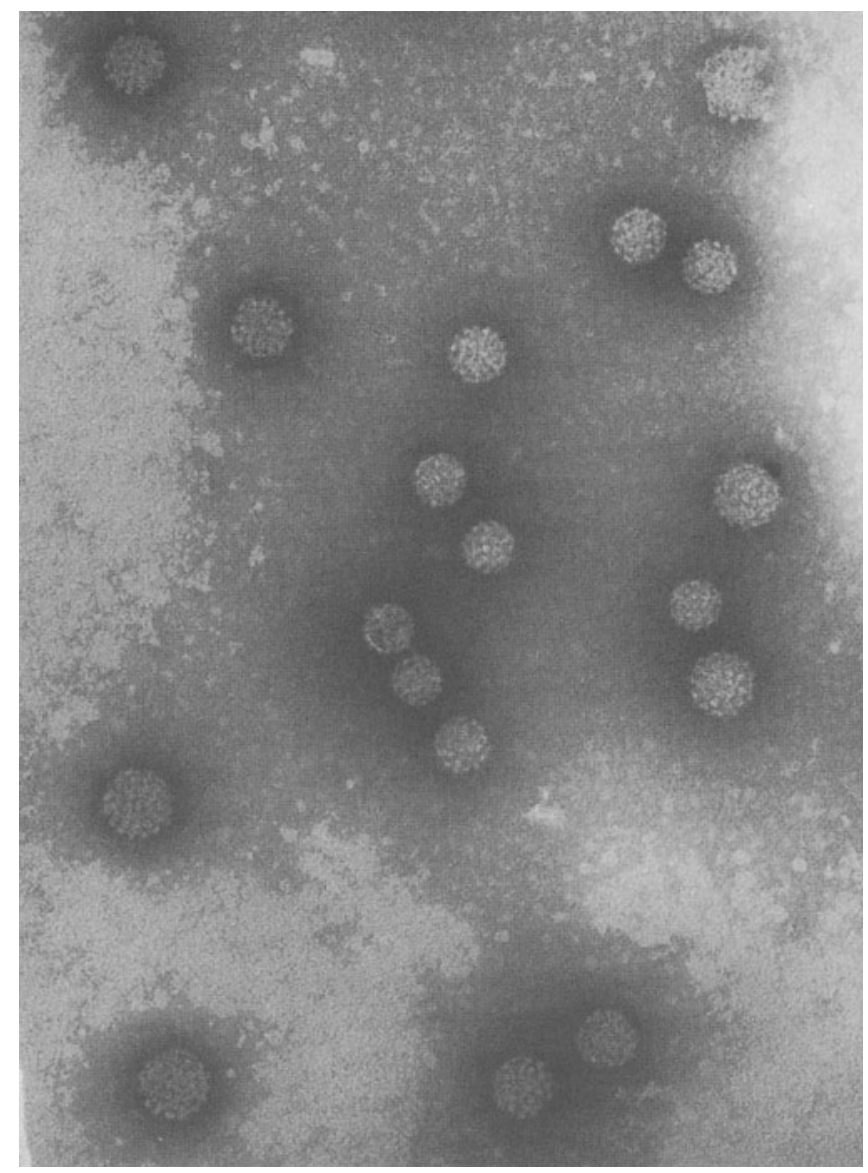

Fig. 12.Polyoma virus (45 $\mathrm{nm}$ diameter) and papilloma virus (human wart; $55 \mathrm{~nm}$ diameter) in a mixed preparation. (Courtesy of L. V. CRAWFORD)

fected cell (SAMBROOK 1977). The different clinical forms of warts are usually diagnosed by their gross appearance. Although warts may persist for years, most warts spontaneously resolve within 2 years; therapy is usually not instituted unless pain or discomfort results from the wart's presence. There are some data to suggest that certain types of warts (condylomata acuminatum and laryngeal warts) have an increased risk for malignant conversion (ZUR HAUSEN et al. 1978). The reason for this malignant transformation is unknown, but has been attributed to secondary factors (local irritation, etc.) rather than differences in the oncogenic properties of the viruses involved (ZUR HAUSEN et al. 1978).

\section{J. Paramyxoviruses}

Paramyxoviruses do not cause extensive cell destruction in vitro and persistent infections are readily established. Syncytium formation (cell fusion) is another characteristic feature of this group of viruses which, unlike the influenza viruses, do not 


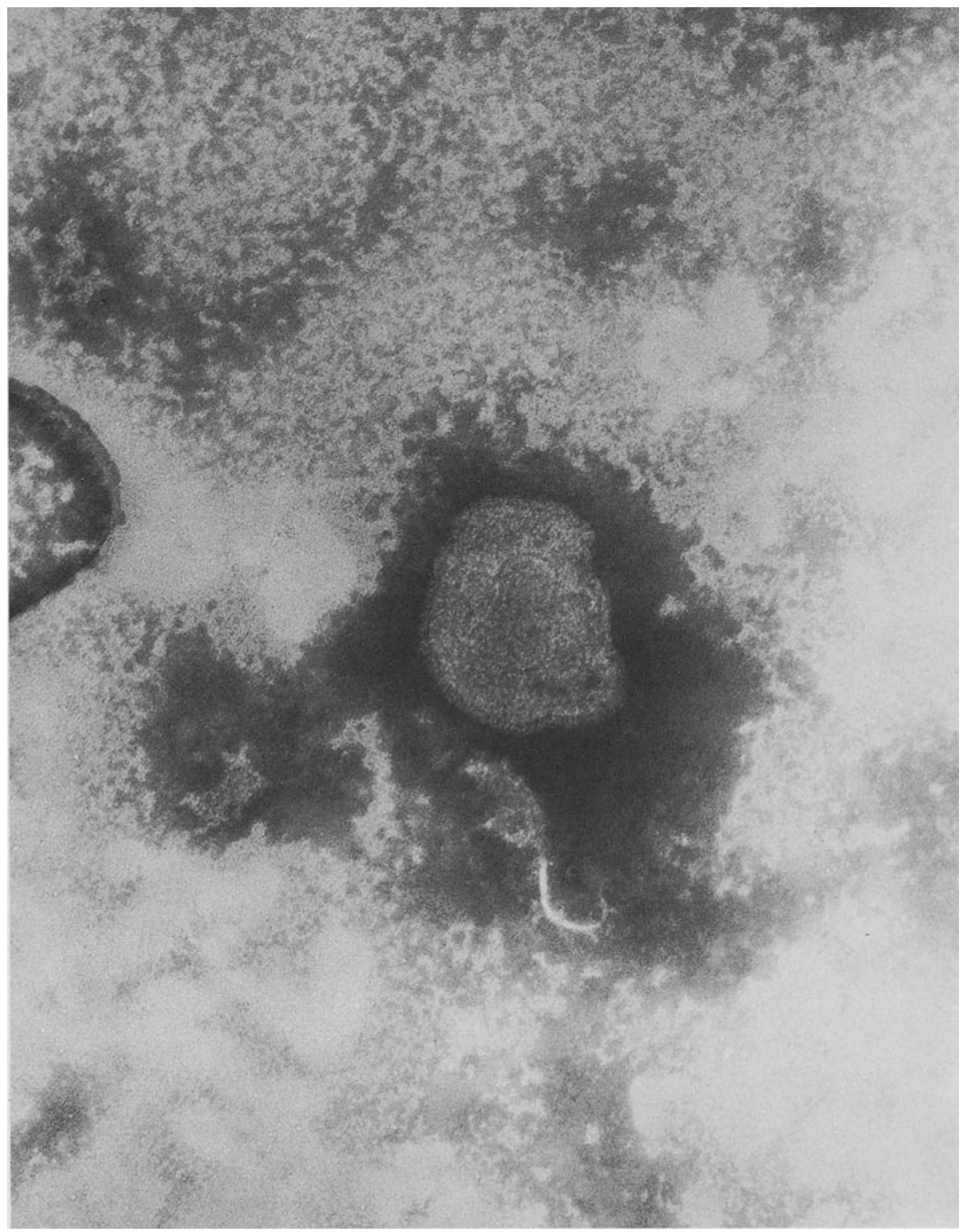

Fig. 13. Electron micrograph of parainfluenza 3 virus. (MADELEY 1978) $\times 200,000$

need an intact cell nucleus for complete growth. Measles, mumps, and respiratory syncytial virus (RSV) have one serotype, while parainfluenza virus has five. Measles has no neuraminidase, while RSV has no hemagglutin, no neuraminidase, no hemolysin, and does not hemadsorb. In addition, RSV particle morphology is different from the other members of the paramyxovirus group: it should probably be considered as a separate virus group. Measles, mumps, and the parainfluenza 
viruses are the viruses with which we are most concerned in this section: however, much of the molecular biology of paramyxovirus replication has been carried out with Newcastle disease virus (NDV), Sendai virus, and simian virus 5 (SV5).

Paramyxovirus particles vary somewhat in size and shape: the most common are 150-200 $\mathrm{nm}$ diameter, but much larger $(5-600 \mathrm{~nm})$ forms and filamentous particles can often be seen (Fig. 13). The internal nucleocapsid is helical ribonucleoprotein and is surrounded by a lipid and glycoprotein-containing envelope. The ribonucleoprotein contains the virion RNA, a single strand of negative polarity (antimessage) with only one segment present and this differentiates the paramyxoviruses from the (segmented) orthomyxoviruses like influenza. The sedimentation coefficient of the RNA is $50 S$, corresponding to a molecular weight of $5-5.6 \times 10^{6}$ daltons (KoLAKOFSKY et al. 1975). Some RNA annealing to genome RNA has been detected in virions, but its significance is obscure (KOLAKOFSKY and BRUTSCHI 1975). The RNA is not infectious and the virion contains an RNA polymerase activity which is presumably needed for successful infection.

Structural polypeptides of the virus consist of five virus-specific proteins, a glycoprotein $\mathrm{G}$ (80,000 daltons, P2 (70,000 daltons), NP (60,000 daltons), $\mathrm{F}_{1}$ (41,000 daltons), and M (31,000 daltons) (STALlCUP et al. 1979; Graves et al. 1978). Three other proteins are also found in the virus, L [a high molecular weight protein of undefined origin, (150,000-200,000 daltons, actin (43,000 daltons), and $F_{2}$ (15,000 daltons)], a probable relative of $F_{1}$ (STALlCUP et al. 1979; TYRRELL and NorRBY 1978; SCHEID and CHOPPIN 1977). The $G$ and $F_{1}$ polypeptides are associated with the external structure of the envelope, while $M$ was confirmed to be the matrix protein of measles. Viral RNA seems to exist in contact with L and NP, with varying amounts of $\mathrm{P} 2$ and $\mathrm{M}$ present, to form the nucleocapsid (STALlCUP et al. 1979). The $F$ polypeptide $\left(F_{1}\right.$ and $F_{2}$; SCHEID and CHOPPIN 1977) and the $G$ polypeptide are both glycosylated and the former is probably hemolysin, while the latter is hemagglutinating (NORRBY and GolLMAR 1975). By analogy with other paramyxoviruses, the L polypeptide is probably involved in RNA polymerase activity (BUETTI and CHOPPIN 1977) and the M protein may also play a role in the regulation of transcription (MARX et al. 1974). Finally, the M protein appears to differ between wild-type measles and SSPE virus in electrophoretic mobility (HALL et al. 1978).

Measles virus particles recognize and attach to surface receptors on susceptible cells by a means different from the other paramyxoviruses: measles does not recognize neuraminic acid, but possesses a neuraminidase activity (NoRRBY 1962). As mentioned previously, the virus has a hemolysis function. Internalization of measles virus is presumably carried out by the same mechanism as for other members of the group; both viropexis and membrane fusion mechanisms have been proposed, with the weight of evidence favoring the latter scheme.

A transcription complex containing virion polypeptides can be isolated from paramyxovirus-infected cells and this complex will transcribe virion RNA into complementary RNA species to form mRNA (BUETTI and CHOPPIN 1977). Messages appear to be of $35 S$ and $18 S$ and, are of sufficient size to code for all of the viral polypeptides. Formation of new virion RNA needs prior protein synthesis in infected cells and it is uncertain whether the same enzymes form both message and new viral genomes. It does seem, however, that message production occurs from 
a single inititation site to give separate mRNA molecules for each polypeptide. Viral message is polyadenylated and capped, the enzymes for which, in addition to others which may be required (e.g., protein kinase) may be of viral origin (CoLONNO and STONE 1976).

Paramyxovirus polypeptides appear to be made in relative amounts consistent with the quantities of specific mRNAs produced in infected cells; in this respect, the negative-strand viruses in general seem to follow the strategy of uninfected and DNA virus-infected animal cells (CoLLINS and BRATT 1973). It seems likely that the control of mRNA abundance is achieved through the use of a single promoter, with the most abundant message being read proximal to the promoter and the least abundant most distal. This "polarity" of reading from a single promoter may be followed by specific cleavage events to form individual messages or other mechanisms may operate (e.g., further promoters are functional only when message has been read from an earlier one; GLAZIER et al. 1977). However this may be, the gene order obtained from UV mapping is (in Sendai) 3'-NP-F-M,P-HN-L-5'. HN would be equivalent to $G$ in measles virus and $F$ to $F_{1}$ and $F_{2}$. Newly formed virion RNA and nucleocapsid proteins self-assemble in the cytoplasm as individual units or aggregates and migrate to the inner surface of the plasma membrane at points at which the M protein (internally) and the glycoproteins (externally) have become incorporated. Arrival of nucleocapsid at the plasma membrane seems to trigger the formation of external spikes on that part of the membrane; the virion then buds out from the surface.

One recurring problem in the analysis of cells infected with measles virus is that the background of synthesis of host proteins remains high (measles is a poor inhibitor of cell synthesis) and the yield of virus from infected cells is not large. Four immunoprecipitable virus polypeptides $(\mathrm{H}, \mathrm{P}, \mathrm{NP}$, and $\mathrm{M}$ ) have recently been made in vitro (NIVELEAU and WILD 1979) and approaches like this may help to solve some of the problems encountered. Recombination with paramyxoviruses (as with all negative polarity RNA viruses) has not been detected, but complementation between mutants is a normal occurrence. There are five complementation groups for NDV and measles (TSIPIS and BRATT 1976; BRESHKIN et al. 1977) and seven for Sendai and RSV (Porter et al. 1974; Gimenez and Pringle 1978).

\section{Measles Infection}

Reported measles cases in the United States before the introduction of vaccine (1963) amounted to 400,000/year. In all likelihood, however, the true incidence was much greater, probably involving, in one form or another, the entire child population. After a 10-12-day incubation period most of those infected develop fever and upper respiratory tract infection symptoms with conjunctivitis, followed by a rash; however, complications are quite common. These range from otitis media and pneumonia caused by subsequent bacterial infection to encephalitis and subacute sclerosing panencephalitis (SSPE). In encephalitis cases there are frequent neurologic sequelae and it may be that in some measles cases not diagnosed as encephalitis, mild neurologic sequelae may be present (FULGITINI et al. 1967). SSPE is a rare disease, invariably fatal, which can develop some time after a measles infection. It is characterized by a slow development of neuronal degeneration and 
very high levels of measles antibody in serum, and specifically, in the cerebrospinal fluid. The virus involved is probably a variant of wild-type measles virus.

Virus administered to the nose or the lower respiratory tract is efficiently infectious (KRESS et al. 1961) and aerosol transmission from infected people is probably the main source. The respiratory mucosa is normally the best source of disseminated virus, but measles will grow in most body tissues. Respiratory secretions are infectious until antibody can be produced and urine remains infectious for a few days longer. There is viremia during the prodromal period, but the study of sequence of spread and release of virus has been hampered by the difficulty of early diagnosis and of efficient virus growth in vitro. However, the Koplik's spots which appear in the oral mucosa toward the end of the prodromal period contain virus (SURINGA et al. 1970), as do the cells in the macule of the measles rash. Levels of virus in the body quickly fall after the rash is evident, but some virus must occasionally persist for a time in SSPE for example, in at least part of the population. It has recently been shown that infection of marmosets offers a laboratory model for distinguishing differences in virulence of natural and attenuated strains of measles virus (AlBRECHT et al. 1980). This should allow, for the first time, a characterization of factors (route of inoculation, virus strain, etc.) important in the pathogenesis of the disease. The vaccine in current use is a highly attenuated live vaccine which causes a mild or inapparent noncommunicable infection. Earlier attempts to control measles with killed vaccine led to hypersensitization of some recipients with subsequent problems, and early types of live vaccine also caused too high a level of reaction. The incidence of measles has not, however, fallen to levels which were predicted in the early days of vaccine use (SPENCER et al. 1967), probably for a number of reasons. The chief one seems to be the failure to reach a high enough percentage of susceptible people (especially in disadvantaged areas), but a second factor may be that the immunity conferred by the vaccine is less reliable than in natural infection and significant numbers are becoming susceptible again (CHERry et al. 1972).

\section{Persistent Measles Infection}

In a recent study, it has been shown that both the vaccine strain (Edmonston) and an SSPE isolate of measles virus can persistently infect a variety of cell types in vitro (neural and nonneural) (LUCAS et al. 1978). When this occurs, virus production becomes thermolabile despite the fact that the virus itself is not temperature sensitive. Thus, a feature of the cell (or the virus-cell interaction) is different in persistent (in contrast to lytic) infection. In hamster cells persistently infected with measles virus, a similar phenomenon occurs which has been traced to temperaturesensitive production of structural polypeptides and temperature-sensitive failure of structural proteins to become associated with infected cell membranes (FISHER and RAPP 1979).

SSPE patients have high levels of circulating antibody (serum and cerebrospinal fluid) against all the major virion polypeptides of measles virus, except the membrane protein M (HALL et al. 1979) and cells cultured from the brain of an SSPE patient do not produce any M protein (HALL and CHOPPIN 1979). Such a failure in production would result in a failure to complete new infectious virus par- 
ticles and could conceivably, lead to an abortive infection. The basis for the failure to produce $\mathrm{M}$ (transcription or posttranscription) is not clear. Persistent infections in HeLa cells seem to be associated with the production of viral mutants (WECHSLER et al. 1979). These cells produced altered structural proteins ( $\mathrm{M}$ and possibly $\mathrm{H}$ and NP) and virus obtained from them is temperature sensitive, continuing to express polypeptide defects in subsequent normal infections. Defective interfering particles from either wild-type measles virus or from an SSPE isolate show both homotypic and heterotypic interference, another indication of the relatedness of the two viruses (FERGUSON and MURPHY 1980).

\section{Mumps Infection}

Mumps is primarily a disease of young school-age children and is generally selflimiting. A wide range of responses to infection reflects the ability of the virus to cause generalized infections with a preference for glandular and nervous tissue. Virus is transmitted via aerosols from infected throat or salivary gland secretions and is somewhat less contagious than measles. After uptake into the respiratory tract, mumps virus multiplies locally and in lymph glands, causing viremia which disseminates the virus widely, e.g., to the testes (orchitis is a quite frequent complication of mumps infection). The virus is present in urine and has been isolated from other human body fluids. The common syndrome is swelling of the parotid gland or glands, but an assortment of other syndromes is found (PHILIP et al. 1959). Mumps is the most common cause of viral encephalitis in the United States and deafness is an important residual complication of the disease.

Among military populations, mumps has always been a major public health problem, and vaccination was first used with any real success by the Finnish armed forces, who treated servicemen with a killed vaccine to give a greater than $90 \%$ reduction in the incidence of the disease (PENTTINEN et al. 1968). The vaccine in current use in the United States was introduced in 1967 and has proved to be a useful, well-tolerated live vaccine. Vaccination usually produces a mild (or subclinical) infection which is noncommunicable and has few side effects. It is too early yet to know whether immunity conferred by the vaccine is permanant, but continued protection over 10 years has been reported. The vaccine is normally given as a trivalent preparation (measles, mumps, rubella), thus while mumps itself is not regarded as a first priority public health problem, its association with these two other vaccines has made the use of mumps vaccine widespread. It has yet to be established whether childhood mumps vaccination will prevent adult infections and their attendant, quite serious, complications.

\section{Parainfluenza Infection}

All four types of parainfluenza virus (parainfluenza 1,2, 3, and 4 viruses) cause lower respiratory tract infections in young children and upper tract infections in older children and adults. Parainfluenza 3 virus appears to be the most effective in spreading through populations (CHANOCK et al. 1963) and is second only to respiratory syncytial virus as a source of pneumonia and bronchiolitis. Parainfluenza 3 infection is endemic; infant infection can occur in the presence of maternal an- 
tibodies and reinfection of older children and adults has been described. The virus is spread via direct contact or by droplet dispersion and presumably replicates in the respiratory tissues. While viremia has been reported (Gross et al. 1973), little clinical sign of disseminated disease is apparent. Clinical signs vary from mild afebrile upper respiratory tract infection to serious (life-threatening) lower respiratory tract disease.

Both parainfluenza 1 and 2 are associated with croup, a function presumably of the severe inflammatory response of the glottal tissues, and disease tends to be epidemic on a 2-year cycle, with parainfluenza 2 responsible for less serious problems than parainfluenza 1. Maternal antibody prevents parainfluenza 1 and 2 infection. Parainfluenza 4 virus is not often encountered and disease associated with it is usually trivial. All of these lesser parainfluenza viruses have antigenically related animal counterparts; for example, Sendai virus shares antigens with parainfluenza 1 virus and SV5 with parainfluenza 2 virus.

\section{K. Picornaviruses}

In humans and in other animals, the picornaviruses constitute one of the largest and most important sources of virus disease. The common cold and, of course, poliomyelitis are problems of which all are aware, even if, in the latter case, the false impression abounds that the disease has disappeared, thanks to effective vaccination programs. In the domestic animal world, there are few more feared infections than foot-and-mouth disease: it follows, therefore, that both medical and veterinary research has traditionally focused on the various members of this family, resulting in the current quite detailed state of knowledge of replication of picornaviruses (PEREZ-BERCOFF 1979).

Four genera; enterovirus, cardiovirus, rhinovirus, and aphthovirus (foot-andmouth) make up the Picornaviridae family and share many common features. Picornaviruses are very stable to inactivation by several agents, for example, but acid lability (correlated with bouyant density) distinguishes the aphthoviruses (unstable below $\mathrm{pH}$ 7) from the rhinoviruses (unstable below $\mathrm{pH}$ 5) and the cardioviruses and enteroviruses (stable to $\mathrm{pH} 4$ or less; NEWMAN et al. 1973).

\section{Structure and Replication}

The picornaviruses (Fig. 14) all have a capsid with cubic symmetry and no envelope surrounding single-stranded RNA of positive (message) polarity. In the capsid are four polypeptides, VP1-4; VP1, 2, and 3 have molecular weights of about 30,000 daltons, while VP4 is about one-third as large. The 60 subunit model for the virion is now generally accepted (BALTIMORE 1971) with each of the polypeptides present in equivalent molar amounts.

The capsid structure is put together in a series of steps (REUKERT 1976). These steps start with the assembly of a precursor chain (1), cleavage and rearrangement of an intermediate (2), assembly of the intermediate and insertion of the RNA (3), and finally (4) cleavage and rearrangement of the complete shell. The protein activity involved in steps 2 and 4 can be detected in cell-free extracts $2-3 \mathrm{~h}$ after infection (ESTEBAN and KERR 1974) but it is difficult to demonstrate the process of 


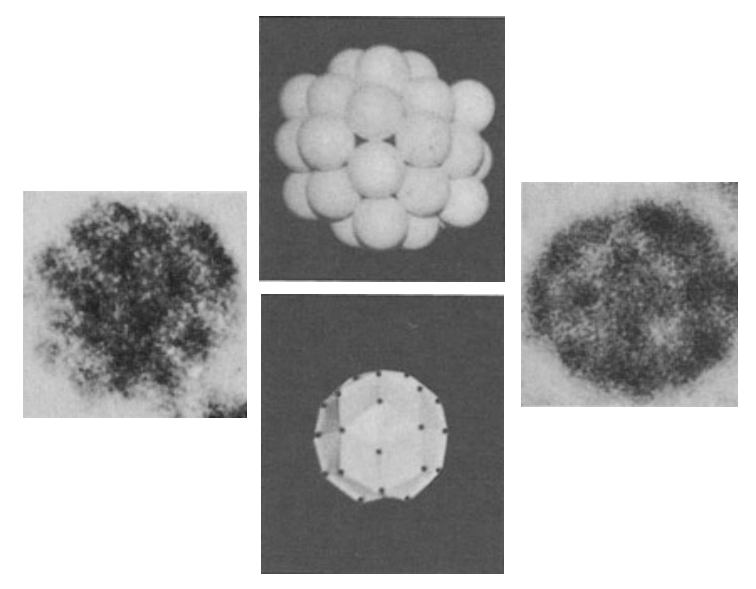

Fig. 14. Electron micrograph of a purified preparation of poliovirus negatively stained. (Courtesy of H. MAYOR) $\times 300,000$

virion assembly in vitro, although reconstitution of some infectivity from dissociated particles has been reported (DrZENIEK and BILlelo 1972). Minor species of polypeptide also occur in picornavirus capsids, including VP0 (the uncleaved VP2 plus VP4), the viral component of the RNA polymerase activity and the uncleaved VP1 and VP3 (REUKerT et al. 1969; Ziola and SCRABA 1974; SANGAR et al. 1976).

The viral RNA of molecular weight about $2.8 \times 10^{6}$ daltons, is replicated via an intermediate involving a complementary RNA strand. The replicative intermediate (RI) is generally thought to be involved in the process of producing several new viral RNA strands and recent work suggests that the basic structure is a double-stranded one (MEYER et al. 1978). Replication of the viral RNA takes place via an RNA polymerase activity, at least a component of which is virus coded (FLANAGAN and BALTIMORE 1979). Also important in RNA replication is the VPg protein which is found covalently bound to the $5^{\prime}$ end of viral RNA during replication, to virion RNA but not to functional messages (LEE et al. 1977; GoLINI et al. 1978; SANGAR 1979). It is not certain that this is a virus-coded protein, but it is attached to the virus RNA through a tyrosine- $0^{4}$-phosphodiester link to uridine monophosphate (UMP; AMBROS and BALTIMORE 1979). VPg can be removed from the RNA by an enzyme (cellular) which leaves the RNA intact, and at least one function for VPg seems to be in initiation of RNA replication (CALIGUIRI 1974; Nомото et al. 1977). Even with VPg removed, however, the $5^{\prime}$ end of picornavirus mRNA is quite different from most other eukaryotic mRNAs in that it has no "cap" structure (SHATKIN 1976). On the other hand, the 3' end of the RNA seems quite oridnary, with a poly(A) tract of between 40 and 100 bases, apparently genetically determined (YOGO and WIMMER 1973); infectivity of viral RNA is related to the presence of a suitable poly(A) sequence (HrUBY and RoBERTs 1976). A second homopolymer tract, poly $(\mathrm{C})$, is found internally in the cardioviruses and aphthoviruses, a point of differentiation between these and the other two picornavirus genera (Brown et al. 1974). This tract is located close to the $5^{\prime}$ end of the RNA and may be related to virulence of the virus in vivo (HARRIS and BROWN 1977). 
The genetic information for the RNA polymerase activity or activities seems to include the sequence for the protease activity (protein 22 in encephalomyocarditis virus) and possibly the VPg protein (PALMENBERG et al. 1979). The poliovirus noncapsid viral protein (NCVP4) is capable of elongation of a RNA chain but cannot initiate new synthesis in vitro without a primer (FLANAGAN and BALTIMORE 1979): it also has poly(U) polymerase activity. Partial purification of a soluble complex which will copy poliovirus RNA without a primer indicates (DASGUPTA et al. 1979) that both NCVP4 and NCVP2 are needed for this activity: this preparation seems to prefer poliovirus RNA to others tested.

Picornavirus mRNA is translated into a single large precursor polypeptide, the result of a single initiation site for protein synthesis: a second ribosome binding seems to occur in vitro in poliovirus RNA (JENSE et al. 1978). A series of specific cleavages occur (at the time of translation) to give several primary products (detectable in vivo) which can be further cleaved. At least some of these proteolytic steps are catalyzed by a virus-coded enzyme [to yield VP0, VP3, and VP4 in poliovirus (KORANT 1979), for example] but others may be cell-specific processes. A control scheme for the balancing of RNA and protein production in poliovirusinfected cells has been put forward by COOPER (1977).

Almost 20 years ago recombination among poliovirus mutants was described, yet the mechanism behind this unique (for nonsegmented RNA viruses) property of the picornaviruses remains obscure (COOPER 1977). A consistent genetic map based on recombination shows that structural polypeptides map at the $5^{\prime}$ end of the genome, while the $3^{\prime}$ end is taken up with RNA-polymerizing activities. Pactamycin mapping, which, owing to preferential inhibition of translation initiation, allows ordering $\left(5^{\prime} \rightarrow 3^{\prime}\right)$ of gene functions in a picornavirus RNA, agrees with the genetic map and gives rather more detail on the individual polypeptides (SUMMERS and MAIZEL 1971). Recently, the center of the poliovirus genome has been shown to code for a protease activity.

\section{Picornavirus Infections}

Many of the picornaviruses have a very restricted host range, like poliovirus, which can only infect humans and some laboratory primates. The primary reason for this seems to be the lack of a suitable receptor on the surface of cells. Permissive-nonpermissive cell hybrids have been constructed which show that chromosome 19 of human cells codes for at least part of the receptor molecule for poliovirus (MILLER et al. 1974). In susceptible cells, the cytopathic effect caused by enteroviruses is extensive, the cells quickly becoming detached from the growing surface. Virus spreads by dissemination into culture medium. While intact virus in incapable of attachment to nonsusceptible cells, the extracted viral RNA can infect a wide range of cell types. Ability (or lack of it) to recognize specific cell surfaces through a receptor would seem to be a major factor in determining the pathogenicity of the picornaviruses. Interference experiments suggest that different receptors exist for the various groups of picornaviruses and even for specific members inside these groups (CROWELL 1976). Attachment per se may only account for part of the ability of a picornavirus to infect a cell successfully; however, examples are known of cells which have receptors for virus but never show signs of infection. What follows 


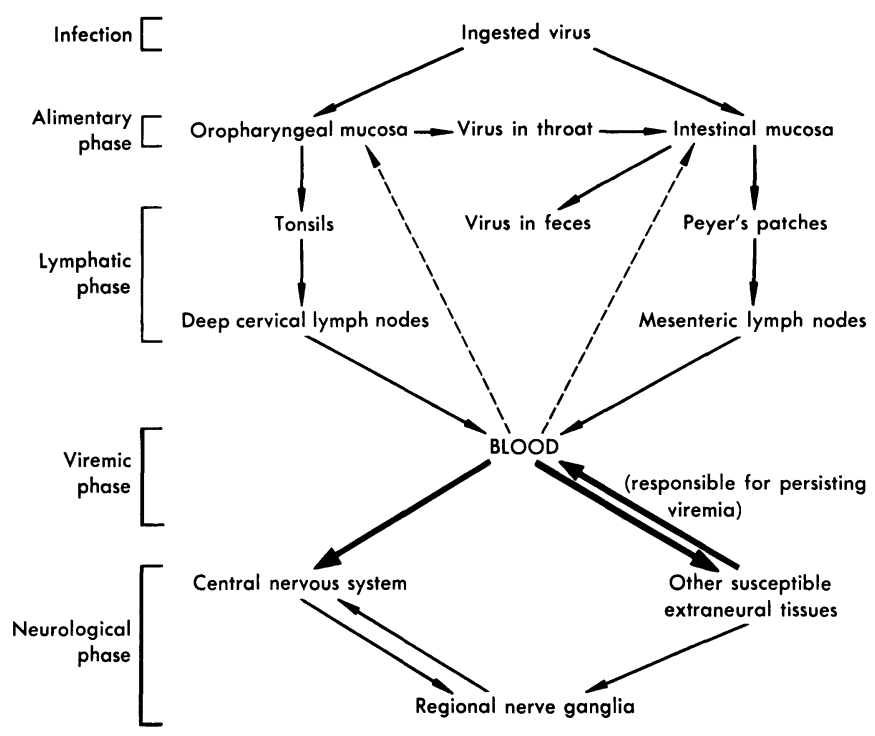

Fig. 15. A model for the pathogenesis of poliomyelitis based on a synthesis of data obtained in humans and chimpanzees. (DAvIS et al. 1973)

attachment on the cell surface presumably is another cell-specific parameter of which we know little, although it does seem to involve partial "uncoating" of the particle with, perhaps, some loss of polypeptide (CROWELL and PHILIPSON 1971).

Of the four capsid polypeptides, VP4 is probably exposed on the virion so as to interact with the cell surface receptor or receptors (WETZ and HABERMEHL 1979) although VP3 may also play an important role on the virion surface (WETZ and HABERMEHL 1979). The crucial factors in neurovirulence of poliovirus are still unknown, but a recent analysis of the Sabin vaccine strain of polio has shown several amino acid alterations in VP1, VP3, and VP4 (KEW et al. 1980). Whether these alterations relate directly to loss of virulence has yet to be established. The nature of the receptor on the cell surface is not known, but seems to be a complex of several types of macromolecule firmly inserted in the cell membrane: inactivation by chymotrypsin needs protein synthesis to restore activity and a soluble extract with some biologic activity against coxsackievirus B3 has recently been prepared (CROWELL and SIAK 1978).

Virus is spread from host to host usually via infected body fluids (e.g., fecaloral for most enteroviruses, from nasal secretion for rhinoviruses), and subclinical virus shedders are common. In rhinovirus infection, virus probably has to reach the nasal (or conjunctival) mucosa for efficient infection (HENDLEY et al. 1973) when localized edema and hyperemia follow with the production of fluid. Virus production takes about 3 days to peak and shedding of virus for several days ensues (Douglas 1970). Initial replication of the enteroviruses is probably in the lymph tissue of the gut and the pharynx, from where virus enters the blood and is distributed to target organs or for further replication in the reticuloendothelial system. Neurovirulent poliovirus will multiply in and kill certain cell types in the brain and spinal cord (MELNICK 1976; Fig. 15). 
Over the past 25 years the incidence of poliomyelitis has decreased dramatically owing to the widespread use of vaccination: in the United States there were 18,000 cases of paralytic disease in 1954 and less than 20 in 1973-1978: The formalin-inactivated poliovirus vaccine (ipv) (Salk) alone was used until 1963 when the trivalent live attenuated oral poliovirus vaccine (opv) (Sabin) was introduced. Each primary vaccination (three doses) with opv will produce long-lasting immunity to all 3 poliovirus types in more than $95 \%$ of those vaccinated.

The opv is the preferred vaccine in the United States for a number of reasons; it is well tolerated, simple to administer, produces good intestinal immunity, causes fortuitous immunization of some contacts of vaccinees and has removed paralytic poliomyelitis as a disease in the United States. Some countries still use ipv, though, and there is little apparent difference between the effectiveness of opv and currently available ipv. Indeed, ipv is preferred over opv for patients with immunodeficiency difficulties. In very rare cases, some paralysis has followed the administration of opv in healthy individuals, but both opv and ipv remain among the best tolerated of all vaccines. The success of the vaccination programs has led to a feeling among the population that polio has disappeared and that vaccination is no longer necessary. Unhappily, this is not true: wild poliovirus strains (the cause of significant acquired immunity in the past) no longer circulate as they once did, and unvaccinated children run the risk of being involved in an outbreak of a kind reminiscient of the prevaccination period.

\section{Reoviruses}

The family Reoviridae is primarily defined by the presence of a segmented, doublestranded RNA genome, and is composed of six genera, Orthoreovirus, orbivirus, cypovirus, phytoreovirus, fijivirus, and rotavirus (JoKLIK et al. 1980). Within the six genera, possible human pathogens are found only in three genera, orthoreovirus, orbivirus, and rotavirus. This section will be primarily concerned with orthoreovirus and orbivirus; the rotaviruses will be covered separately. While all the groups are classified as Reoviridae, on the basis of the presence of a segmented double-stranded RNA genome, their relationship ends there. There appears to be no antigenic relationship between genera, the number of genome segments vary from 12 to 2, and virion structure is different (JoKLIK et al. 1980a). The name reovirus is a siglum for "respiratory enteric orphan"; when these viruses were first isolated they were not found in association with any disease (FENNER and WHITE 1976). Since that time new viruses have been discovered in a variety of animal species, but the name has stuck.

The reoviruses contain double-stranded RNA, which is enclosed in a characteristic double capsid shell structure of icosahedral symmetry (SHATKIN et al. 1977; Fig. 16). The orbiviruses appear to possess a single capsid (FenNeR and White 1976). The double-stranded RNA (ds RNA) of the reoviruses (types 1, 2, 3) consists of ten molecules in three categories of molecular weight: large RNA, L1-3, $2.3-2.7 \times 10^{6}$ daltons; medium RNA, M1-3, 1.3-1.6 $\times 10^{6}$ daltons, and small RNA, S1, $0.6-0.9 \times 10^{6}$ daltons, the total molecular weight being about $15 \times 10^{6}$ daltons (SHATKIN et al. 1977). The nature of the arrangement of the ten segments within the genome is unknown. The plus strand (same polarity as mRNA) of each 


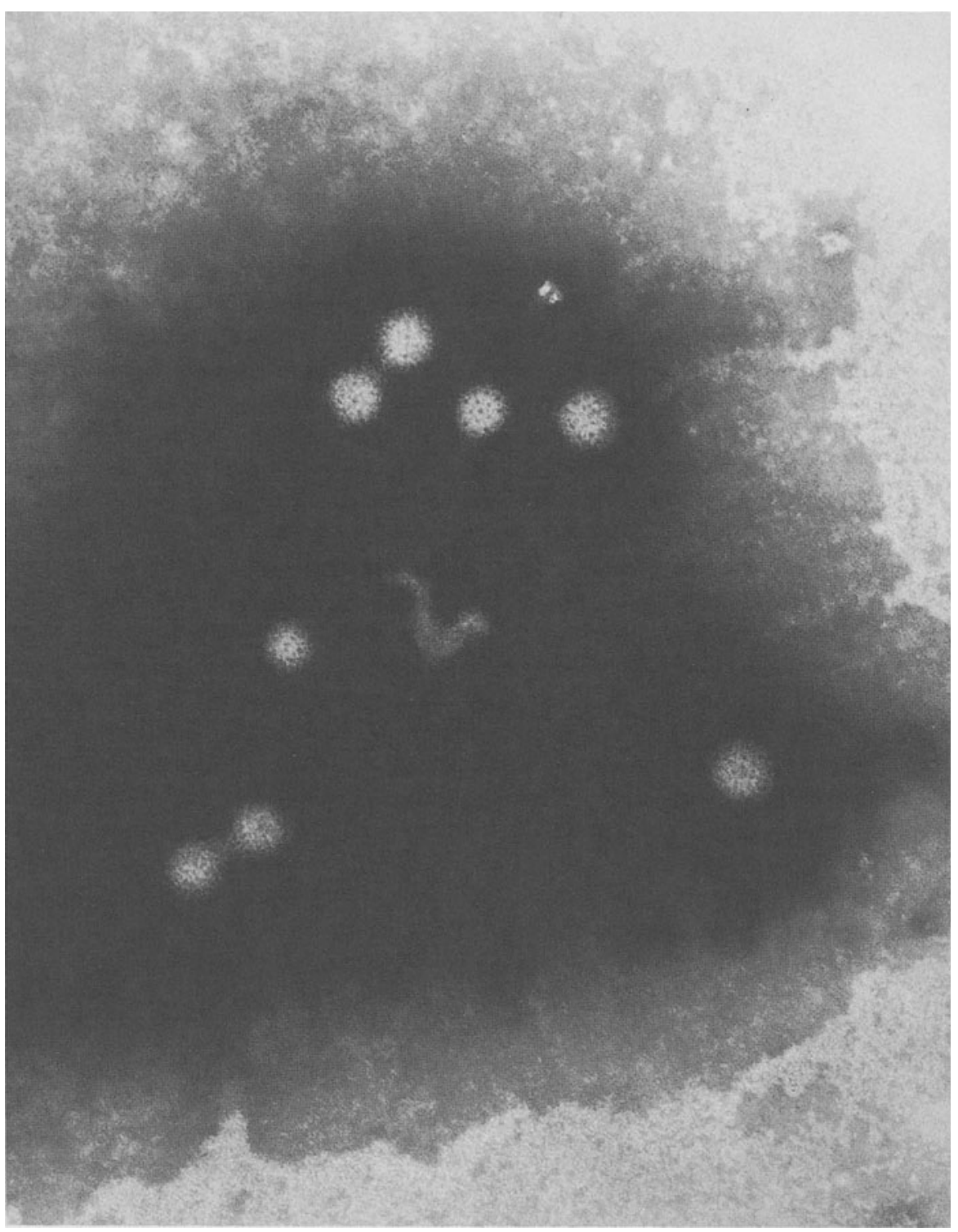

Fig. 16. Reovirus type 3. Particles demonstrate the characteristic double-shell structure of reovirions. (MADELEY 1978) $\times 200,000$

dsRNA segment has been shown to be "capped" at the 5 ' end (FURUICHI et al. $1975 \mathrm{a})$ and each segment serves as a monocistronic message for the production of a unique polypeptide (BoTH et al. 1975).

The polypeptides of reoviruses fall into three size classes $\lambda, \mu$, and $\delta$ (ZWEERINK et al. 1971; SHATKIN et al. 1976) which are composed of seven capsid proteins, $\lambda 1-2$, $\mu 1-2, \delta 1-3$. All are primary gene products except $\mu 2$ which is derived from $\mu 1$ 
(ZWEERINK et al. 1971). Three proteins $\sigma 3, \mu 2$, and $\sigma 1$ constitute the outer shell of the virion and account for about $65 \%$ of the virion protein (JoKLIK 1974); $\lambda 1, \lambda 2$, $\delta 2$, and $\mu$ l make up the core proteins (JOKLIK 1974). A recent report (CARTER 1979) indicates that some structural proteins may contain a covalently linked oligoadenylate moiety, the function of which is unknown.

Reovirions also contain approximately 3,500 molecules of single-stranded oligonucleotide composed of two classes; one class, pyrimidine-rich heteropolymers 3-8 nucleotides long (Bellamy and Hole 1970; Nichols et al. 1972; StoltzFus and BANERJEE 1972), and a second class composed of polyadenylic acid 10-20 bases long (Stoltzfus and BANERJEe 1972; Nichols et al. 1972; CARTER et al. 1974a). They do not appear to be necessary for infectivity (CARTER et al. 1974) and are thought to be products of abortive transcription (NICHOLS et al. 1972; STOLTZFUS and BANERJEE 1972).

Reoviruses enter the cell by phagocytosis, become enclosed in phagocytic vesicles which then fuse with liposomes (DALES et al. 1965). In the liposomes the virions are converted to subviral particles (SVP) by removal of the outer protein shell (SILVERSTEIN and DALES 1968), a process which activates a virion-associated polymerase (SILVERSTEIN et al. 1970). Transcription of the dsRNA is by a conservative mechanism (SKEHEL and JOKLIK 1969), viral plus strands being synthesized from only one strand. These plus strands serve as both mRNA and as templates for synthesis of minus strand RNA to form dsRNA (SKEHEL and JoKLIK 1969; ACs et al. 1971). Parental genomes remain in SVPs for the entire replication cycle (ZwEERINK et al. 1972). These SVPs contain the enzymes responsible for methylating (capping) reovirus mRNA (SHATKIN 1974), however, these mRNA molecules produced during infection do not contain poly(A) (STOLTzFus et al. 1973). Two recent reports have demonstrated that progeny SVPs are not capable of "capping" mRNA, therefore, leaving early mRNA "capped" and later mRNA "uncapped" (SKuP and MILLWARD 1980; ZARBL et al. 1980). This may be the mechanism for reovirus inhibition of host protein synthesis (SKUP and MILLWARD 1980; ZARBL et al. 1980). The processes involved in the final maturation of reoviruses are poorly understood, but the virus particles are probably released when the infected cell lyses (JoKLIK 1974).

The human reoviruses have not been proven to have a causal relationship to any disease, but are, however, frequently isolated from people with respiratory infection, and gastroenteritis. They are also frequently recovered from healthy individuals. Infection of volunteers has shown the virus to occur both in the respiratory and gastrointestinal tract and a recent report has shown that reovirus is capable of inducing diabetes mellitus in mice, raising the possibility of a similar situation in humans owing to the ubiquity of reovirus infections (ONODERA et al. 1978). Orbiviruses are responsible for Colorado tick fever (caused by Colorado tick fever virus). The onset of the disease is sudden, characterized by fever, chills, and generalized aches, but serious complications are limited almost exclusively to children. The disease is transmitted by the bite of an infect tick (FENNER and WHITE 1976).

Despite the lack of major epidemiologic importance, reoviruses have been important in defining some molecular factors in viral virulence. A recent publication indicated that the $\mathrm{S} 1$ gene was responsible for the differing cell tropisms seen among the three types and also was the major determinant of neurovirulence 
(WEINER et al. 1977, 1980). The type $1 \mathrm{~S} 1$ gene was shown to be responsible for ependymal damage with subsequent hydrocephalus and the type $3 \mathrm{~S} 1$ gene was responsible for neuronal necrosis and neurovirulence (WEINER et al. 1977, 1980). The authors postulated that these differences were due to the specific interaction of $\sigma 1$, the outer capsid polypeptide (the $\mathrm{S} 1$ gene product) with receptors on either ependymal or neuronal cells (WeINER et al. 1977, 1980). The S1 gene has also been shown to be the predominant gene determining the specificity of cytotoxic T-cells (FINBERG et al. 1979) and the gene responsible for the type-specific hemagglutination observed with these viruses (WEINER et al. 1978).

\section{RNA Tumor Viruses}

During the past decade, research on RNA tumor viruses, their replication, transforming capabilities, and possible role or roles in human cancers has been of primary interest in molecular virology. The attractiveness of this group of viruses stems from their ability to cause (in many animal species) a variety of types of tumors (leukemia, sarcomas, etc.), from the finding that the genome of these viruses may be a part of the "normal" genome of many animals (PANEM et al. 1975), and from the feeling that by studying these viruses we may begin to understand the interactions which lead to cell transformation. However, despite a clear role in animal tumors, there is still no definitive proof that any of these viruses are related to any human cancers.

The RNA tumor viruses have been classified as a family called Retroviridae. This family contains viruses with similar structural and physical characteristics, but not necessarily oncogenic potential. The family is defined by four major characteristics: (a) the architecture of the virion; (b) a diploid single-stranded RNA genome of positive polarity; (c) the presence of reverse transcriptase in the virion; and (d) a requirement for a DNA intermediate in viral replication (BISHOP 1978). Within this group the viruses are classified into genera based on morphological characteristics. The first genus, oncornavirus $C$, contains the $C$ particles (Fig. 17). This is the largest genus and contains many of the sarcoma and leukemia agents. These particles are released in an immature form and mature, following release, into $\mathrm{C}$ particles. The second genus oncornavirus $\mathrm{B}$, contains the viruses which were formerly classified as having B-type morphology. This group contains the mouse mammary tumor viruses. The third genus, oncornavirus $\mathrm{D}$, contains viruses with morphology intermediate between $\mathrm{A}$ and $\mathrm{B}$ and contains two subfamilies Lentiviridae and Spumaviridae. The two subfamilies contain the viruses of the Retroviridae family with unknown natural oncogenic potential. There also exists one other morphological group, the A particles, which appear to be nucleocapsids or immature forms of B and D particles. The RNA tumor viruses are often further subdivided on the basis of their ability to transform fibroblasts in vitro; those which can are designated sarcoma viruses and those which cannot are designated leukemia viruses (JoKLIK et al. 1980 b). The sarcoma viruses contain the avian sarcoma viruses which can both transform and replicate without helper functions and mammalian sarcoma viruses which transform, but are defective for replication. The leukemia viruses contain genes essential for replication, but not for transformation. 


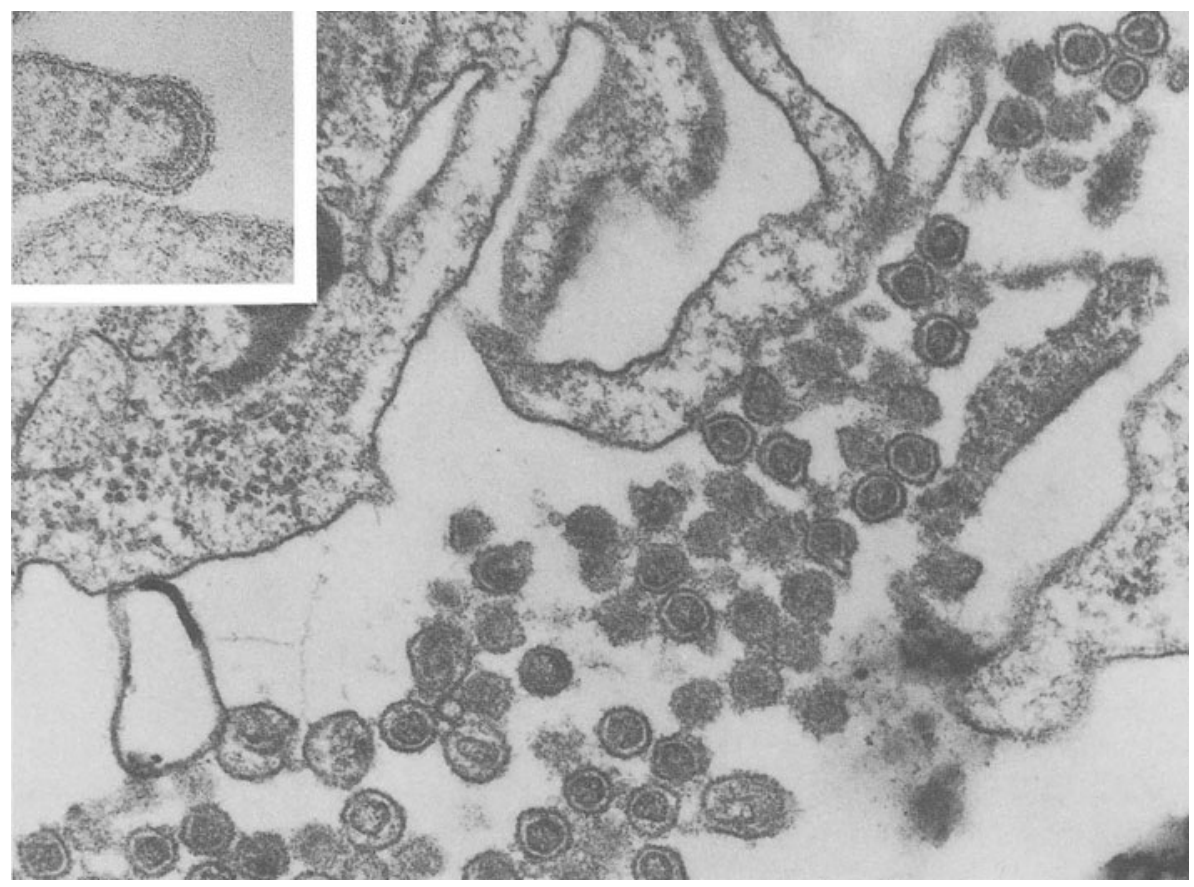

Fig. 17. RNA tumor virus. The large micrograph illustrates mature type $C$ virions at the surface of a mouse cell grown in tissue culture. The small inset depicts a type $\mathrm{C}$ virion budding from the plasma membrane. In these budding virions, and in recently detached virions, the electron-dense nucleoid and intermediate layers can be distinguished, while in mature virions they have condensed into a single irregular layer under the limiting membrane. The mechanism of synthesis and release of retroviruses is generally not cytolytic, and many cell lines produce virus indefinitely. (Courtesy of J.DAHLBERG) $\times 70,000$

It is believed that they become transforming viruses by picking up transforming sequences from the host cell (JoKLIK et al. 1980).

The RNA tumor viruses are enveloped particles having a coiled nucleocapsid in an icosahedral shell. They are approximately $150 \mathrm{~nm}$ in diameter. The genome of the RNA tumor viruses is diploid (COFFIN and BILLETER 1976). It consists of a 60-70 $S$ complex composed of two identical RNA subunits which are terminally redundant (HASELTINE et al. 1977) approximately $35 S$ in size, and having a molecular weight of $3 \times 10^{6}$ daltons. Subunits are linked together via their $5^{\prime}$ ends, through a palindromic sequence (HASELTINE et al. 1977). The individual subunit RNA species are also adenylated (LAI and DUESBERG 1972; GILLESPIE et al. 1972; Ross et al. 1972), capped (FURUICHI et al. 1975 b), and messenger RNA species produced during infection are spliced molecules (MELLON and DuESBERG 1977). A tRNA molecule from the host cell is linked near the $5^{\prime}$ end and serves as a primer for replication (DAHLBERG et al. 1974). The genome of these viruses encodes four genes whose order is 5'-gag-pol-env-src-3'. The gag gene codes for a polyprotein which gives rise to several structural proteins of the viral coat, the pol gene codes for the DNA polymerase (reverse transcriptase), the $e n v$ gene specifies the envelope 
glycoproteins, and the src (sarcoma) gene codes for the function responsible for the transformation of host cells (DUESBERG et al. 1976).

The replication of RNA tumor viruses has been shown to proceed via an integrated DNA intermediate. The idea of a DNA intermediate in retrovirus replication was first suggested by TEMIN (1964) and several years later the enzymatic activity responsible for this reaction was discovered (BALTIMORE 1970; TEMIN and MiZUTANI 1970). The enzyme, since termed reverse transcriptase (RNA-dependent DNA polymerase), explained the conceptual problem of how a viral RNA molecule could transform, by allowing the RNA genome to be transcribed into a double-stranded DNA genome.

After entry into the cell, the polymerase becomes activated (BALTIMORE 1970; TEMIN and MITZUTANi 1970) and transcribes the viral RNA into DNA, via singleand then double-stranded DNA intermediates (BISHOP and VARMUS 1975). The viral DNA circularizes, migrates to the nucleus, and integrates (HATANAKA et al. 1971; GianNi and WeINBERg 1975; TAKANO and HATANAKA 1975). The integration appears to be obligatory for both transformation and progeny production (GUNTAKA et al. 1975; ROA and Bose 1974). It appears that while the viral genome may integrate into the host genome at several sites, only sites which contain specific neighboring cellular DNA sequences allow viral expression (O'REAR et al. 1980). It was also shown that cell death in the acute phase of infection is the result of integration of infectious DNA at multiple sites and that only cells with integration at a single site survive (BATTULA and TEMIN 1978). These retrovirus proviral sequences have also been shown to resemble transposable elements in bacteria (SHIмотонNO et al. 1980). The virus matures in the cytoplasm and receives its envelope by budding through the plasma membrane (DALTON 1962).

As mentioned earlier, those retroviruses which carry the src gene can transform fibroblasts and induce sarcomas in animals. However, the gene responsible for leukemia induction has not been found (ROSENBERG and BALTIMORE 1976; GraF et al. 1976). A functional gene product of the $s r c$ gene is essential for morphological transformation (SEFTON et al. 1980). The gene product is a 60,000 dalton phosphoprotein, with protein kinase activity (BRUGGE and ERIKSON 1977; LEVINSON et al. 1978; RÜBSAMEN et al. 1979) which is essential for transforming activity (SELFTON et al. 1980). Finally, it appears that the $s r c$ genes from a variety of avian sarcoma virus strains encode a polymorphic family of $s r c$ proteins (BEEMON et al. 1979). This and similar data have led to the hypothesis that the $\operatorname{src}$ genes were derived from the genomes of various species of origin of those viruses (STEHELIN et al. 1976; SCOLNICK et al. 1973).

\section{N. Rhabdoviruses}

Rabies infection of humans, once established, is invariably fatal; although one case of recovery is quite well documented (HATTWICK et al. 1972) it remains a celebrated exception to a general rule. It is a rare disease in the United States (only 1-2 cases/ year) but more prevalent in some other countries, and has declined in the United States, probably owing to the great decrease in rabies amongst the domestic (cat and dog) animal population. At the same time, rabies in the wild animal population has not diminished and is a constant source of potential disease. 


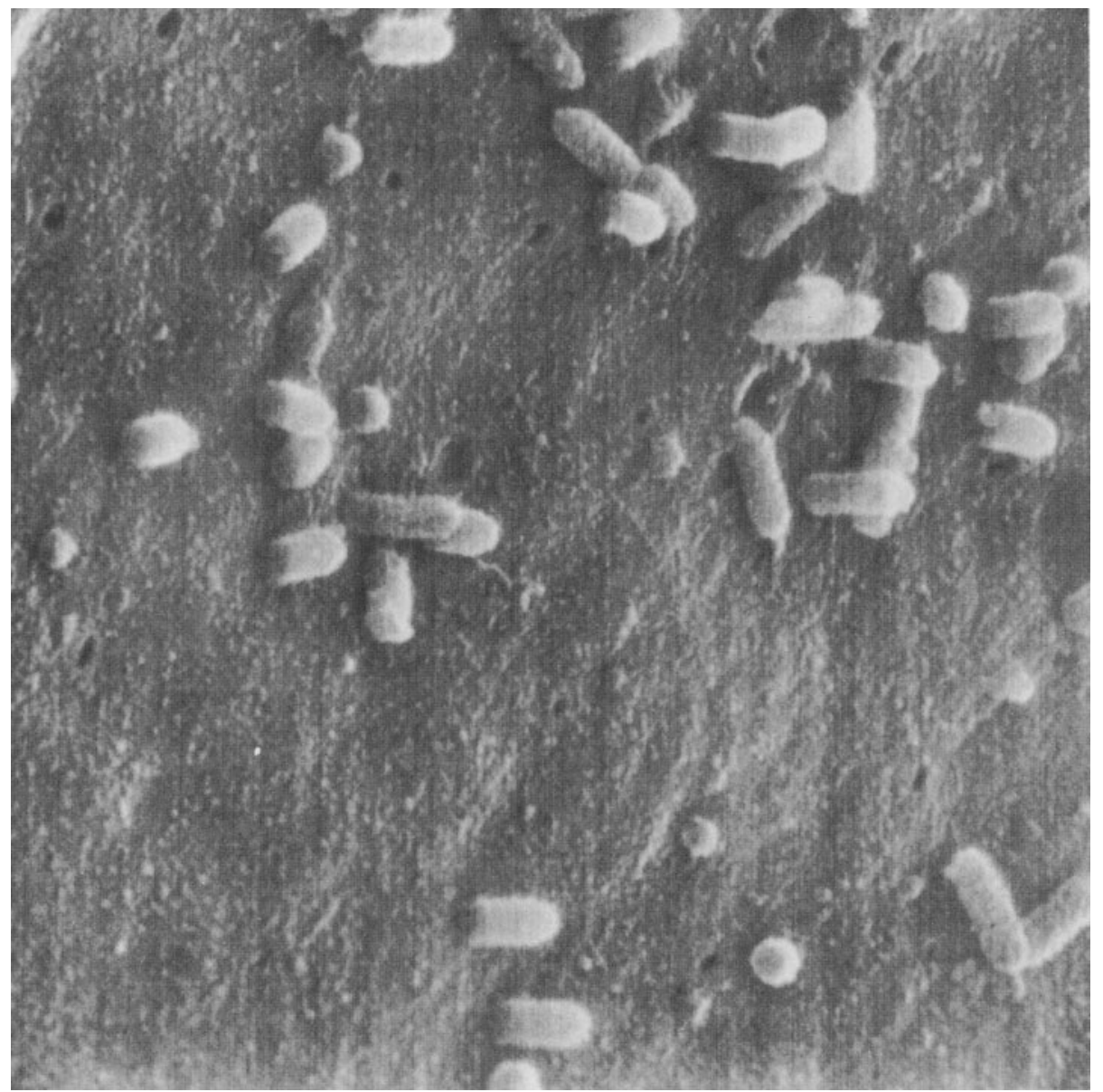

Fig. 18. High resolution scanning electron micrograph of vesicular stomatitis virus maturing at the surface of a BHK-21 cell. (Courtesy of M. DuBOIS-DALCQ) $\times 132,000$

\section{Structure and Replication}

The structure of rabies virus is that of a typical rhabdovirus (Fig. 18). The bulletshaped enveloped virion contains two membrane proteins $\left(\mathrm{M}_{1}\right.$ and $\left.\mathrm{M}_{2}\right)$ which are not glycosylated, and a glycoprotein $\mathrm{G}$. The nucleocapsid consists of a single strand of negative-polarity RNA which is not infectious on its own and is associated with a phosphoprotein (N). The RNA has a molecular weight of about $4.6 \times 10^{6}$ daltons and is associated in the virion with an RNA polymerase activity (FLAMAND et al. 1978); a fifth polypeptide (L) is also found in virions and in infected cells and is probably part of the RNA polymerase activity (KAWAI 1977). The ability of rabies virions to transcribe RNA in vitro is very low compared with vesicular stomatitis virus (VSV), however.

The virion surface contains spikes, which seem largely to be composed of the $\mathrm{G}$ protein, the major factor in the neutralizing antigenic activity of the virus (WIK- 
TOR et al. 1973). Spikes also seem to be the source of the very weak hemagglutinating activity of rabies virus and the recognition point on the virus surface for susceptible cells. Having recognized and bound to the cell, the virion gains entry either by fusion of its envelope with the cell membrane or by phagocytosis (SimPSON et al. 1969; HeINE and SchNaITMAN 1969). Either way, the nucleocapsid appears in the cytoplasm of the infected cell and is then functional as a transcriptional unit, forming the mRNA species for virus protein production. Then messages (capped and polyadenylated) individually corresponding to each of the five polypeptides found in VSV-infected cells and are derived from the entire sequence of the virion RNA with the exception of a small number of intervening sequences (CLEWLEY and BISHOP 1979).

In VSV, the gene order on virion RNA is $3^{\prime}-\mathrm{N}-\mathrm{NS}-\mathrm{M}-\mathrm{G}-\mathrm{L}-5^{\prime}$ as determined by UV inactivation and in vitro transcription (ABRAHAM and BANERJEE 1976; BALL and WHITE 1976) with production of transcripts, dependent on the synthesis of the previous ones in sequence. The mRNA for $\mathrm{N}$ polypeptide starts 51 nucleotides in from the 3' end of virion RNA and is preceded by a leader RNA and a short A-rich sequence which is not transcribed. Other data suggest that an A-rich sequence specifies the end of all transcripts in VSV, either by terminating transcriptase activity or via processing (KEENE et al. 1980). Of course, during replication of the virus RNA to give new genomic material these A-rich sequences must be copied and thus some suppression mechanism must exist to ensure faithful reproduction of the virus genome. The simplest concept for formation of new genome RNA is via a replicative intermediate containing intact genome-sized RNA of positive polarity. It has not been possible, so far, to make the full-length plus strand in vitro, suggesting that the suppression mechanism outlined earlier only operates in infected cells.

Defective interfering (DI) particles of VSV contain various bits of RNA, and have been suggested to originate via premature termination of minus strands with copyback synthesis at their own $5^{\prime}$ end to give panhandle structures with $3^{\prime}$ polymerase initiation sites (Perrault and LeavitT 1977). Both glycoprotein and matrix protein are rapidly incorporated into infected cell cytoplasmic membranes while the nucleocapsid is generated separately from its component RNA and polypeptides. How the two components of the virion recognize each other is not clear but, depending on the cell type, budding and final assembly are able to take place both at intracytoplasmic membranes and from the outher surface of the cell.

In general, rabies virus replication seems to follow the broad scheme set out above for VSV, but it has yet to be shown that rabies virus has a virion transcriptase (BISHOP and FLAMAND 1975) or that it can multiply in enucleate cells (WIKTOR and KoprowsKi 1974); this could indicate a fundamental difference between the strategy of these two rhabdoviruses. No recombination can be detected between rhabdovirus mutants, although resumptive "recombinants" can be isolated which subsequently fail to breed true (because of polyploid particle formation?). However, complementation has been widely studied and is an effective way of defining the functional areas of the viral genome. There are five (Cocal, New Jersey strains) or six (Indiana strain) complementation groups for VSV, but no complementation of rabies mutants has so far been described. Indiana group I mutants probably have a transcriptase defect, group III a matrix protein defect, and group V a glycoprotein defect (PRINGLE 1977). 
In 1970, HuANG and BALTIMORE suggested that defective particles may play a role in the pathogenesis of slow virus diseases. This idea was confirmed 3 years later when it was shown that defective VSV particles injected into mouse brain would, upon challenge with large doses of normal virus, cause a slow virus disease rather than the more common rapid, fatal infection (DoYLE and Holland 1973). The same defective particles protected mice against low doses of VSV, however. Persistent infection may also be established in cell cultures by means of large amounts of defective particles; in this case, the course of the persistent infection and its establishment was accompanied by the accumulation of spontaneous $t s$ mutants, which may behave as conditionally defective interfering particles. Low input multiplicities of $t s$ mutant can also trigger persistent infections in cell cultures, presumably by a similar mechanism (YOUNGNER et al. 1976).

In a similar vein, a VSV $t$ s mutant has been shown to cause delayed death and neurologic symptoms when injected into newborn hamsters. In this experiment, virus was localized in the brain, while infection with wild-type VSV usually causes a rapid disseminated disease. This effect appears, however, not to be related to a specific (genetic) feature of a mutant, but rather to the ability of the animal to survive infection long enough; the virus seems to be poorly cleared from the central nervous system (STANNERS and GOLDBERG 1975). Two mutants of VSV cause a disease in mice similar to the spongiform encephalopathies (RABINOWTZ et al. 1976). One of these, $t s \mathrm{G} 31$, when taken from the brain of an infected mouse, is no longer identical to the original mutant. It appears to have lost the ability to synthesize normal viral proteins, but makes unique high molecular weight species. Nor can this central nervous system isolate inhibit host protein synthesis effectively (HuGHES et al. 1979) although it still retains the $t s$ character of its parent. It has also been shown, using the mutants of VSV, that not only did the disease process vary depending on the mutant, but the expression of neurovirulence was intimately tied to the host employed (DAL CANTO et al. 1979). Infection of newborn mice with certain rabies virus $t s$ mutants much reduces their virulence and incubation period. Animals injected with one of the mutants, $t s 2$, conferred resistance to challenge by wild-type rabies virus (CLARK and KoPROWSKI 1971).

It was proposed that DI particles were generated in infected cells as part of the host cells defense against virus. Support for this view comes from work with defective particles of VSV, whose generation is dependent on an actinomycin D-sensitive (directly or indirectly) host function: this host role in formation of DI particles of VSV does not apply to replication of already formed defective particles, however, and different cell types seem to be capable of the formation of quite different types of defective particle (KANG and ALLEN 1978).

\section{Rabies Virus Infection}

While a bite is the most frequently encountered means of human infection from an animal, a lick may be enough to infect a scratch and cause disease. Infection of humans is not productive for the virus, as humans do not usually transmit the virus to keep the infective cycle turning. Nevertheless, the virus persists in nature by being secreted from the salivary glands of animals whose nervous system it has infected to the extent that they are driven to dash about and bite other animals. 
A bite from a rabid animal may not cause disease (low dose of virus, no skin breakage, etc.) and the incubation time in those individuals who have been successfully inoculated with the virus is extremely variable. Often, 6 months or more will pass before symptoms appear: there is a correlation, too, between the site of inoculation and the length of incubation. Generally, the further away from the head the bite is, the longer the incubation period.

Other means of infection with rabies have been described (e.g., airborne, CoNSTANTINE 1962); ingestion of rabid animal flesh, FISCHMAN and WARD 1968) but, for humans, the bite appears to be the usual route. There is probably some virus replication at the site of inoculation (MURPHY et al. 1973b) from where the virus spreads to ganglia via the peripheral nerves. Thorough cleansing of the wound area is one of the best means of reducing the risk of infection and amputation of an infected limb is efficacious for some time after inoculation (in the mouse; BAER and ClEARY 1972). The virus grows in infected ganglia and quickly spreads throughout the central nervous system. Viremia is not normally at a level high enough to suggest that it is an important factor in pathogenesis but almost all of the organs in the body eventually become infected, perhaps via the nerve supply. As soon as symptoms are seen in humans, antivirus antibody can be detected in the cerebrospinal fluid (BELL et al. 1966) and virus antigen is present in a number of different tissues. In biting animals, the salivary gland titer of the virus is usually very high (higher than in the central nervous system, for example). In the human infection, the course of obvious disease lasts 4-10 days, starting with fever and general malaise, and ending with various neurologic problems and death. Whether the effect on the host is a direct result of infection or an indirect consequence mediated through an immunologic response is in doubt (TIGHOR et al. 1974), nor is it clear why the infection has such a long incubation period.

Preexposure vaccination of high-risk groups (e.g., veterinarians) has been carried out for some time, using the inactivated duck embryo vaccine (DEV), with reasonable $(80 \%-90 \%)$ success (seroconversion). The same vaccine is used for postexposure treatment, and is usually effective because of the long incubation time of the disease. However, a high frequency of local reaction to the vaccine plus a low frequency of more serious (neurologic) considerations has led to the development of a human diploid cell strain vaccine (HDCS). It is still not generally available (it may be obtained from the Center for Disease Control, Atlanta, Georgia), but is more effective (greater seroconversion and lower rate of adverse reactions) and is likely to supersede the DEV soon. Antirabies globulin is frequently used to treat bites (locally) soon after inoculation.

\section{O. Rotaviruses}

Rotaviruses have emerged only recently as a cause of acute gastroenteritis in children (FLEWETT et al. 1973) although the initial isolation of the virus type was from calves with diarrhea (MEBUs et al. 1969). Infection of humans with rotaviruses is worldwide and a wide variety of animal species are susceptible to infection (MCNulTY 1978). 


\section{Structure and Replication}

The virus particle is about $70 \mathrm{~nm}$ in diameter and, intact, appears to be a doubleshelled sphere (Fig. 19). The morphology resemble that of reoviruses and seems to be the same for rotaviruses from different species (WoODE et al. 1976). Negatively stained preparations have a dense core structure (about $40 \mathrm{~nm}$ ) and it has been pro-

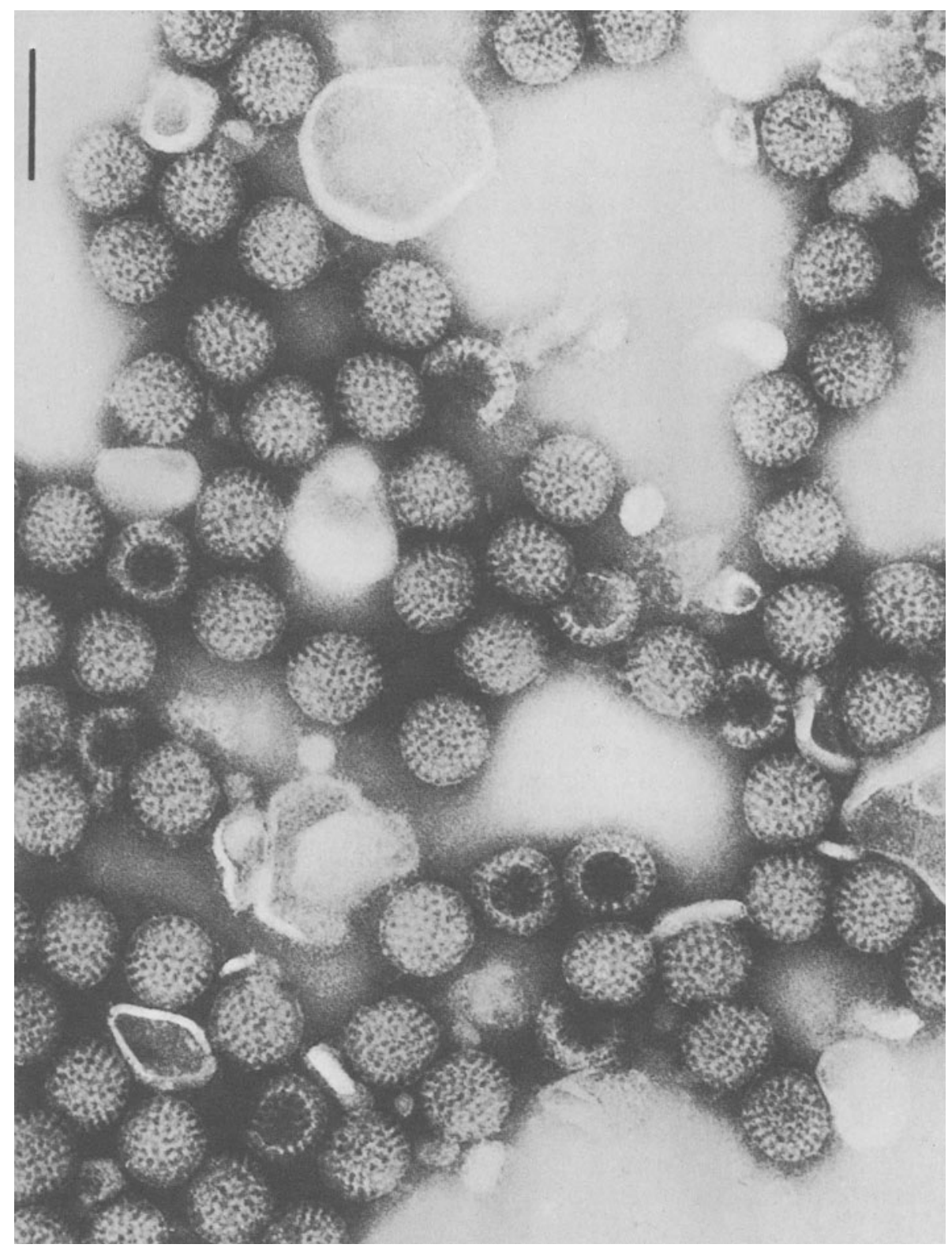

Fig. 19. Rotavirus particles observed by electron microscopy in a stool filtrate prepared from an infant with acute gastroenteritis. Bar $=100 \mathrm{~nm}$. (KAPIKIAN et al. 1974) 
posed (STANNARD and SCHOUB 1977; ESPARZA and GiL 1978) that the structure of both inner and outer shells is the same, with subunits arranged as an open mesh around 5- and 6-coordinated holes, although the number of holes has not been agreed upon. Removal of the outer core gives a $60 \mathrm{~nm}$ (roughly) orbivirus-like particle, which is usually seen (with intact particles) in preparations of virus from infected animals. Human rotaviruses appear to be assembled in the cytoplasm of infected cells, from tangles of fibrous virus precursor material (HoLMES et al. 1975) outside the cisternae. Some particles appear to bud through the endoplasmic reticulum and can obtain an envelope in the process; the virus particles are released from infected cells after the cells lyse.

The virus particle contains a group-specific antigen (KAPIKIAN et al. 1976) associated with the single-shelled structure $(60 \mathrm{~nm})$ and convalescent sera will agglutinate such particles. The outer shell of the virion is associated with species-specific antigenic activity and with a hemagglutinin (FAUVEL et al. 1978) and at least two serotypes of human rotavirus exist (THOULESS et al. 1978). No serologic relationships exist, however, between the rotaviruses and human reoviruses and orbiviruses (KAPIKIAN et al. 1976). The RNA in rotavirus particles occurs as a double-stranded structure, present as eleven fragments (molecular weight about $0.5-$ $1.9 \times 10^{6}$ daltons; $11-12 \times 10^{6}$ daltons total) whose migration behavior in gel electrophoresis can be used to differentiate at least three human strains (KALICA et al. 1978). Single- and double-shelled virus particles (the former have very low infectivity) can be separated by density; the double-shelled particles have eight polypeptides, the single-shelled four, and there are probably three others in infected cells.

Comparison of various animal rotaviruses shows a remarkable similarity in the polypeptides they produce; also, there appear to be about as many polypeptides as there are RNA genome fragments. The major polypeptide of the outer shell is a glycoprotein (RODGER et al. 1977) and the calf virion is relatively acid stable and insensitive to $\mathrm{CHCl}_{3}$ and ether as well as a variety of proteases. Heat or versene treatment of virions allows the expression of a particle RNA polymerase activity which copies the genome RNA into single-stranded material in vitro (COHEN 1977).

Rotaviruses do not grow well in tissue culture as a rule and do not seriously inhibit cell protein synthesis: this tends to make studies of the molecular biology difficult. This is in contrast to their in vivo ability to spread easily from animal to animal. However, it has been shown that the simian rotavirus SA11 grows well in homologous cell culture and seems to exhibit a wide and varied host range in vitro, although fetal calf serum contains an inhibitor of its growth (ESTES et al. 1979). Virus yield in a number of cell lines does not correlate with obvious cytopathic effect.

Replication of rotavirus in cell culture can give rise to the production of coreless particles, suggesting that lack of effective virus production in such a system may be a function of the failure of the cell to allow complete virus replication rather than a simple failure to adsorb the virus (MCNULTY et al. 1976). In addition, however, the suggestion has been made that a lactase activity is important for the uncoating and adsorbing of rotavirus to epithelial cells in vivo (HoLMES et al. 1976) and it has been shown that proteolytic enzymes may assist in the infection process via appropriate modification of the surface of rotavirus particles (THEIL et al. 1977). A plaque assay is available in simian cells (MATsumo et al. 1977). 


\section{Rotavirus Infections}

Rotavirus infection is ubiquitous, infecting young children ( $0.5-3$ years) to give a diarrheal illness, chiefly during the winter, similar to the seasonal incidence of respiratory syncytial virus. Adults may acquire the disease from infected children and can seroconvert without obvious signs of illness. Rotavirus infection is usually confirmed by direct electron microscope identification of virus from stools or by immunologic testing of stool material, either directly or after culture in mammalian cells. Both radioimmunoassay and enzyme linked immunosorbant assay tests have been worked out (Middleton et al. 1977; Ellens and DeLeEuw 1977) and may be more suitable for widespread use than traditional methods. A few days after the onset of disease in humans, seroconversion takes place and this can be also used as a diagnostic tool (complement fixation, immunofluorescence; DAVIDSON et al. 1975); it is not clear though, what role circulating, as opposed to local, antibody plays in the prevention and control of disease.

Direct inoculation of the human virus into calf small intestine can cause (after passage in vivo) both diarrhea and virus shedding with seroconversion and it is possible that in nature rotaviruses of different animal strains may cross-infect (MEBUS et al. 1976). In this animal model, the pathogenesis of the virus was as follows: viral antigens appeared in epithelial cells of the lower small intestine very soon after the start of diarrhea; over the next several hours, degenerative changes in the villi took place with disappearance of the viral antigens; 2 days later, all was normal again (MeBus et al. 1977). Virus appeared in the feces for the first 2 days only. Thus, this infection is a very rapid process, probably spreading in a cephalocaudal direction: circulating antibody may not be protective. While virus forms chiefly in the villous epithelial cells of the small intestine, it has also been isolated from other tissues (lung, stomach, etc.). Virus replication causes shedding of celles and their replacement by immature epithelial cells which may be resistant to infection (HoLMES et al. 1976). The pathogenicity of the virus may be related to the impaired capacity of these immature cells to process dietary sugars successfully, leading to changes in tonicity and increased loss of water in the feces, and may be exacerbated by bacterial production of fatty acids and a consequent inflammatory effect (MCNulTy 1978). No human vaccine is available at present and it is not clear that the available attenuated calf vaccine works at all well (ACRES and RADSOTIS 1976).

\section{P. Poxviruses}

Since smallpox can kill about one-half of the people it infects given the appropriate circumstances, it is no surprise that it has long been considered one of the real scourges of the human race. All the more reason, therefore, to congratulate those involved in the complete eradication of the disease, which was recently achieved after much work. Eradication was always a possibility with the disease, since the virus appears to have no latent or persistent state and there appears to be no animal reservoir. Whether a poxvirus of another species can (sooner or later) fill the void occupied by smallpox is not known at present, but is a possibility we should not entirely discount. For these reasons we shall not discuss smallpox in detail since, with any luck, we may not have to deal with it again in human populations. 
The Poxviridae have six main groupings based on a variety of criteria, (FENNER et al. 1974) and the orthopoxvirus (vaccinia-variola subgroup) can be further divided into four groupings on the basis of polypeptides in infected cells and of restriction enzyme cleavage of DNA (HARPER et al. 1978; EsPOSITO et al. 1978).

\section{Structure and Replication}

The particle is a complex (brick-shaped) entity with a biconcave core (lateral bodies in the concavities) and an envelope, (Fig. 20) containing DNA of molecular weight about $125-130 \times 10^{6}$ daltons (vaccinia) while other poxviruses possess genomes of much greater length (about $180 \times 10^{6}$ daltons; GAFFORD et al. 1978). The particle also contains lipid, carbohydrate, and protein. The DNA is a linear double strand, with $95 \%$ of its sequences unique and perhaps $4 \%$ as highly reiterated sequences

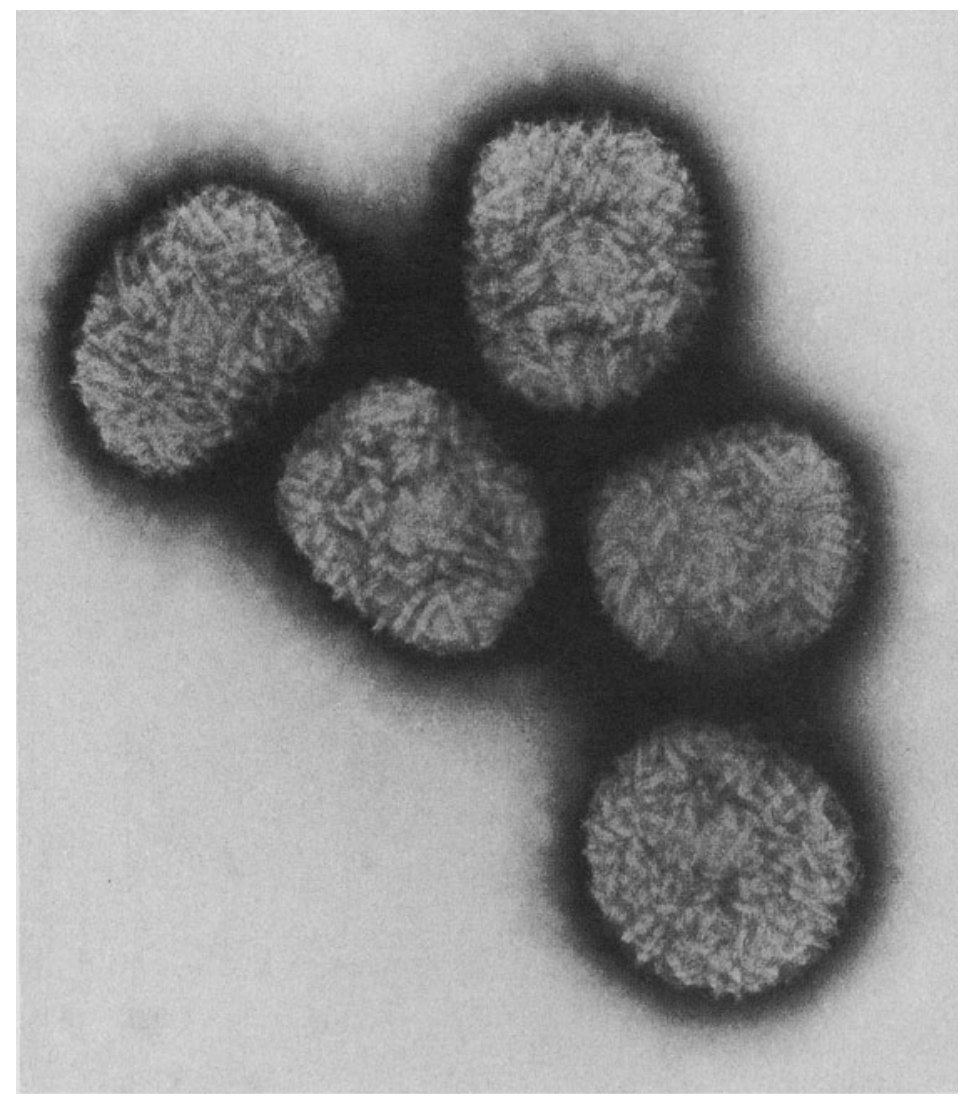

Fig. 20. Suspension of highly purified vaccinia virus particles examined after negative staining with phosphotungstate. The surface of each particle is convoluted into characteristic tubular ridges (GOLD and DALES 1968) $\times 120,000$ 
(Grady and PAOLETTI 1977). The vaccinia genome also contains cross-links at or near the molecular termini which do not allow separation of two single strands of the viral DNA (BERNS and SILVERMAN 1970). The virion may contain as many as 100 polypeptides judged by two-dimensional polyacrylamide gel electrophoresis (ESSANI and DALES 1979) a number of which are modified by glycosylation or phosphorylation. Vertebrate poxviruses show a group-specific antigen but its identity is not clear, while an antigenic difference does seem to exist between virus particles found inside infected cells and those which are naturally exported from the cell (APPLEYARD et al. 1971). As a rule, vaccinia virus is not well released from infected cells and the majority of particles remain intracellular. Unlike other DNA animal viruses, the poxvirus particles contain a number of enzyme activities, mostly affecting nucleic acid metabolism. There are three deoxyribonucleosides, nucleoside triphosphatases, a reversible DNA ligating activity, a protein kinase, an RNA polymerase with poly(A) adding activity, and capping enzymes. The RNA polymerase was presumed to be necessary since poxvirus replicated, it was thought, wholly in the cytoplasm of infected cells: recent data have shown that the nucleus is required for complete vaccinia replication, however (PENNINGTON and FolLETT 1974). The particle also has a hemagglutinin activity associated with one of the glycoproteins (PAYNE 1979).

The extracellular form of the virus appears to penetrate the infected cell largely by membrane fusion (PAYNE 1979) and is then uncoated in the cytoplasm in a twostage process. The first part removes the lipid and one-half of the protein (JOKLIK 1964) and the second part needs a virus product or products, producing deoxyribonuclease-sensitive DNA. RNA synthesis is started using the particle RNA polymerase activity which transcribes a limited fraction of the genome and translation produces virus-specific early products including enzymes and presumably the uncoating activity for the second stage. About one-third to one-half of the genome is transcribed early (PAOLETTI and GRADY 1977); later, the entire genome is represented by transcripts, although the synthesis of some early products (i.e., enzymes) rapidly declines at late times. The mRNAs can be capped and polyadenylated (Moss et al. 1976) and appear likely to be produced from high molecular weight precursors. At least part of this process can be duplicated in vitro and cleavage appears to be via an endogenous viral RNAse activity associated with cores. Recently a population of low molecular weight RNAs has been described after vaccinia infection which act as precursor to the cap and polyadenylation of mature mRNAs (PAOLETTI et al. 1980). Early protein synthesis declines quickly after DNA is synthesized, signalling the late phase of polypeptide production, chiefly virion components. It is not clear which RNA polymerase is responsible for the later transcription events. Viral DNA synthesis occurs within discrete foci in the cytoplasm and appears to involve the viral DNA polymerase activity, although recent data suggest that isolated nuclei in vitro may be capable of some viral DNA replication (LA Colla and Weissbach 1976). Assembly of virus particles takes place in cytoplasmic factories where DNA is produced. Both cupule and spherical structures can be seen in the electron microscope (EASTERBROOK 1972) which develop into virus particles; these may further develop into an intracellular double-membranecoated virion which can migrate to the cell surface. This particle fuses one membrane with the cytoplasmic membrane and is released minus one membrane: this 
form seems likely to be responsible for the dissemination of poxvirus infection (PAYNE and KRISTENSSON 1979) both in vivo and in vitro.

Poxvirus infection generally leads to cell death rather rapidly and a cell-fusion factor appears to be associated with certain members of the group (APPLEYARD et al. 1962). In keeping with these biologic parameters, host cell molecular synthesis (DNA, RNA, and protein) also appear to be efficiently depressed after infection (Moss 1974). In other circumstances, however, poxviruses can stimulate cell proliferation and, in a kind of persistent infection, cause cell alterations reminiscent of transformation with other viruses (KozIOROWSKA et al. 1971).

Recently, L. PAYNE (personal communication 1980) has suggested that the form of vaccinia virus responsible for both in vitro and in vivo spread of infection is the extracellular enveloped form of the virus; for example, treatment of mice with antienvelope serum would protect them from lethal vaccinia infection whereas inactivated intracellular virus antiserum would not. The major human problem arising from poxvirus infection is, as we have pointed out, smallpox. The various host responses to infection have been categorized (CHRISTIE 1969) and much of the epidemiologic and descriptive clinical picture has been obtained in India where the disease (until very recently) was part of everyday life and surrounded by various religious implications.

There are several different types of smallpox, some with characteristic lesions and some (e.g., hemorrhagic smallpox) with an almost certain prognosis of death. Incubation periods are of the order of 2 weeks and vaccination in most cases allows a $90 \%$ reduction in fatality rate. The standard vaccination for smallpox is, of course, vaccinia virus, which multiplies locally to express smallpox cross-reacting antigens but does not, normally, disseminate. A second attack of smallpox is rare and vaccination protects for about 5 years or so. Levels of circulating antibody are a major factor in the prevention of disease (vaccination quickly after exposure can protect) although local control via interferon and some T-cell-mediated response are also likely.

\section{Poxvirus Infections}

The studies of FENNER (1948) using mousepox virus in mice has provided us with a clear basis for understanding the pathogenesis of poxviruses. The general picture of pathogenesis has been described by DownIE (1970). The virus enters via the respiratory route, undergoes primary replication in lymph nodes and spreads to a number of organs where a secondary replication takes place to give a viremia which leads to skin and mucous membrane infection (Fig. 21). Virus localized in the skin or the mucous membranes multiplies, in the first case to give macules, papules, a pustule owing to recruitment of polymorphonuclear cells, and finally a crusted lesion under which the epithelium can reform. In the second case, the lesion remains open and a great deal of infectious virus is released. Deep scars are often the result of a secondary bacterial infection. High levels of circulating infectivity usually mean severe consequences and in hemorrhagic disease, vast amounts of virus can be found in skin with evidence of virus replication in internal organs which are not normal sites for virus multiplication. 


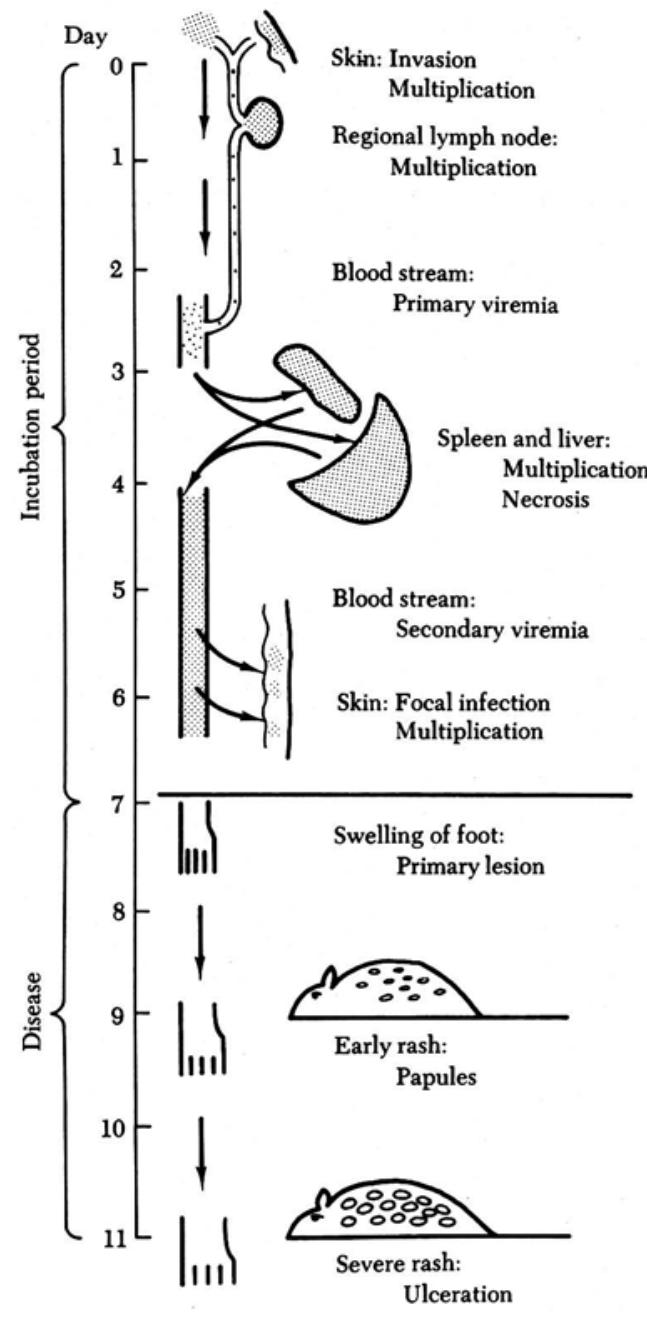

Fig. 21. Scheme illustrating the possible sequence of events during the incubation period and development of signs of disease in mousepox. (FENNER 1948)

\section{Q. Togaviruses and Bunyaviruses}

The togaviruses and bunyaviruses were formerly classified along with many other viruses under the broad heading of arboviruses (arthropod-borne viruses). In recent years, it has become apparent that the arboviruses are composed of a very heterogeneous group of unrelated viruses. These viruses have now been classified into the following families: Togaviridae, Bunyaviridae, Reoviridae, and Rhabdoviridae (FENNER 1976). In this section we will be concerned only with the Togaviridae and Bunyaviridae, two families composed of RNA viruses which vary widely in physical characteristics. 


\section{Togaviruses}

The Togaviridae are composed of four separate genera, alphavirus, flavivirus, rubivirus, and pestivirus. The first two groups contain viruses transmitted by arthropod vectors and were formerly classified as the group A and B arboviruses. The alphavirus genus includes about 20 viruses including Western, Eastern, and Venezualan encephalitis viruses, Sindbis and Semliki Forest viruses. The flavivirus genus contains more than 40 types, including dengue virus, St. Louis encephalitis virus, and yellow fever virus, the prototype virus for this group (PFEFFERKORN and SHAPIRO 1974). Rubivirus contains only one member, rubella virus, and the pestivirus genus contains agents of animal disease transmitted by contact.

The Togaviruses are small icosahedral viral particles enclosed within a lipid envelope (Fig. 22). The enveloped particles have a diameter of $40-75 \mathrm{~nm}$, the alphaviruses and rubivirus being overall somewhat larger than the flaviviruses and pestiviruses. These viruses were initially classified as togaviruses on the basis of structual similarities; however, classification of the viruses within the different genera is based on antigenic similarities (CASALS 1972). All togaviruses are sensitive to detergents and ether, owing to their lipid envelope (VENTURA and SCHERER 1970) and are relatively heat labile (PURIFOY et al. 1968). The lipid envelope which the virus obtains by budding through the host cell plasma membrane contains host cell lipids but only virus-specified proteins. The envelope proteins contain the hemagglutinin and neutralization antigens. Unenveloped virions fail to absorb to susceptible cells, indicating absorption as another function of the envelope (BOSE and SAGIK 1970). Viral nucleocapsids, unlike those of the picornavirus are susceptible to RNAse attack (ACHESON and TAMM 1970; KäÄRIANIEN and SODERLUND 1971). The virion proteins consist of two glycoproteins found in the envelope and one nucleocapsid protein (SCHLESINGER et al. 1972; SIMONS et al. 1973). The virion contains a single, linear, infectious RNA molecule, $42 S$ and about $4 \times 10^{6}$ daltons in molecular weight (DoBOs and FAULKNER 1970; Boulton and WeSTAWAY 1972). Replication of the RNA proceeds through a multistranded intermediate similar to the picornaviruses (FRIEDMAN 1968) and the RNA polymerase required to carry out replication is coded for the viral genome (CARDIFF et al. 1973). Viral structural proteins are coded for by the $26 S$ messenger RNA present in infected cells, which represents two thirds of the 3 '-end of the virion RNA and produces a polycistronic protein which is cleaved into the structural proteins (PFEFFERKORN 1977). The morphogenesis of the viruses includes assembly of nucleocapsid and virion $42 S$ RNA in the cytoplasm, modification of the cellular plasma membrane, and budding of the nucleocapsid through the modified cellular membrane (PFEFFERKORN and SHAPIRO 1974).

High multiplicity passage of the virus leads to the generation of stocks of virus having a high ratio of physical to infectious particles. Such stocks interfere with the growth of wild-type virus and appear to be defective intefering (DI) particles (INGLOT and CHUDZIO 1972; SCHLESINGER et al. 1972; EATON and FAULKNER 1973; SHENK and Stollar 1973a). The interference is homotypic (SHENK and StOLLAR $1973 \mathrm{~b})$ and the DI RNA appears to be a deletion mutant of the $42 S$ RNA (BRUTON and KENNEDY 1976). 


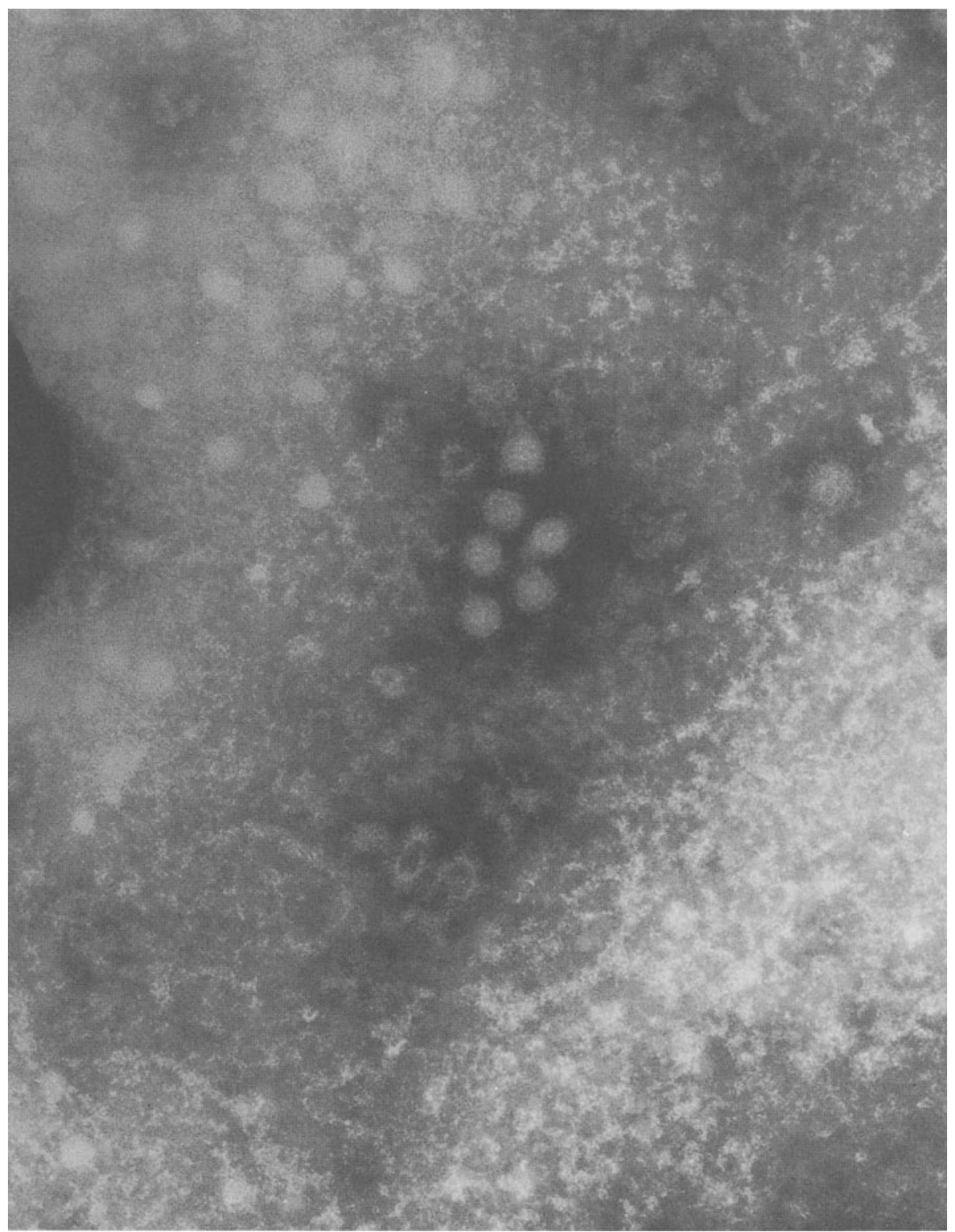

Fig. 22. Morphology of Sindbis virus, a member of the alphavirus group. (MADELEY 1978) $\times 200,000$

The large number of togaviruses does not permit a comprehensive description of all the viruses. Within each genus, the viral infections are relatively similar. A generalized description for each genus will be used to illustrate the features Table 1. All alphaviruses have mosquitoes as vectors. The viruses are maintained in nature by a cycle involving wild birds and the mosquito vector (RUSSELL 1979a). The in- 
fections are transmitted by the bite of the vector, with the virus being deposited directly into the blood or lymph stream (Downs 1976). The infection usually has two phases, the first characterized by replication in nonneural tissue, viremia, usually accompained by fever, chills, and aching. The infection is usually terminated at this point and most infections are subclinical (Downs 1976). The second stage, viral invasion of the central nervous system, may follow the viremic stage and a fulminant form of systemic disease leading to shock and death which may be attributed to the lymphocytolytic properties of the virus (DOHERTY 1977; EHRENKRANZ and VENTURA 1974; GREGG 1972). It has recently been shown that the death of mice infected with Sindbis virus is determined by virus genotype and that time of death is determined by the ability of a mutant virus to revert to wild-type (BARRETT and ATKINS 1979).

The flaviviruses constitute the largest genus of the togaviruses. Approximately 20 have been shown to cause disease in humans. With the exception of dengue virus which requires only a mosquito vector, the flaviviruses have complex cycles of transmission involving arthropods, wild birds, or mammals with humans being accidental hosts (MONATH 1979). Dengue hemorrhagic fever is characterized by fever, chills, severe headache, and muscle and joint pain of sudden onset (RHODES and VAN RoOYEN 1968). Dengue infection may proceed through the hemorrhagic stage to a shock syndrome (dengue shock syndrome) which is often fatal. One explanation is that the shock syndrome occurs in persons who have had a previous dengue infection and who react to the different dengue subtype with an exaggerated antibody response (HALSTEAD 1970). Recent work supports the hypothesis that severe primary dengue hemorrhagic fever with shock is related to the maternal immune status (MARCHETTE et al. 1979), and has also demonstrated that higher virus titers are present in animals with antisera to virus, again suggesting that severity is regulated by antibody (HALSTEAD 1979). The clinical syndromes associated with St. Louis encephilitis are fever and headache, aseptic meningitis, and encephilitis with increasing severity with advancing age (MonATH 1979). Yellow fever virus is viscerotropic, causing primary damage in the liver, kidney, and heart (STRODE 1951). In the early stages, yellow fever mimicks dengue but then may manifest the normal syndrome with patients becoming icteric (ELTON et al. 1955).

The sole member of the genus rubivirus is rubella virus. Rubella virus is classified as a togavirus on the basis of structural and physical characteristics. It appears to be closely related to the alphaviruses, but no vector is needed for transmission and it is not antigenically related (ANDREWES 1970). There appears to be only one antigenic type of rubella virus (METTLER et al. 1968). Primarily, replication is thought to occur in the respiratory epithelium or lymph nodes, viremia follows the virus shedding in the throat (GREEN et al. 1965). In fetal infection, transmission is by hematogenous spread. Most cases of infection are subclinical but, in patients who do develop symptoms, the adults may have a prodromal phase consisting of malaise, fever, and anorexia for several days (HoRSTMANN 1971). The major symptoms are adenopathy and rash, the rash usually lasting 3-5 days. Fever is usually present only during the first day of the rash (HEGGIE and RoBBINS 1969). Complications from rubella virus infection are uncommon but may include arthritis, arthraligia, hemmorhagic manifestations (probably secondary to thrombocytopenia) and encephalitis (HeGGIE and RoBBINS 1969). 
While postnatal rubella is usually a subclinical noncomplicated disease, rubella can be a tragic disease in early gestation causing fetal death, premature birth, and a host of congenital defects. The incidence of rubella varies. The epidemic of 1964 left 30,000 affected infants while a more recent 5-year period (1969-1973) produced only 180 cases of congenital rubella in the United States (MODLIN and BRANDLINGBENNETT 1974; COOPER 1975, GERSHON 1979). The effects of the virus are dependent on the time of infection. In general, the younger the fetus, the more severe the disease, with infection in the first two months having a $40 \%-60 \%$ chance of affecting the fetus (COOPER 1975). The most common congenital defects are deafness, cataracts or glaucoma, congenital heart disease, and mental retardation (COOPER 1975). There is no specific treatment indicated for rubella. A live attenuated vaccine has been available since 1969 . The vaccine may cause viremia, and is not recommended for use in pregnant women (GERSHON 1979). It is recommended that women vaccinated against rubella do not become pregnant for 3 months.

All togavirus infections may be diagnosed by virus isolation or through serologic studies. There are no specific treatments other than supportive therapy. Immunity following infection appears to be lifelong.

\section{Bunyaviruses}

The bunyaviruses are members of the family Bunyaviridae that are arthropod-borne, enveloped, and whose virions contain a single-stranded, segmented, RNA genome (PORTERFIELD et al. 1976). There are approximately 90 bunyaviruses, which have been divided into 11 groups. A member of each group being more related to members of its group than to members of other groups (PORTERFIELD et al. 1976; Berge 1975; MuRPHY et al. 1973 b). The 11 groups constitute the Bunyamwera supergroup of viruses (PORTERFIELD et al. 1976; BERGE 1975; MURPHY et al. 1973) and there remain over 80 other bunyaviruses unrelated serologically to the supergroups but which show structural similarities to its members (PORTERFIELD et al. 1976).

The virions of the family Bunyaviridae are spherical, enveloped particles approximately $90-100 \mathrm{~nm}$ in diameter. The virions contain three major proteins (OBIJESKI et al. 1976a), two glycoproteins of $120 \times 10^{3}$ and $34 \times 10^{3}$ daltons molecular weight and a nucleocapsid protein of molecular weight $23 \times 10^{3}$ daltons. The virion also contains a RNA-dependent RNA polymerase (BISHOP 1977). The genome of the viruses is composed of three unique RNA species (CLEwLEY et al. 1977; PETTERSSON et al. 1977); the molecular weights of the three species for La Crosse virus are $3 \times 10^{6}, 1.9 \times 10^{6}$, and $0.5 \times 10^{6}$ daltons. The nucleocapsid is similarly segmented (OBIJESKI et al. 1976a). Complementation and recombination have been shown to occur between temperature-sensitive mutants at a relatively high frequency, suggesting that genome reassortment occurred in mixed infections (GENTSCH and BISHOP 1976). The formation of recombinants also suggests that the genetic information of the virus resides on more than one piece of viral RNA (GENTSCH et al. 1977) while pathogenicity tests of the recombinants indicated they were either no more or less pathogenic than the prototype viruses (GENTSCH et al. 1977). Viral morphogenesis occurs intracellularly, virions mature by budding from Golgi and endoplasmic reticulum vesicles. Virions appear to be released by fusion 
Table 1. Spectrum of arboviral infections. (Adapted from FENNER and WHITE 1976)

\begin{tabular}{|c|c|c|c|c|}
\hline Virus/disease & Genus & Distribution & Vector & Reservoir \\
\hline \multicolumn{5}{|l|}{ Encephalitis } \\
\hline Eastern equine encephalitis & Alphavirus & Americas & Mosquito & Birds \\
\hline Western equine encephalitis & Alphavirus & Americas & Mosquito & $\begin{array}{l}\text { Birds, } \\
\quad \text { reptiles? }\end{array}$ \\
\hline Venezuelan equine encephalitis & Alphavirus & Americas & Mosquito & Rodents \\
\hline St. Louis encephalitis & Flavivirus & Americas & Mosquito & Birds \\
\hline Japanese B encephalitis & Flavivirus & East Asia & Mosquito & Birds \\
\hline Australian encephalitis & Flavivirus & Australia & Mosquito & Birds \\
\hline West Nile encephalitis & Flavivirus & Africa, Europe & Mosquito & Birds \\
\hline Tick borne encephalitis & Flavivirus & Eastern Europe & Tick & Mammals \\
\hline Russian spring-summer encephalitis & Flavivirus & U.S.S.R., Europe & Tick & Rodents \\
\hline Louping îll & Flavivirus & Britain & Tick & Sheep \\
\hline Powassan & Flavivirus & North America & Rick & Rodents \\
\hline California encephalitis & Bunyavirus & North America & Mosquito & $\begin{array}{l}\text { Rodents, } \\
\text { rabbits }\end{array}$ \\
\hline \multicolumn{5}{|l|}{ Hemorrhagic fever } \\
\hline Chikungunya & Alphavirus & Africa, Asia & Mosquito & Monkeys? \\
\hline Dengue $1-4$ & Flavivirus & Widespread & Mosquito & Monkeys? \\
\hline Yellow fever & Flavivirus & $\begin{array}{l}\text { Africa, } \\
\text { South Africa }\end{array}$ & Mosquito & $\begin{array}{l}\text { Monkeys, } \\
\text { man }\end{array}$ \\
\hline Kyasanur Forest disease & Flavivirus & India & Tick & $\begin{array}{r}\text { Monkeys, } \\
\text { rodents }\end{array}$ \\
\hline Omsk hemorrhagic fever & Flavivirus & U.S.S.R. & Tick & Mammals \\
\hline Crimean Congo & Bunayvirus & $\begin{array}{l}\text { Central Asia, } \\
\text { Africa }\end{array}$ & Tick & Mammals? \\
\hline \multicolumn{5}{|l|}{ Fever-arthralgia-rash } \\
\hline Chikungunya & Alphavirus & Asia, Africa & Mosquito & Monkeys? \\
\hline O’nyong-nyong & Alphavirus & Africa & Mosquito & ? \\
\hline Ross River & Alphavirus & Australia & Mosquito & Mammals? \\
\hline Sindbis & Alphavirus & Widespread & Mosquito & $\begin{array}{l}\text { Birds, } \\
\text { mammals }\end{array}$ \\
\hline Dengue (types 1-4) & Flavivirus & $\begin{array}{l}\text { Widespread, } \\
\text { esp. Asia,Pacific, } \\
\text { Caribbean }\end{array}$ & Mosquito & Monkeys? \\
\hline West Nile & Flavivirus & Africa, Asia & Mosquito & Birds \\
\hline Sandfly fever & Bunyavirus & Mediterranean & Sandfly & ? \\
\hline Oropouche & Bunyavirus & South America & Mosquito & ? \\
\hline Rift Valley fever & Bunyavirus & Africa & Mosquito & Sheep, cattle \\
\hline Colorado tick fever & Orbivirus & United States & Tick & Rodents \\
\hline
\end{tabular}

of vesicle membranes with the plasma membrane or by cell lysis; budding through the plasma membrane is rare (MURPHY et al. 1968).

Members of several groups within the Bunyaviridae are of medical importance, Table 1. The California encephalitis group is a major cause of mosquito-borne enchephalitis in the United States, the only group of Bunyaviridae of medical importance in North America (RUSSELL 1979 b). The sandfly fever group causes acute febrile illness in Central and South America, Rift Valley fever virus causes major epidemics in Africa, and Crimean hemorrhagic fever virus causes hemorrhagic fever in the U.S.S.R. and Pakistan (BISHOP 1977). Infection of humans by the 
California encephalitis group usually results in an asymptomatic infection, but occassionally may present as a severe and sometimes fatal encephalitis. Rift Valley fever virus infection may present as a fever, and arthralgia, and Crimean hemorrhagic fever may present with sudden onset of fever, headache and chills, with hemorrhagic manifestations (FENNER and WHITE 1976; Downs 1976). Diagnosis is usually made by demonstration of a rise in antibody to a particular virus (DowNS 1976) and this immunity is type specific, probably lasting for life.

\section{R. Slow Viruses}

Two categories of slow virus disease have been recognized in humans and other animals. First are those caused by known viruses such as subacute sclerosing paraencephalitis (SSPE, paramyxovirus) or progressive multifocal leukoencephalopathy (PML, papovavirus) in which a long incubation period is followed by an inflammatory reaction and serologic symptoms; second are the disease caused by unknown infectious agents such as scrapie, Creutzfeldt-Jakob disease (CJD), and kuru, in which no immunologic signs are apparent and there is no inflammatory response. In both cases, however, the course of the disease leads via degeneration of the central nervous system to death.

Such chronic diseases, although rare, certainly, in humans, are intriguing from several standpoints. First, there is the puzzle of which mechanisms are involved in the slow but inevitable degeneration of tissue, and the possibility that such chronic infection is much more widespread but is either not recognized as an "infectious disease" or is contained by cellular defence mechanisms such that clinical signs may be absent or diffuse. Second, the agent or agents responsible for the subacute spongiform encephalopathies do not behave as any known microorganism, although they seem to be small and infectious. Recent hypotheses that this organism or organisms resembled a plant viroid have not been substantiated.

\section{Unconventional Agents}

The pathology of these conditions is characteristic: there is no febrile response and no inflammatory response, but an obvious intracellular vacuolation in the gray matter of the brain (astrocytes and neurons). Four diseases have been classically associated with these symptoms, kuru and CJD in humans, and scrapie and mink encephalopathy in other animals: in all cases the responsible agent has been transmitted (via infected brain tissue) experimentally to animals (homologously and heterologously). In these instances, a long incubation period (0.2-8 years) is followed by a 1-6-month period of increasing symptoms and death. Recently, on the basis of such transmision studies, two other human diseases (familial Alzheimer's disease and progressive supranuclear palsy) have been tentatively added to the four original members of the group.

It has been possible to grow in vitro the agents of these diseases by culturing explants of nerve tissue from infected hosts. This procedure establishes a persistent infection in which the agent continues to be present over long periods, but can be detected only by inoculation of the material into an experimental animal: no gen- 
eral cytopathic effect is seen, but some vacuolation of cells in vitro has been reported (EsPaNA et al. 1975-1976). It does not seem possible at present to detect any viral (noncellular) macromolecules in these infected cells, nor to observe unusual structures in the electron microscope. Transmission of infectivity from persistently infected cultures to heterologous cell lines has not been feasible for any length of time (GiBBS and GADJUSEK 1978).

Despite the fact that infected nervous tissue from animals with these diseases has high concentrations of infectivity (e.g., kuru-infected brains have more than $10^{8}$ infectious doses $/ \mathrm{g}$ ), density gradient fractionation of the agent (in scrapie) yielded a preparation which resembled smooth vesicular membranes in the electron microscope (SiAKOTOS et al. 1976) with no sign of virus-like material, and freezefracture work on infected cells was similarly unrewarding (DUBOIS-DALCQ et al. 1977).

In many ways these agents are like viruses in that they are small $(25-100 \mathrm{~nm}$ filtration), transmissible subject to genetic variation in the host (PARRY 1960), and can show altered infectious properties upon passage in vivo (BURGER and HARTSOUGH 1965). However, they are exceedingly stable to inactivation by procedures which would normally kill conventional viruses (MiLlison et al. 1976) and this has led to the formulation of several ideas as to their structure, varying, in the case of scrapie, from a replicating polysaccharide (ADAMS and CASPARY 1968) to a conventional virus (EKLUND et al. 1967).

As has been discussed, these diseases can be transmitted experimentally into a number of species, including the "normal" host. Scrapie will replicate in the mouse to cause disease, which is a useful model of the natural infection. In this system the agent seems to replicate first in the spleen, then in the brain (and other tissues such as kidney, lymph nodes, spinal cord) without causing obvious "viremia." Also, for some time after experimental inoculation, no infectious agent was detectable anywhere in the animal (GIBBS and GADJUSEK 1978).

No antibody against the virus nor any involvement of the immune response in pathogenesis has been seen. Infectivity-neutralizing tests have been negative as have attempts at passive protection with infected animal serum (PORTER et al. 1973). Splenectomized and thymectomized mice showed essentially the same pathogenesis as normal animals. Interferon does not seem to play a role in the disease process. It may be, of course, that the agents produce no recognizably antigenic material in the course of their life cycle.

One important feature of the spread of these agents must be their extreme stability to a number of normally inactivating conditions. GIBBS and GADJUSEK (1978) have described spread of CJD from electrodes which had been "sterilized" with $70 \%$ ethanol and formaldehyde vapor. Also, disease can be spread by oral infection, subcutaneously, intramuscularly, and intracerebrally; in the sheep, contact of the lamb with an infected ewe at birth (infectious placenta) is enough (PATTISON et al. 1977). It is also possible for scrapie to be contacted by sheep grazing in infected meadows, but numerous different routes appear possible. In humans, kuru has a fascinating epidemiology, with which most microbiologists are probably familiar owing to the work and pen of GADJUSEK and his colleagues (GADJUSEK and GIBBS 1973). Transmission by cannibalism of brain material is efficient but no other means of spread has been documented; it will be interesting to see if, with 
the total eradication of the practice and the death of the practicing generation, the disease disappears entirely. Kuru is confined to a remote corner of the globe, but CJD is worldwide and does not rely on cannibalism for its spread. Its natural transmission route or routes are not clear, but consumption of animal brain has been suggested (BовоwICK et al. 1973), although some genetic involvement seems a strong possibility (GADJUSEK and GIBBS 1973). These encephalopathies, are caused by a microorganism, with virus dimensions and with virus-like pathogenesis which neither looks like nor behaves immunologically like a virus; it may well be a totally new form of infectious agent.

\section{Conventional Agents}

Several conventional viruses cause slow disease under a variety of special conditions (e.g., immunosuppression of the host): these include PML and SSPE, and the latter are discussed in the sections dealing with paramyxovirus infection. PML normally occurs (and even then rarely) in patients with reticuloendothelial system problems of some kind, and seems to be due to papovavirus infection (ZU RHEIN 1969). Two human papovaviruses, JC and BK (PADGETT et al. 1971; GARDNER et al. 1971) appear on serologic grounds to be normal and widespread human infectious agents but only JC (of the two) is capable of causing PML. Perhaps surprisingly, SV40, a simian virus, is also a (rarer) cause of PML. After the onset of neurologic degeneration typical of the disease, the patient's death normally occurs within months and it is not clear whether the virus responsible for PML has been inactive (latent) in tissues for some time or if recent infection (in the presence of a predisposed immunocompromised host) is responsible. No doubt the lack of knowledge of the pathogenesis of the disease is directly related to its infrequent occurrence.

Papovaviruses in general are capable of two kinds of interaction with cells lytic infection and transformation; they may also cause tumors in a particular animal. JC virus can also be oncogenic in hamsters (WALKER et al. 1973) but has proved difficult to grow in cell culture. Recent attempts to obtain infection in cells other than human fetal glial cells using the infectivity of viral DNA proved fruitless, although a reasonable level of infectivity in these cells was obtained (FRISQUE et al. 1979). Interestingly, therefore, failure of certain cells to allow replication of JC virus may not simply be a lack of suitable cell surface receptors, but perhaps a block at some point in the replication cycle.

JC virus DNA is about 5,000 base pairs long (almost identical to SV40) and restriction maps of it have recently become available (MARTIN et al. 1979). There is no consensus yet on the extent of genetic homology between JC virus and SV40, but they do share $\mathrm{T}$ and $\mathrm{V}$ antigens. Lacking information to the contrary, it is assumed that the replication of JC virus is similar to that of SV40. These viruses have small genomes and employ several interesting means to increase their coding capacity. For example, several coding sequences are read in differant ways to give more than one product and, particularly in the early region of the DNA, polypeptides expressed have more than one function. A good review of this area has been provided by SAMBROOK (1977). 


\section{References}

Abraham G, Banerjee AK (1976) Sequential transcription of the genes of vesicular stomatitis virus. Proc Nat Acad Sci USA 73:1504-1508

Acheson NH, Tamm I (1970) Ribonuclease sensitivity of Semliki Forest virus nucleocapsids. J Virol 5:714-717

Acres SD, Radsotis OM (1976) The efficacy of a modified live REO-like virus vaccine and E. coli bacterin for prevention of acute undifferentiated neonatal diarrhoea of beef calves. Can Vet J 17:197-212

Acs G, Klett H, Shonberg M, Christman JK, Levin DH, Silverstein SL (1971) Mechanisms of reovirus double-stranded ribonucleic acid synthesis in vivo and in vitro. J Virol 8:684 689

Adam E, Rawls WE, Melnick JL (1974) The association of herpesvirus type 2 infection and cervical carcinoma. Prev Med 3:122-141

Adams DH, Caspary EA (1968) The incorporation of nucleic acid and polysaccharide precursors into a post-ribosomal fraction of scrapie-infected mouse brain. Biochem $\mathrm{J}$ 108:38

Albrecht P, Lorenz D, Klutch MJ, Vickers JH, Ennis FA (1980) Fatal measles infection in marmosets: pathogenesis and prophylaxis. Infect Immun 27:969-978

Albrecht T, Rapp F (1973) Malignant transformation of hamster embryo fibroblasts following exposure to ultraviolet-irradiated human cytomegalovirus. Virology 55:53-61

Allaudeen HS, Bertino JR (1978) Isolation of a herpesvirus-specific DNA polymerase from tissues of an American patient with Burkitt lymphoma. Proc Nat Acad Sci USA 75:4504-4508

Almeida JD, Rubenstein D, Stott EJ (1971) New antigen antibody system in Australia antigen positive hepatitis. Lancet 2:1225-1227

Alter JH, Purcell RH, Gerin JL et al. (1977) Transmission of hepatitis B to chimpanzees by hepatitis B surface antigen positive saliva and semen. Infect Immun 16:928-933

Alwine JC, Steinhart WL, Hill CW (1974) Transcription of herpes simplex type 1 DNA in viruses from infected HEp-2 and KB cells. Virology 60:302-307

Ambros V, Baltimore D (1978) Protein is linked to the $5^{\prime}$ end of poliovirus RNA by a phosphodiester link to tyrosine. J Biol Chem 253:5263-5266

Andrewes CH (1970) Generic names of viruses of vertebrates. Virology 40:1070-1080

Appleyard G, Westwood JCN, Zwartouw HT (1962) The toxic effect of rabbitpox virus in tissue culture. Virology 18:159-169

Appleyard G, Hapel A, Boulter EA (1971) An antigenic difference between intracellular and extracellular rabbit pox virus. J Gen Virol 13:9-17

Arens W, Yamashita T, Padmanabban R, Tsumo T, Green W (1977) Adenovirus deoxyribonucleic acid replication. Characterisation of the enzyme activities of a soluble replication system. J Biol Chem 252:7947-7954

Arrand JR, Roberts RJ (1979) The nucleotide sequences at the termini of adenovirus - 2 DNA. J Mol Biol 128:577-594

Aurelian L, Cornish JD, Smith MF (1975) Herpesvirus type 2 induced tumor specific antigen (AG-4) and specific antibody in patients with cervical cancer and controls. IARC Sci Publ 2:79-83

Baer GM, Cleary WF (1972) A model in mice for pathogenesis and treatment of rabies. J Infect Dis 125:520-527

Ball LA, White CN (1976) Order of transcription of genes of vesicular stomatitis virus. Proc Nat Acad Sci 73:442-446

Baltimore D (1970) Viral RNA-dependant DNA polymerase. Nature 226:1209-1211

Baltimore D (1971) Is poliovirus dead? Perspect Virol 7:1-12

Bar, De Lor J, Claussen KP, Hurtubise P, Henle W, Hewetson JF (1974) Fatal infectious mononucleosis. Am J Med 29:43-54

Baringer JR (1975) Herpes simplex virus in sensory ganglia. IARC Sci Publ 2:73-78

Baringer JR, Swoveland P (1973) Persistent herpes simplex infection in rabbit trigeminal ganglia. Lab Invest 30:230-240

Barker LF, Maynard JE, Purcell RH et al. (1975) Hepatitis B infection in chimpanzees: titration of subtypes. J Infect Dis 132:451-458 
Barrett PN, Atkins GJ (1979) Virulence of temperature-sensitive mutants of Sindbis virus in neonatal mice. Infect Immun 26:848-852

Bartkoski MJ, Roizman B (1976) RNA synthesis in cells infected with herpes simplex virus. XIII. Differences in methylation patterns of viral RNA during the reproduction cycle. J Virol 20:583-588

Battula N, Temin H (1980) Sites of integration of infectious DNA of avian reticuloendotheliosis viruses in different cellular DNAs. Cell 13:387-398

Becker WB, Kipps A, McKenzie D (1968) Disseminated herpes infection: its pathogenesis based on virological and pathological studies in 33 cases. Am J Dis Child 115:1-8

Beemon K, Hunter T, Sefton BM (1979) Polymorphism of avian sarcoma virus src proteins. J Virol 30:190-200

Bégin M, Weber J (1975) Genetic analysis of adenovirus type 2: isolation and genetic characterization of temperature-sensitive mutants. J Virol 15:1-7

Bell JF, Codemell DL, Moore GJ, Raymond GH (1966) Brain neutralization in rabies virus to distinguish recovered animals from previously vaccinated animals. J Immunol 97:747-753

Bellamy AR, Hole LV (1970) Singe-stranded RNA from reovirus type-3. virology 40:808819

Berge TD (1975) International catalog of arboviruses, 2 nd edn. U.S. Department of Health, Education and Welfare Publ. (CDC) 75-8301. Center for Disease Control, Atlanta, Ga

Berk, AJ Sharp PA (1978) Structure of the adenovirus 2 early mRNAs. Cell 14:695-711

Berns KI, Silverman C (1970) Natural occurrence of cross-linked vaccinia virus deoxyribonucleic acid. J Virol 5:299-304

Bishop DH (1977) Virion polymerases. In: Comprehensive virology, vol 10, chap 8. Plenum, New York, pp 117-253

Bishop DHL, Flamand A (1975) The transcription of vesicular tomatitis virus and its mutants in vivo and in vitro. In: Mahy BWJ, Barry RD (eds) Negative strand viruses, vol 1. Academic Press, New York, pp 327-352

Bishop JM (1978) Retroviruses. Ann Rev Biochem 47:35-88

Bishop JM, Varmus H (1975) Molecular biology of RNA tumor viruses. In: Becker FF (ed) Cancer, vol 2. Plenum, New York, pp 3-48

Blumberg BS (1977) Australia antigen and the biology of hepatitis B. Science 197:17

Bose HR, Sagik BP (1970) The virus envelope in cell attachment. J Gen Virol 9:159-161

Bobowick AR, Brodey JA, Matthews MR, Ross R, Gadjusek DD (1973) CJD: a case control study. Am J Epidemiol 98(5):381-394

Both GW, Lavi S, Shatkin AJ (1975) Synthesis of all the gene products of reovirus genome in vivo and in vitro. Cell 4:173-180

Boulton RW, Westaway EG (1972) Comparisons of Togaviruses: Sindbis virus (group A) and Kunjuin virus (group B). Virology 49:283-289

Bradburne AF, Bynoe ML, Tyrrell DA (1967) Effects of a "new" human respiratory virus in volunteers. Br Med J 3:767-769

Bradley DW, Fields HA, McCaustland KA (1978) Biochemical and biophysical characterization of light and heavy density hepatitis A virus particles: evidence that HAV is an RNA virus. J Med Virol 2:175-187

Breshkin AM, Rapp F, Payne FE (1977) Complementation analysis of measles virus temperature-sensitive mutants. J Virol 21:439-441

Brison O, Kedinger C, Clauson P (1979) Adenovirus DNA template for late transcription is not a replicative intermediate. J Virol 32:91-97

Bruton CJ, Kennedy SIAT (1976) Defective interfering particles of Semliki Forest virus: structural differences between standard virus and defective interferring particles. J Gen Virol 31:383-395

Brown F, Newman JFE, Stott J et al. (1974) Poly C in animal viral RNAs. Nature 251:342344

Brown SM, Subak-Sharpe JH, Warren KG, Wroblewska Z, Koprowski H (1979) Detection by complementation of defective or uninducible HSV-1 virus genomes latent in human ganglia. Proc Nat Acad Sci USA 76:2366-2368

Brugge JS, Erikson RL (1977) Identification of a transformation-specific antigen induced by an avian sarcoma virus. Nature 269:346-348 
Buckley SM, Casals J (1970) Lassa fever, a new virus disease of man from West Africa. III. Isolation and characterization of the virus. Am J Trop Med Hyg 19:680-691

Buetti E, Choppin PW (1977) The transcriptase complex of the paramyxovirus SV5. Virology 82:493-508

Burger D, Hartsough GR (1965) Encephalopathy of mink. II. Experimental and natural transmissions. J Infect Dis 115:393-399

Burkitt DP, Wright DH (1966) Geographical and tribal distribution of the African lymphoma in Uganda. Br Med J 5487:569-573

Caliguiri LA (1974) Analysis of RNA associated with the poliovirus RNA replication complex. Virology 58:526-535

Caliguiri LA, Compans RW (1974) Analysis of the in vitro product of an RNA-dependent RNA polymerase isolated from influenza-virus infected cells. J Virol 14:191

Caliguiri LA, Holmes KV (1979) Host dependent restriction of influenza virus maturation. Virology 92:15-30

Cardiff RD, Dalrymple JM, Russell PK (1973) RNA polymerase in group B arbovirus (dengue-2) infected cells. Arch Gesamte Virusforsch 40:392

Carter C (1979) Polyadenylation of proteins in reovirions. Proc Nat Acad Sci USA 30873091

Carter CA, Kilbourne ED (1952) Activation of latent herpes simplex by trigeminal sensory root section. N Eng J Med 246:172-176

Carter C, Stoltzfus CM, Banerjee AK, Shatkin AJ (1974 a) Origin of reovirus oligo A. J Virol 13:1331-1337

Carter MF, Biswal N, Rawls WE (1973) Characterization of the nucleic acid of Pichinde viruses. J Virol 11:61-68

Carter MF Biswal N, Rawls WE (1974b) Polymerase activity in Pichinde virus. J Virol 13:577-583

Casals J (1972) Antigenic characteristics of Venezuelan equine encephalitis virus: relation to other viruses. In: Venezuelan encephalitis. Proceedings of the Workshop-Symposium on Venezuelan Equine Encephalitis Virus. Pan American Health Organization, Washington, DC, p 77

Center for Disease Control (1977) Reported morbidity and mortality in the United States: MMWR annual summary. Center for Disease Control, Atlanta, Ga

Chanock RM, Parrott RH, Johnson KM, Kapikian AS, Bell JA (1963) Newly recognized myxoviruses from children with respiratory disease. Am Rev Resp Dis 88:152-154

Cheng Y-C, Tsou TY, Hackstadt T, Mallavia LP (1979) Induction of thymidine kinase and DNase in varicella zoster virus infected cells and kinetic properties of the virus-induced thymidine kinase. J Virol 31:172-177

Cherry JD, Feigin RD, Cobes LA Jr et al. (1972) Urban measles in the vaccine era: a clinical epidemiological and serological study. J Pediatr 81:217-230

Chisari FV, Edgington TS, Routenberg JA (1978) Cellular immune reactivity in HBV-induced liver disease. In: Vygas GN, Cohen SN, Schmidt R (eds) Viral hepatitis. Franklin, Philadelphia, pp 245-266

Christie AB (1969) Infectious diseases: epidemiology and clinical practice. Livingstone, Edinburgh, pp 185-237

Clark HF, Koprowski H (1971) Isolation of temperature-sensitive conditional lethal mutants of "fixed" rabies virus. J Virol 7:295-300

Clements JB, Hay J (1977) RNA and protein synthesis in herpesvirus-infected cells. J Gen Virol 35:1-12

Clements JB, Watson R, Wilkie NM (1977) Temporal regulation of herpes simplex virus type 1 transcription: location of transcripts on the viral genome. Cell 12:275-285

Clewley JP, Bishop DHL (1979) Assignment of the large oligonucleotides of vesicular stomatitis virus to the N, NS, M, G, and L genes and oligonucleotide gene ordering within the L gene. J Virol 30:116-123

Clewley J, Gentsch J, Bishop DHL (1977) Three unique viral RNA species of snowshoe hare and La Crosse Bunyaviruses. J Virol 22:459-468

Clough W (1979) Deoxyribonuclease activity found in Epstein-Barr virus producing lymphoblastoid cells. Biochemistry 18:4517-4521 
Coffin JM, Billeter MA (1976) A physical map of the Rous sarcoma virus genome. J Mol Biol 100:293-318

Cohen J (1977) Ribonucleic acid polymerase activity associated with purified calf rotavirus. J Gen Virol 36:395-402

Collins BS, Bratt MA (1973) Separation of the mesenger RNAs of Newcastle disease virus by gel electrophoresis. Proc Nat Acad Sci USA 70:2544-2548

Colonno RJ, Stone HO (1976) Isolation of a transcription isoflex from Newcastle disease virions. J Virol 19:1080-1089

Compans RW, Bishop DHL, Meier-Ewert H (1977) Structural components of influenza C virions. J Virol 21:658-665

Conlepis AG, Locarnini SA, Ferris AA, Lehman NI, Gust ID (1978) The polypeptides of hepatitis A virus. Intervirology 10:24-31

Constantine DG (1962) Rabies transmission by nonbite route. Public Health Rep 77:287289

Cook ML Barstow VB, Stevens JG (1974) Evidence that neurones harbor latent herpes simplex virus. Infect Immun 9:946-951

Cooper LZ (1975) Congenital rubella in the United States. In: Krugman S, Gershon A (eds) Infections of the fetus and the newborn infant. Liss, New York, pp 1-22

Cooper PD (1977) Genetics of picornaviruses. In: Fraenkel-Conrat H, Wagner RR (eds) Comprehensive virology, vol 9. Plenum, New York, pp 133-196

Craig CP, Nahmias AJ (1973) Different patterns of neurological involvement with herpes simplex virus types 1 and 2: isolation of herpes simplex type 2 from the buffy coat of two adults with meningitis. J Infect Dis 127:365-372

Crowell RL (1976) Comparative characteristics of picornavirus receptor interactions. In: Been RF Jr, Barrett EG (eds) Cell membrame receptors for viruses, antigens or antibodies, polypeptide hormones and small molecules. Raven, New York, pp 179-202

Crowell RL, Philipson L (1971) Specific alterations of coxsackievirus B3 eluted from hela cells. J Virol 8:509-518

Crowell RL, Siak J-S (1978) Receptor for group B coxsackieviruses: characterization and extraction from hela cell plasma membranes. Perspect Virol 10:39-55

Cuifo CM, Wayward GS (1980) Tandem repeat defective DNA from the L segment of the herpes simplex virus genome

Dahlberg JE, Sawyer RC, Taylor JM et al. (1974) Transcription of DNA from the $70 \mathrm{~S}$ RNA of Rous sarcoma virus. I. Identification of a specific $4 \mathrm{~S}$ RNA which serves as primer. J Virol 13:1126-1133

Dal Canto MC, Rabinowitz SG, Johnson TC (1979) Subacute infection with temperaturesensitive vesicular stomatitis virus mutant G41 in the central nervous system of mice. II. Immunofluoresence, morphologic, and immunologic studies. J Infect Dis 139:36-51

Dales S, Gamatos PJ, Hsu KC (1965) The uptake and development of reovirus in strain L cells followed with labeled viral ribonucleic and ferritin-antibody conjugates. Virology 25:193-211

Dalton AJ (1962) Micromorphology of murine tumor virus and of affected cells. Fed Proc 21:936-941

Dambaugh T, Nkrumah FK, Biggar RJ, Kieff E (1979) Epstein-Barr virus RNA in Burkitt tumor tissue. Cell 16:313-322

Dasgupta A, Baron MH, Baltimore D (1979) Poliovirus replicase: a soluble enzyme able to initiate copying of polioviral RNA. Proc Nat Acad Sci USA 76:2679

Datta AK, Feighry RJ, Pagano JS (1980) Induction of Epstein-Barr virus associated DNA polymerase by 12-0-Tetradecanoylphorbol-13-acetate. J Biol Chem 255:5120-5125

Davidson GP, Goller I, Bishop RF, Townley RRW, Holmes IH, Rude BJ (1975) Immunofluoresence in duodenal mucosa of children with acute enteritis due to a new virus. J Clin Pathol 28:263-266

Delius H, Clements JB (1976) A partial denaturation map for herpex simplex type 1 DNA: evidence for inversion of the unique regions. J Gen Virol 33:125-133

Demarchi JM, Kaplan AS (1977) Physiological state of human embryonic lung cells alters their response to human cytomegalovirus. J Virol 23:126-132 
Demarchi JM, Blankenship ML, Brown GO, Kaplan AS (1978) Size and complexity of human cytomegalovirus DNA. Virology 89:643-646

De Thé G (1977) Is Burkitt's lymphoma related to a perinatal infection by Epstein-Barr virus? Lancet 1:335-338

De Thé G (1979) The epidemiology of Burkitt's lymphoma; evidence for a causal association with Epstein-Barr virus. Epidemiol Rev 1:32-54

De Thé G, Geser A, Day NE et al. (1978) Epidemiological evidence for a causal relationship between Epstein-Barr virus and Burkitt's lymphoma from Ugandan prospective study. Nature 274:756-761

D'Halluin J-C, Martin GR, Torpier G, Boulanger PA (1978) Adenovirus type 2 assembly analyzed by reversible cross-linking of labile intermediate. J Virol 26:357-363

Dijkema R, Dekker BMM, Feltz VD, Van Der Eb AJ (1979) Transformation of primary rat kidney cells by DNA fragment of weakly oncogenic adenoviruses. J Virol 32:943-950

Dingle J, Langmuir AD (1968) Epidemiology of acute respiratory disease in military recruits. Am Rev Respir Dis 97:1-65

Dobos P, Faulkner P (1970) Molecular weights of Sindbis virus ribonucleic acid as measured by polyacrylamide gel electroporesis. J Virol 6:145-147

Doherty RL (1977) Viral encephalitidies. In: Hoeprich P (ed) Infectious diseases. Harper \& Row, Hagerstown, Md, pp 919-927

Douglas RG Jr (1970) Pathogenesis of rhinovirus common colds in human volunteers. Ann Otol Rhinol Laryngol 79:563-571

Downie AW (1970) Infectious agents and host reaction. In: Mudd S (ed). Saunders, Philadelphia, pp 487-518

Downs W (1976) Arboviruses. In: Evans AS (ed) Viral infections of humans. Plenum, New York, $\mathrm{p} 84$

Doyle M, Holland JJ (1973) Persistent noncytocidal vesicular stomatitis virus infections mediated by defective $T$ particles that suppress virion transcriptase. Proc Nat Acad Sci USA 71:2956-2960

Drzeniek R, Billelo P (1972) Dissociation and reassociation of infectious poliovirus particles. Nature New Biol 240:118-122

Dubbs DR, Kit S (1964) Mutant strains of herpes simplex deficient in thymidine kinase-inducing ability. Virology 22:693

Dubois-Dalcg M, Rodriguez M, Reese TS, Gibbs CJ Jr, Gadjusek DC (1977) Search for a specific marker in the neural membranes of scrapie mice. Lab Invest 36:547-553

Dudding BA, Top FH, Winter PE, Buescher EL, Lawson TH, Leibovitz A (1973) Acute respiratory disease in military trainees: the adenovirus surveillance program. Am J Epidemiol 97:187-198

Duesberg PH, Wang L-H, Mellon P, Mason WS, Vogt PK (1976) ICN-UCLA Symp Mol Cell Biol 4:109-125

Duff R, Rapp F (1971) Oncogenic transformation of hamster cells after exposure to herpes simplex virus type 2. Nature New Biol 233:48-50

Dumas AM, Geden JLMC, Maris W, Van der Noordaa J (1980) Infectivity and molecular weight of varicella zoster virus DNA. J Gen Virol 47:233-235

Easterbrook KB (1972) Crystalline aggregates observed in the vicinity of freezeetched poxvirus inclusions. Can J Microbiol 18:403-406

Eaton BT, Faulkner P (1973) Altered pattern of viral RNA synthesis in cells infected with standard and defective Sindbis virus. Virology 51:85-93

Ehrenkranz NJ, Ventura AK (1974) Venezuelan equine encephalitis infection in man. Annu Rev Med 25:9-14

Eisinger M, Kularova O, Sarkar NH, Good RA (1975) Propagation of human wart virus in tissue culture. Nature 256:432-434

Eklund CM, Kennedy RC, Hadlow WJ (1967) Pathogenesis of scrapie virus infection in the mouse. J Infect Dis 117:15-22

Eleftheriou N, Thomas HC, Heathcote J, Sherlock S (1975) Incidence and clinical significance of e antigen and antibody in acute and chronic liver disease. Lancet 2:1171

Ellens DJ, Deleeuw PW (1977) Enzyme-linked immunosorbet assay for diagnosis of rotavirus infections in calves. J Clin Microbiol 6:530-532 
Elton NW, Romero A, Trejos A (1955) Clinical pathology of yellow fever. Am J Clin Pathol 25:135-146

Epstein MA, Achong BG (1977) Recent progress in Epstein-Barr virus research. Annu Rev Microbiol 31:421-445

Epstein MA, Achong BA, Barr YM (1964) Virus particles in cultured lymphoblasts from Burkitt's lymphoma. Lancet 1:702-703

Esiri MM, Tomlinson AH (1972) Herpes zoster: demonstration of virus in trigeminal nerve and ganglia by immunofluorescence and electron microscopy. J Neurol Sci 15:35-48

Esparza J, Gil F (1978) A study on the ultrastructure of human rotavirus. Virology 91:141150

Esposito JJ, Obijeski JF, Nakano JH (1978) Orthopoxvirus DNA: strain differentiation by electrophoresis or restriction endonuclease fragmented virion DNA. Virology 89:53-66

Espana C, Gadjusek DD, Gibbs CJ Jr, Lock K (1976) Transmission of Creutzfeldt-Jakob disease to the Patas monkey (Erythrocebus patas) with cytopathological changes in in vitro cultivated brain cells. Intervirology 6:150-155

Essani K, Dales S (1979) Biogenesis of vaccinia: evidence for more than 100 polypeptides in the virion. Virology 95:385-394

Esteban M, Kerr IM (1974) The synthesis of EMC virus polypeptides in infected L-cells and in cell-free systems. Eur J Biochem 45:567-576

Estes MK, Graham DY, Gerba CP, Smith EM (1979) Simian rotavirus SA11 replication in cell cultures. J Virol 31:810-815

Evans AS (1958) Latent adenovirus infections of the human respiratory tract. Am J Hyg 67:256-266

Evans AS (1960) Infectious mononucleosis in University of Wisconsin students: report of a five year investigation. Am J Hyg 71:342-362

Evans AS, Niederman JC (1977) Epstein-Barr virus. In: Evans ASC (ed) Viral infections of humans. Plenum, New York, pp 209-233

Everitt E, Meador SA, Levine AJ (1977) Synthesis and processing of the precursor to the major core protein of adenovirus type 2. J Virol 21:199-219

Farber FE, Rawls WE (1975) Isolation of ribosome-like structures from Pichinde virus. J Gen Virol 26:21-31

Farmer TW, Janeway CA (1942) Infections with the virus of lymphocytic choriomeningitis. Medicine 21:1-63

Fauvel M, Spence L, Babiuk LA, Petro R, Bloch S (1978) Haemagglutination and haemagglutination-inhibition studies with a strain of Nebraska calf diarrhoea virus (bovine rotavirus). Intervirology 9:95-105

Fenner F (1948) The pathogenesis of the acute exanthems. Lancet 2:915

Fenner F (1976) The classification and nomenclature of viruses. Summary of the results of meetings of the international committee on taxonomy of viruses in Madrid, September 1975. Virology 71:371-378

Fenner F, White D (1976) Medical virology, 2nd edn. Academic Press, New York

Fenner FL, Pereira HG, Porterfield JS, Joklik WK, Downie AW (1974) Family and generic names for viruses approved by the international committee on taxonomy of viruses, June 1974. Intervirology 3:193-198

Ferguson M, Murphy MJ (1980) Homotypic and heterotypic interfering activity associated with measles and subacute sclerosing panencephalitis. J Infect Dis 141:414-419

Fialkow P, Klein E, Klein G, Clifford P, Singh S (1973) Immunoglobulin and glucose 6 phosphate dehydrogenase as markers of cellular origin in Burkitt's lymphoma. J Exp Med 138:89-102

Finberg R, Weiner HS, Fields BN, Benacerraf B, Burakoff SJ (1979) Generation of cytolytic T lymphocytes after reovirus infection: role of S1 gene. Proc Nat Acad Sci USA 76:442446

Fischman HR, Ward FE (1968) Oral transmission of rabies in experimental animals. Am J Epidemiol 88:132-138

Fisher LE, Rapp F (1979) Temperature-dependent expression of measles virus structural proteins in persistently infected cells. Virology 94:55-60 
Flamand A, Delagreau JF, Bunerean F (1978) An RNA polymerase activity in purified rabies virions. J Gen Virol 40:233-238

Flanagan JB, Baltimore D (1979) Poliovirus uridylic acid polymerase and RNA replicase have the same viral polypeptide. J Virol 29:352-360

Flewett TH, Bryden A, Davies H (1973) Virus particles in gastroenteritis. Lancet 2:1497

Flint J (1977) The topography and transcription of the adenovirus genome. Cell 10:153-166

Fox JP, Brandt CD, Wassermann RE, Hall CE, Spigland I, Kojan A, Elveback LR (1969) The virus watch program: a continuing surveillance of viral infections in metropolitan New York families. VI. Observations of adenovirus infections: virus excretion patterns, antibody response, efficiency of surveillance, patterns of infection and relation to illness. Am J Epidemiol 89:25-50

Frame JD, Baldwin JM Jr, Gocke DJ, Troup JM (1970) Lassa virus, a new virus disease of man from West Africa. I. Clinical description and pathological findings. Am J Trop Med Hyg 19:670-676

Francis DP, Maynard JE (1979) Transmission and outcome of hepatitis A, B, and non-A, non-B: a review. Epidemiol Rev 1:17-31

Francis T Jr (1940) A new type of virus from epidemic influenza. Science 92:405-408

Francis T, Salk JE, Quilligan JJ (1947) Experience with vaccination against influenza in the spring of 1947. Am J Public Health 37:1013-1016

Frenkel N, Roizman B (1972) Separation of herpesvirus deoxyribonucleic acid duplex into unique fragments and intact strand or alkaline products. J Virol 10:565-572

Frenkel N, Roizman B, Cassai E, Nahmias A (1972) A DNA fragment of herpes simplex 2 and its transcription in human cervical cancer tissue. Proc Nat Acad Sci 69:3784-3789

Frenkel N, Locker H, Batterson W, Hayward GS, Roizman B (1976) Anatomy of herpes simplex virus DNA. VI. Defective DNA originates from the S component. J Virol 20:527-531

Friedman RM (1968) Replicative intermediate of an arbovirus. J Virol 2:547-552

Frisque RJ, Martin JD, Padgett BJ, Walker DL (1979) Infectivity of DNA from four isolates of JC virus. J Virol 32:476-482

Fulgitini VA, Eller JJ, Downie AW, Kempe CH (1967) Altered reactivity to measles virus: atypical measles in children previously immunized with inactivated measles virus vaccine. JAMA 202:1075-1080

Furlong D, Swift J, Roizman B (1972) Arrangement of herpesvirus deoxyribonucleic acid in the core. J Virol 10:1071-1074

Furuichi Y, Muthukrishnan S, Shatkin AJ (1975a) 5'-terminal $M^{7} G\left(5^{\prime}\right)$ ppp (5) $G_{P}^{m}$ in vivo: identification in rovirus genome. Proc Natl Acad Sci USA 72:742-745

Furuichi Y, Shatkin AJ, Stavnezer E, Bishop JM (1975b) Blocked, methylated 5'-terminal sequence in avian sarcoma virus RNA. Nature 257:618-620

Furukawa T, Tanaka S, Plotkin SA (1975) Stimulation of macromolecular synthesis in guinea pig cells by human CMV. Proc Soc Exp Biol Med 148:211-214

Gadjusek DC, Gibbs CJ Jr (1973) Subacute and chronic diseases caused by atypical infections with unconventional viruses in aberrant hosts. Perspect Virol 8:279-311

Gafford LG, Mitchell EB, Randall CC (1978) Sedimentation characteristics and molecular weights of three poxvirus DNAs. Virology 89:229-239

Gallimore PH, Sharp PA, Sambrook J (1974) Viral DNA in transformed cells. II. A study of the sequence of Ad2 DNA in nine lines of transformed rat cells virus specific fragments of the viral genome. J Mol Biol 89:49-72

Gardner SD, Field AM, Coleman DV, Hulme B (1971) New human papovavirus (BK) isolated from urine of renal transplantation. Lancet 1:1253-1257

Garon CF, Berry KW, Rose JA (1972) A unique form of terminal redundancy in adenovirus DNA molecules. Proc Natl Acad Sci USA 69:2391-2394

Geder L, Lausch R, O’Neill F, Rapp F (1976) Oncogenic transformation of human embryo lung cells by human cytomegalovirus. Science 192:1134-1136

Gentsch J, Bishop DHL (1976) Recombination and complementation between temperature sensitive mutants of a bunyavirus, snowshoe hare virus. J Virol 20:351-354

Gentsch J, Wynne LR, Clewley JP, Shope RE, Bishop DHL (1977) Formation of recombinants between snowshoe hare and La Crosse bunyaviruses. J Virol 24:893-902 
Gergely L, Klein G, Ernberg I (1971) The action of DNA antagonists on Epstein-Barr virus $(E B V)=$ associated early antigen (EA) in Burkitt lymphoma lines. Int J Cancer 7:293302

Gerhart W, Webster RG (1978) Antigenic drift in influenza A viruses. I. Selection and characterization of antigenic variants of $\mathrm{A} / \mathrm{PR} / 8 / 34$ [HON1] influenza virus with monoclonal antibodies. J Exp Med 148:383-392

Gershon A (1979) Rubella virus (German measles). In: Mandell GL, Douglas RG, Bennett TE (eds) Principles and practice of infectious disease, part III, chap 112. John Wiley and Sons, New York, pp 1258-1265

Gianni AM, Weinberg RA (1975) Partially single-stranded form of free Maloney viral DNA. Nature 255:646-648

Gibbs CJ Jr, Gadjusek DC (1978) Slow viruses and human disease. Perspect Virol 10:161198

Gibson W, Roizman B (1971) Compartmentalization of spermine and spermidine in herpes simplex virions. Proc Natl Acad Sci USA 68:2818-2821

Gibson W, Roizman R (1974) Proteins specified by herpes simplex virus. X. Staining and radiolabeling properties of B capsid and virion proteins in polyacrylamide gels. J Virol 13:155-165

Gillespie D, Marshall S, Gallo RC (1972) RNA of RNA tumor viruses contains poly A. Nature New Biol 236:227-231

Gimenez HB, Pringle CR (1978) Seven complementation groups of respiratory syncytial virus temperature-sensitive mutants. J Virol 27:459-464

Ginsberg HS, Young CSH (1977) Genetic of adenovirus. In: Comprehensive virology, vol 9. Plenum, New York, pp 27-88

Gissman C, Pfister H, Zur Hausen H (1977) Human papilloma viruses (HPV): characteristics of four different isolates. Virology 76:569-580

Gissman L, Zur Hausen H (1976) Human papilloma virus DNA: physical mapping and genetic heterogeneity. Proc Natl Acad Sci USA 73:1310-1313

Given D, Kieff ED (1978) DNA of Epstein-Barr virus. IV. Linkage map of restriction enzyme fragments of the B95-8 and W91 strains of EBV. J Virol 28:524-542

Given D, Kieff E (1979) DNA of Epstein-Barr virus. VI. Mapping of the internal tandem reiteration. J Virol 31:315-324

Glazier K, Raglow R, Kingsbury DW (1977) Regulation of sendai virus transcription: evidence for a single promoter in vivo. J Virol 21:863-871

Gold P, Dales S (1968) Localization of nucleotide phosphohydrolase activity within vaccinia. Proc Natl Acad Sci USA 60:845-852

Goldschmidt H, Klingman AM (1958) Experimental inoculation of humans with ectodermotropic viruses. J Invest Dermatol 31:175-182

Golini F, Nomoto A, Wimmer E (1978) The genome-linked protein of picornavirus. IV. Difference in the $\mathrm{VP}_{\mathrm{g}} \mathrm{s}$ of EMC virus and poliovirus as evidence that the genome linked proteins are virus-coded. Virology 89:112-118

Grady LJ, Paoletti E (1977) Molecular complexity of vaccinia DNA and the presence of reiterated sequences in the genome. Virology 337-341

Graessman A, Wolf H, Bornkamm GW (1980) Expression of Epstein-Barr virus genes in different cell types after microinjection of viral DNA. Proc Nat Acad Sci USA 77:433436

Graf T, Boyer-Pokora B, Beng H (1976) In vitro transformation of specific target cells by avian leukemia viruses. ICN-UCLA Symp Mol Cell Biol 4:321-338

Grafstrom RH, Alwine JC, Steinhart WL, Hill CW (1974) Terminal repetitions in herpes simplex virus type 1 DNA. Cold Spring Harbor Symp Quant Biol 39:679-681

Graham FC, Van der Eb AJ (1973) A new technique for the assay of infectivity of human adenovirus. Virology 52:456-462

Graves MX, Silver SM, Choppin PW (1978) Measles virus polypeptide synthesis in infected cells. Virology 86:254-263

Grayston JF, Yang YF, Johnston PB, Ko LS (1964) Epidemic keratonconjunctivitis on Taiwan: etiological and clinical studies. Am J Trop Med 13:497-498

Green M (1970) Oncogenic viruses. Ann New Biol 39:701-739 
Green M, Maskey JK, Wold WSM, Rigden P (1979a) Thirty one human adenovirus serotypes (Ad1-Ad31) from five groups (A-E) based upon genome homologies. Virology 93:481-492

Green M, Wold WSM, Brackmann KH, Lartas MA (1979b) Identification of families of overlapping polypeptides coded by early "transforming" gene region 1 of human adenovirus type 2: Virology 97:275-286

Green M, Wold WS, Mackey JK, Rigden P (1979c) Analysis of human tonsil and cancer DNA, and RNAs for DNA sequences of group C (serotypes 1, 2, 5, \& 6) human adenoviruses. Proc Natl Acad Sci USA 76:6606-6610

Green RH, Balsamo MR, Giles SP, Krugman S, Mirick GS (1965) Studies on the natural history and prevention of rubella. Am J Dis Child 110:348-365

Gregg M (1972) Human disease-USA, In: Venezuelan encephalitis. Proceedings of the Workshop-Symposium on Venezuelan Encephalits Virus. Pan American Health Organization, Washington, DC, p 225

Gross L (1970) Oncogenic viruses. Pergamon, Oxford

Gross PA, Green RH, Cumen MCM (1973) Persistent infection with parainfluenza type 3 virus in man. Am Rev Respir Dis 108:894-898

Guntaka RV, Mahy BWJ, Bishop JM, Varmus HE (1975) Ethidium bromide inhibits appearance of closed circular viral DNA and integration of viral specific DNA in duck cells infected by avian sarcoma virus. Nature 253:507-511

Gutekünst RR, Heggie AD (1961) Viremia and viruria in adenovirus infections: detenction in patients with rubella or rubelliform illnes. N Engl J Med 264:374-378

Halbert DN, Spector DJ, Raskas HJ (1979) In vitro translation product specified by the transforming region of adenovirus type 2. J Virol 31:621-629

Hall WW, Choppin PW (1979) Evidence for lack of synthesis of the M polypeptide of measles virus in brain cells in subacute sclerosing panencephalitis. Virology 99:493

Hall WW, Kiessling W, Ter Meulen V (1978) Membrane proteins of subacute sclerosing panencephalitis and measles viruses. Nature 272:460-462

Hall WW, Lamb RA, Choppin PW (1979) Measles and subacute sclerosing panencephalitis virus proteins: lack of antibodies to the $M$ protein in patients with subacute sclerosing panencephalitis. Proc Natl Acad Sci USA 76:2047-2051

Halstead SB (1970) Observations relating to pathogenesis of dengue hemorrhagic fever. VI. Hypothesis and discussion. Yale J Biol Med 42:350-362

Halstead SB (1979) In vivo enhancement of dengue virus infection in rhesus monkeys by passively transferred antibody. J Infect Dis 140:527-533

Harper L, Bedson HS, Buchan A (1978) Identification of orthopoxviruses by polyacrylamide gel electrophoresis of intracellular polypeptides. 1. Four major groupings. Virology 93:435-444

Harris B, Roeder RG (1978) Structure relationships of low molecular weight viral RNAs synthesized by RNA polymerase III in nuclei from adenovirus 2 -infected cells. J Biol Chem 253:4120-4127

Harris T Jr, Brown F (1977) Biochemical analysis of a virulent and avirulent strain of foot and mouth disease virus. J Gen Virol 34:75-105

Harter ML, Lewis JB, Anderson CW (1979) Adenovirus type 2 terminal protein: purification and comparison of tryptic peptides with known adenovirus coded proteins. J Virol $31: 823-835$

Haseltine WA, Maxam AM, Gilbert W (1977) Rous sarcoma virus genome is terminally redundant: the 5' sequence. Proc Natl Acad Sci USA 74:989-993

Hatanaka M, Kakefuda T, Gilden RV, Callan EAD (1971) Cytoplasmic DNA synthesis induced by RNA tumor viruses. Proc Natl Acad Sci USA 18:1844-1847

Hattwick MAW, Weiss TT, Stechshulte J, Baer GM, Gregg MB (1972) Recovery from rabies: a case report. Ann Intern Med 76:931-942

Hay AJ, Lomniczi B, Bellamy AR, Skehel JJ (1977) Transcription of influenza virus genome. Virology 83:337-355

Hayward GS, Jacob RJ, Wadsworth SC, Roizman B (1975) Anatomy of herpes simplex virus DNA: evidence for four populations of molecules that differ in the relative orientations of their long and short components. Proc Natl Acad Sci 72:4243-4247 
Hayward SD, Kieff ED (1976) Epstein-Barr virus specific RNA. I. Analysis of viral RNA in cellular extracts and in the polyribosomal fraction of permissive and non-permissive lymphoblastoid cell lines. J Virol 18:518-525

Hayward SD, Kieff ED (1977) DNA of Epstein-Barr virus. II. Comparison of molecular weights of restriction endonuclease fragments of the DNA of Epstein-Barr virus strains and identification of end fragment of the B95-8 strain. J Virol 23:421-429

Hayward SD, Nogee L, Hayward GS (1980) Organization of repent region within the Epstein-Barr virus DNA molecule. J Virol 33:507-821

Heggie AD, Robbins FC (1969) Natural rubella acquired after birth. Am J Dis Child 118:12-17

Heine JW, Schnaitman CA (1969) Fusion of vesicular stomatitis virus with cytoplasmic membranes of L-cells. J Virol 3:619

Hendley JO, Wenzel RP, Gwaltney JM (1973) Transmission of rhinovirus colds by self-inoculation. N Engl J Med 288:1361-1364

Henle G, Henle W, Diehl V (1968) Relation of Burkitt's tumor-associated herpes type virus to infectious mononucleosis. Proc Natl Acad Sci USA 59:94-101

Henle W, Henle G, Ho HC et al. (1970) Antibodies to Epstein-Barr virus in nasopharyngeal carcinoma, other head, and neck neoplasms and control groups. J Natl Cancer Inst 44:225-231

Heubner RJ (1967) Adenovirus-directed tumor and T antigens. Perspect Virol 5:147-166

Hierholzer JC, Torrence AE, Wright PF (1980) Generalized viral illness caused by an intermediate strain of adenovirus $(21 / \mathrm{H} 21+35)$. J Infect Dis 141:281-288

Hinman AR, Frazer DW, Douglas RG (1975) Outbreak of lymphocytic choriomeningitis virus infection in medical center personnel. Am J Epidemiol 101:103-110

Hoagland RJ (1955) The transmission of infectious mononucleosis. Am J Med Sci 229:262272

Hoagland RJ (1964) The incubation period of infectious mononucleosis 1. Am J Public Health 54:1699-1705

Holmes IH, Ruck BJ, Bishop RF, Davidson GP (1975) Infantile enteritis viruses: morphogenesis and morphology. J Virol 16:937-943

Holmes IH, Rodgers SM, Schnagl RD, Ruck BJ, Gust ID, Bishop RF, Barnes GL (1976) Is lactase the receptor and uncoating enzyme for infantile anteritis (rota) viruses? Lancet $1: 1387-1389$

Honess RW, Roizman B (1974) Regulation of herpes virus macromolecular synthesis 1. Cascade regulation of the synthesis of three groups of viral proteins. J Virol 14:8-19

Horstmann DM (1971) Rubella: the challenge of its control. J Infect Dis 123:640-654

Hruby DE, Roberts WK (1976) Variations in poly A content and biological activity. J Virol 25:413-415

Hruska JF, Clayton DA, Rubenstein JLR, Robinson WS (1977) Structure of the hepatitis B Dane particle DNA before and after the Dane particle DNA polymerase reaction. $J$ Virol 21:666-672

Huang AS, Baltimore D (1970) Defective viral particles and viral disease processes. Nature 226:325-327

Huang AS, Baltimore D (1977) Defective interfering animal viruses. In: Fraenkel-Conrat $\mathrm{H}$, Wagner RR (eds) Comprehensive virology, vol 10, chap 2. Plenum, New York

Huang E-S (1976) Human cytomegalovirus IV: specific inhibitor of virus-induced DNA polymerase activity and viral DNA replication by phosphonoacetate. J Virol 16:15601565

Hughes JV, Johnson TC, Rabinowitz SG, Dal Canto MC (1979) Growth and maturation of a vesicular stomatitis virus temperature-sensitive mutant and its central nervous system isolate. J Virol 29:312-321

Inglot AD, Chudzio T (1972) Incomplete Sindbis virus. In: Melnick HL (ed) Proceedings of the second international congress for virology. Karger, New York

Ishibashi M, Maizel JV (1974) The polypeptides of adenovirus: VI. Early and late glycopeptides. Virology 58:345-361

Jense H, Knauert F, Ehrenfeld E (1978) Two initiation sites for the translation of poliovirus RNA in vitro; comparison of LSC and Mahoney strains. J Virol 28:387-394 
Johnson KM (1975) Status of arenavirus vaccines and their application. Bull WHO 52:729735

Johnson KM (1977) Epidemic hemorrhagic fevers. In: Hoeprich PD (ed) Infectious diseases, 2nd edn. Harper \& Row, Hagerstown, Md, pp 721-725

Joklik WK (1964) Intracellular uncoating of poxvirus DNA. I. The fate of radioactivelylabeled rabbit-pox virus. J Mol Biol 8:263-276

Joklik WK (1974) Reproduction of reoviridae. In: Comprehensive virology, vol 2, Chap 5. Plenum, New York

Joklik WK, Willett HP, Amos DB (eds) (1980a) Zinsser microbiology, 17 th edn. AppletonCentury-Crofts, New York

Joklik WK, Willett HP, Amos DB (eds) (1980 b) Zinsser microbiology, 17 th edn, chap 69. Appleton-Century-Crofts, New York

Jondal M, Klein G (1973) Surface markers on human B and T lymphocytes. II. Presence of Epstein-Barr virus receptors on B lymphocytes. J Exp Med 138:1365-1378

Jones KW, Kinross J, Maitland N, Norval M (1979) Normal human tissues contain RNA and antigens related to adenovirus type 2. Nature 277:274-279

Jou WM, Verhoeyen M, Devos R et al. (1980) Complete structure of the hemagglutinin gene from the human influenza $\mathrm{A} / \mathrm{Victoria} / 3 / 75(\mathrm{H} 3 \mathrm{~N} 2)$ strain as determined from cloned DNA. Cell 19:683-696

Juel-Jensen BE, MacCallum FO (1972) Herpes simplex, varicella and zoster: clinical manifestation and treatment. Lippincott, Philadelphia

Kääriainen L, Soderlund H (1971) Properties of Semliki Forest virus nucleocapsid. 1. Sensitivity to pancreatic ribonuclease. Virology 43:291-310

Kalica AH, Sereno MM, Wyatt RG, Mebus CA, Chanock RM, Kapikian AZ (1978) Comparison of human and animal rotavirus strains by gel electrophoresis of viral RNA. Virology 87:247-255

Kang CY, Allen R (1978) Host function-dependent induction of defective interferring particles of vesicular stomatitis virus. J Virol 25:202-206

Kapikian AZ (1969) Coronavirus. In: Diagnostic procedures for viral and rickettsial infection, chap 27. American Public Health Association, pp 941-946

Kapikian AZ, Kim HW, Wyatt RG et al. (1974) Reovirus-like agent in stools: association with infantile diarrhea and development of serological tests. Science 185:1049-1053

Kapikian AZ, Cline WL, Kim HW et al. (1976) Antigenic relationships among five reoviruslike (RVL) agents by complement fixation (CF) and development of new substitute (CF) antigens for the human RVL agents of gastroenteritis. Proc Soc Exp Biol Med 152:535539

Kaschka-Dierich C, Adams A, Lindahl R et al. (1976) Intracellular forms of Epstein-Barr virus DNA in human tumor cells in vivo. Nature 260:302-306

Kawai A (1977) Transcriptase activity associated with rabies virions. J Virol 29:826-835

Keene JD, Shubert M, Lazzarini RA (1980) Intervening sequence between the leader region and the nucleocapsid gene of vesicular stomatitis virus RNA. J Virol 33:789-794

Keir HM, Gold E (1963) Deoxyribonucleic acid nucleotidyl transferase and deoxyribonuclease from cultured cells infected with herpes simplex virus. Biochim Biophys Acta 72:263-276

Kendall AP (1975) A comparison of "influenza C" with prototype myxoviruses: receptor destroying activity (neuraminidase) and structural polypeptides. Virology 65:87-99

Kennedy DA, Johnson-Lussenburg CM (1978) Inhibition of coronavirus 229E replication by actinomycin D. J Virol 29:401-404

Kew OM, Pallansch MA, Omilianowski DR, Reukert RR (1980) Changes in three of the four coat proteins of oral polio vaccine strain derived from type 1 poliovirus. J Virol 33:256-263

Kieff ED, Bachenheimer SL, Roizman B (1971) Size, composition, and structure of the deoxyribonucleic acid of subtypes 1 and 2 herpes simplex virus. J Virol 8:125-132

Kilbourne ED (1968) Recombination of influenza A viruses of human and animal origin. Science 160:74-75

Kolakofsky D, Brutschi A (1975) Antigenomes in Sendai virions and Sendai virusinfected cells. Virology 66:185-191 
Kolakosky D, Boy de la Tour E, Delius H (1975) Molecular weight determinations of parainfluenza virus RNA. In: Mahy BWJ, Barry RD (eds) Negative stand viruses, vol 1. Academic Press, London, pp 243-251

Kozak M, Roizman B (1974) RNA synthesis in cells infected with herpes simplex virus IX. Evidence for accumulation of abundant symmetric transcripts in nuclei. J Virol 15:3640

Koziorowska J, Wlodarski K, Mazurowa N (1971) Transformation of mouse embryo cells by vaccinia virus. J Natl Cancer Inst $26: 225$

Kress S, Schluederberg AE, Horrick RB, Morse LJ, Cole JL, Slater EA, McCrumb FR (1961) Studies with live attenuated measles vaccine II. Clinical and immunological response of children in an open community. Am J Dis Child

Krugman S, Giles JP (1973) Viral hepatitis type B (MS-2 strain). Further observations on natural history and prevention. N Engl J Med 288:755-760

Krugman S, Giles JP, Hammond J, (1967) Infectious hepatitis: evidence for two distinct clinical, epidemiological, and immunological types of infection. JAMA 200:365

La Colla P, Weissbach A (1975) Vaccinia virus infection of HeLa cells. I. Synthesis of vaccinia DNA in host cell nuclei. J Virol 15:305-315

Lai MMC, Duesberg PH (1972) Adenylic acid-rich sequence in RNAs of Rous sarcoma virus and Rauscher mouse leukemia virus. Nature 235:383-386

Lai MC, Stohlman SA (1978) RNA of mouse hepatitis virus. J Virol 26:236-242

Lamb RA, Choppin PW (1979) Segment of the influenza virus genome is unique in coding for two polypeptides. Proc Natl Acad Sci USA 76:4908-4912

Lavail JH, Lavail MM (1972) Retrograde axonal transport in the central nervous system. Science 176:146-147

Laver WG (1970) Isolation of an arginine-rich protein from particles of adenovirus type 2. Virology 41:488-496

Laver WG, Downie JL (1976) Influenza virus recombination. I. Matrix protein markers and segregation during mixed infections. Virology 70:105-117

Laver WG, Webster RG (1973) Studies on the origin of pandemic influenza. III. Evidence implicating duck and equine influenza viruses as possible progenitors of the Hong Kong strain of human influenza. Virology 51:383-391

Laver WG, Webster RG (1979) Ecology of influenza viruses in lower mammals and birds. Br Med Bull 35:29-33

Lee YF, Nomoto A, Detjen BM, Wimmer E (1977) A protein covalently linked to the poliovirus genome RNA. Proc Natl Acad Sci USA 74:59-63

Leifer E, Gocke DJ, Bourne H (1970) Lassa fever, a new virus disease of man from West Africa. II. Report of a laboratory-acquired infection treated with plasma from a person recently recovered from the disease. Am J Trop Med Hyg 19:677-679

Lemon SM, Hutt LM, Shaw JE, Li J-LH, Pagano JS (1977) Replication of EBV in epithelial cells during infectious mononucleosis. Nature 268:268-270

Lenard J, Compans RW (1975) Polypeptide composition of incomplete influenza virus grown in MDBK cells. Virology 65:418-426

Levine AJ, Ginsberg HS (1967) Mechanism by which fiber antigen inhibits multiplication of type 5 adenovirus. J Virol 1:747

Levinson AD, Opperman H, Levintow L, Varmus HE, Bishop JM (1978) Evidence that the transforming gene of avian sarcoma virus encodes a protein kinase associated with a phosphoprotein. Cell 15:561-572

Lewis JB, Atkins J, Baum PR, Solem R, Gesteland R, Anderson CW (1976) Location and identification of the genes for adenovirus type 2 early polypeptides. Cell 7:141-151

Lindahl T, Adams A, Bjursell G, Bornkamm GW, Kaschka-Dierich C, Jehn U (1976) Covalently closed circular duplex DNA of Epstein-Barr virus in a human lymphoid cell line. J Mol Biol 102:511-530

Lodmell DL, Niwa A, Hayashi K, Notkins A (1973) Prevention of cell-to-cell spread of herpes simplex virus by leukocytes. J Exp Med 137:706-720

Lomniczi B, Kennedy L (1977) Genome of infectious bronchitis virus. J Virol 24:99-107

Lonsdale DM, Brown SM, Subak-Sharpe JH, Warren KG, Koprowski H (1979) The polypeptide and DNA restriction enzyme profiles of spontaneous isolates of HSV-1 from explants of human trigemial superior cervical and vagus ganglia. J Gen Virol 43:151-171 
Lucas A, Coulter M, Anderson R, Dales S, Flintoff W (1978) In vivo and in vitro modes of demyelinating diseases. II. Persistence and host-regulated thermosensitivity in cells of neural derivation infected with mouse hepatitis and measles virus. Virology 88:325337

Mackenzie RB (1965) Epidemiology of Machupo virus infection. I. Patterns of human infection, San Joaqu $\gtrsim$, Bolivia, 1962-1964. Am J Trop Med Hyg 14:808-813

Macnab JCM (1974) Transformation of rat embryo cells by temperature sensitive mutants of HSV. J Gen Virol 24:143-153

MacNaughton MR, Madge MH (1977) The characterization of the virion RNA of avian infectious bronchitis virus. FEBS Lett 77:311-313

Madeley CR (1978) Virus morphology. Churchill Livingstone, Edinburgh London

Maizel JV, White DD, Scharff MD (1968) The polypeptides of adenovirus: evidence for multiple protein components in the virion and a comparison of types $2,7 \mathrm{~A}, \& 12$. Virology 36:115-125

Mak I, Ezoe U, Mak S (1979) Structure and function of adenovirus type 12 defective virions. J Virol 32:240-250

Mak S (1971) Defective virions in human adenovirus type 12. J Virol 7:426-433

Malluci L (1965) Observations on the growth of mouse hepatitis virus (MHV-3) in mouse macrophages. Virology 25:30-37

Mandell GL, Douglas RG, Bennett JE (1979) Lymphocytic choriomeningitis virus, Lassa virus, and the Tacarihe group of virus. In: Fraser DW (ed) Principles and practice of infectious disease. John Wiley and Sons, New York, pp 1231-1239

Marchette HJ, Halstead SB, O'Rourke T, Scott R, Bancroft WH, Vanapruks V (1979) Effect of immune status on Dengue 2 virus replication in cultured leukocytes from infants and children. Infact Immun 24:47-50

Marion PL, Salazar FH, Alexander JJ, Robinson WS (1980) State of hepatitis B viral DNA in a human hepatoma cell line. J Virol 38:795-806

Markey JK, Word WSM, Rigden P, Green M (1979) Transforming region of group A, B, $\& \mathrm{C}$ adenoviruses: DNA hemology studies with twenty-nine human adenovirus serotypes. J Virol 29:1056-1064

Marsden HS, Stow ND, Preston VG, Timbury MC, Wilkie NM (1978) Physical mapping of herpes simplex virus-induced polypeptides. J Virol 28:624-642

Martin JD, Frisque RJ, Padgett BL, Walker DL (1979) Restriction endonuclease cleavage map of the DNA of JC virus. J Virol 29:846-855

Marx PA, Porter A, Kingsbury DW (1974) Sendai virion transcriptase complex: polypeptide composition and inhibition by virion envelope proteins. J Virol 13:107-112

Matsumo S, Inouye S, Kono R (1977) Plaque assay of neonatal calf diarrhoea virus and the neutralizing antibody in human sera. J Clin Microbiol 5:1-4

McGeoch DJ, Kitron N (1975) Influenza virion RNA-dependent RNA polymerase: stimulation by guanosine and related compounds. J Virol 15:686

McGeoch DJ, Fellner P, Newton C (1976) Influenza virus genome consists of eight distinct RNA species. Proc Natl Acad Sci USA 73:3045-3049

McIntosh K (1974) Coronaviruses: a comparative review. Curr Top Microbiol Immunol 63:85-129

McIntosh K (1979) Coronaviruses. In: Principles and practice of infectious disease, part 3, chap 103. John Wiley and Sons, New York, pp 1212-1217

McNulty MS (1978) Review article: rotaviruses. J Gen Virol 40:1-18

McNulty MS, Allan GM, Pearson GR, McFerran JB, Curran WL, McCraken RM (1976) Reovirus-like agent (rotavirus) from lambs. Infect Immun 14:1332-1338

Mebus CA, Wyatt RG, Sharpee RL, Sereno MM, Kalica AR, Kapikian AZ, Twiehaus MJ (1976) Diarrhoea in gnotobiotic calves caused by the reoviruslike agent of human infantile gastroenteritis. Infect Immun 14:471-474

Mebus CA, Wyatt RG, Kapikian AZ (1977) Intestinal lesions induced in gnotobiotic calves by the virus of human infantile gastroenteritis. Vet Pathol 14:273-282

Mebus CA, Underdahl NR, Rhodes MB, Twiehaus MJ (1969) Calf diarrhoea (scours): reproduced with a virus from a field outbreak. Univ Nebraska Agric Exp Stat Res Bull 233 
Mellon P, Duesberg PH (1977) Subgenomic, cellular Rous sarcoma virus RNAs contain oligonucleotides from the $3^{\prime}$ half and the $5^{\prime}$ terminus of virion RNA. Nature 270:631-634

Melnick JL (1976) Enteroviruses. In: Evans AS (ed) Viral infection of humans. Plenum, New York

Mettler NE, Petrelli RI, Casals J (1968) Absence of cross-reactions between rubella virus and arbovirus. Virology 36:503-504

Meyer HM, Hilleman MR, Miesse ML, Crawford IP, Bankhead AS (1957) A new antigenic variant in Far East influenza epidemic, 1957. Proc Soc Exp Biol Med 95:609-616

Meyer J, Lundquist RE, Maizel JV Jr (1978) Structural studies of the RNA component of the poliovirus replication complex: II. Characterization by electron microscopy and autoradiography. Virology 85:445-455

Middleton PJ, Holdaway MD, Petric M, Szymanski MT, Tarn JS (1977) Solidphase radioimmunoassay for the detection of rotavirus. Infect Immun 16:439-446

Miller DA, Miller OJ, Vaithilingham GD, Hashmi S, Tantrauahi R, Medrano L, Green H (1974) Human chromosome 19 carries a poliovirus receptor gene. Cell 1:167-173

Millison GC, Hunter GD, Kimberlin RH (1976) Slow virus disease of animals and man. Front Biol 44:243-264

Mims CA (1976) The pathogenesis of influenza. In: Selby P (ed) Influenza virus vaccines and strategy. Proceedings of a working group on pandemic influenza, Rougernent, 2628 January 1976. Academic Press, London, pp 95-105

Mims CA, Subrahmanyan TP (1966) Immunoflourescence study of the mechanism of resistance to superinfection in mice carrying the lymphocytic choriomeningitis virus. J Pathol Bacteriol 91:403-415

Modlin JF, Brandling-Bennett AD (1974) Surveillance of the congenital rubella syndrome 1969-1973. J Infect Dis 130:316-318

Monath TP (1975) Lassa fever: review of epidemiology and epizootiology. Bull WHO 52:577-592

Monath TP (1979) Flavivirus (St. Louis encephalitis and dengue). In: Mandell G, Douglas RG, Bennett JE (eds) Principles and practice of infectious disease. John Wiley and Sons, New York, p 1248

Monath TP, Casals J (1975) Diagnosis of Lassa fever and the isolation and management of patients. Bull WHO 52:707

Monto AS (1974) Medical reviews, coronavirus. Yale J Biol Med 47:234

Monto AS (1976) Coronaviruses. In: Evans AS (ed) Viral infections of humans. Plenum, New York

Monto AS, Lim SK (1974) The Tecumseh study of respiratory illness. VI. Frequency of and relationship between outbreaks of coronavirus infection. J Infect Dis 129:271-276

Mocarski ES, Stinski MF (1979) Persistance of the cytomegalovirus genome in human cells. J Virol 31:761-775

Morse LS, Pereira L, Roizman B, Schaffer PA (1978) Anatomy of herpes simplex virus (HSV) DNA. X. Mapping of viral genes by analysis of polypeptides and functions specified by HSV1 X HSV2 recombinants. J Virol 26:389-410

Moss B (1974) Reproduction of poxviruses. In: Frankael-Conrat H, Wagner RR (eds) Comprehensive virology, vol 3. Plenum, New York, pp 405-474

Moss B, Gershowitz A, Wei CM, Boone R (1976) Formation of the guanylated and methylated 5'-terminus of vaccinia virus mRNA. Virology 72:341-351

Munyon W, Kraiselbund E, Davies D, Mann J (1971) Transfer of thymidine kinase to thymidine kinase-less cells by infection with ultraviolet-inactivated herpes simplex virus. $J$ Virol 1:813-820

Murphy BL, Maynard JE, Bradley DW, Ebert JW, Mathiesen LR, Purcell RH (1978) Immunofluorescence of hepatitis A virus antigen in chimpanzies. Infect Immun 21:663-665

Murphy FA, Whitfield SG (1975) Morphology and morphogenesis of arenaviruses. Bull WHO 52:409-419

Murphy FA, Whitfield SG, Coleman PH et al. (1968) California group arboviruses: electron microscopic studies. Exp Mol Pathol 9:44-56

Murphy FA, Harrison AK, Whitfield SG (1973) Bunyaviridae: morphologic and morphogenetic similarities of Bunyamwera serologic supergroup viruses and several other arthropod-borne viruses. Intervirology 1:297-316 
Murray V, Holliday R (1979) Mechanism for RNA splicing of gene transcripts. FEBS Lett 106:5-7

Nahmias AJ, Roizman B (1973) Infection with herpes simplex virus 1 \& 2. N Engl J Med 289:667-674, 719-726, 781-789

Nahmias AJ, Shore SL, Kohl S, Starr SE, Ashman RB (1976) Immunology of herpes simplex virus infections. Cancer Res 36:836-844

Nakajima K, Ueda M, Sugiura A (1979) Origin of small RNA in Von Magnus particles of influenza virus. J Virol 29:1142-1148

Nayak DP, Tobita K, Jander JM, Davis AR, De BK (1978) Homologous interference mediated by defective interfering influenza virus derived from a temperature-sensitive mutant of influenza virus. J Virol 28:375-386

Nevins JR, Darnell JE Jr (1978) Steps in the processing of Ad2 mRNA: poly (A) + nuclear sequences are conserved and poly (A) addition precedes splicing. Cell 15:1477-1493

Nevins JR, Winkler JJ (1980) Regulation of early adenovirus transcription: a protein product of early region 2 specifically represses region 4 transcription. Proc Natl Acad Sci USA 77:1893-1897

Nevins JR, Ginsberg HS, Blanchard JM, Wilson MC, Darnell JE (1979) Regulation of the primary expression of the early adenovirus transcription units. J Virol 32:727-733

Newman JFE, Rowlands DJ, Brown F (1973) A physico-chemical subgrouping of the mammalian picornaviruses. J Gen Virol 18:171-180

Nichols JL, Bellamy AR, Joklik WK (1973) Identification of the nucleotide sequences of the oligonucleotides present in reovirions. Virology 49:562-572

Niederman JC, McCollum RW, Henle G, Henle W (1968) Infectious mononucleosis: clinical manifestation in relation to EB virus antibodies. JAMA 203:205-209

Nishoka Y, Silverstein S (1977) Degradation of cellular mRNA during infection by herpes simplex virus. Proc Natl Acad Sci USA 74:2370-2374

Niveleau A, Wild TF (1979) In vitro transcription of measles virus-induced RNA. Virology 96:295-298

Nomoto A, Detjen B, Pozzatti R, Wimmer E (1977) The location of the polio genome protein in viral RNAs and its implication for RNA synthesis. Nature 268:208-213

Nonoyama M, Pagano JS (1973) Homology between Epstein-Barr virus DNA and viral DNA from Burkitt's lymphoma and nasopharyngeal carcinoma determined by DNADNA reassociation kinetics. Nature 242:44-47

Norby E (1962) Hemagglutination of measles virus. II. Properties of the hemagglutinin and of the receptors on the erythrocytes. Arch Gesamte Virusforsch 12:164-169

Norby E, Gollmar Y (1975) Identification of measles virus-specific hemolysisinhibiting antibodies separate from hemagglutination-inhibiting antibodies. Infect Immun 11:231239

Obijeski JF, Bishop DHL, Murphy FA, Palmer EL (1976a) Structural proteins of La Crosse virus. J Virol 19:985-997

Obijeski JF, Bishop DHL, Palmer EL, Murphy FA (1976b) Segmented genome and nucleocapsid of La Crosse virus. J Virol 20:664-675

O'Callaghan DJ, Randall CC (1976) Molecular anatomy of herpesviruses: recent studies. Prog Med Virol 22:152-210

Onodera R, Jenson AB, Won Yoon J, Notkins AL (1978) Virus-induced diabetes mellitus: reovirus infection of pancreatic $\beta$ cells in mice. Science 201:529-531

O'Rear JJ, Mizutani S, Hoffman G, Fiandt M, Temin HM (1980) Infectious and non-infectious recombinant clones of the provirus of SNV differ in cellular DNA and are apparently the same in viral DNA. Cell 20:423-430

Orellana T, Kieff E Epstein-Barr virus specific RNA. II. Analysis of polyadenylated viral RNA in restringent, abortive, and productive infections. J Virol 22:321-330

Padgett BL, Zu Rhein GM, Walker DL, Eckroade RJ, Dessel BH (1971) Cultivation of papova-like virus from human brain with progressive multifocal leukoencephalopathy. Lancet 1:1257-1260

Pagano JS (1975) Latency and cellular transformation. J Infect Dis 132:209-223

Palese P, Ritchey MB (1977) Live attenuated influenza virus vaccines: strains with temperature-sensitive defects in P3 protein and neuraminidase. Virology 78:183-191 
Palese P, Shulman JL (1976) Differences of RNA patterns of influenza A virus. J Virol 17:876-884

Palese P, Tobita K, Ueda M, Compans RW (1974) Characterization of temperaturesensitive influenza virus mutants defective in neuraminidase. Virology 61:397-410

Palese P, Schulman JL, Ritchey MD (1978) Influenza virus genes: characterisation and biologic activity. Perspect Virol 10:57-71

Palmenberg AC, Pallansch MA, Reuckert RR (1979) Protease required for processing picornaviral core protein resides in the viral replicase gene. J Virol 32:770-779

Panem S, Prochonik EV, Reale FR, Kirsten WH (1975) Isolation of type C virions from a normal human fibroblast strain. Science 189:297-299

Paoletti E, Grady LJ (1977) Transcriptional complexity of vaccinia virus in vivo and in vitro. J Virol 23:608-615

Paoletti E, Lipinskas BR, Paricali D (1980) Capped and adenylated low-molecular weight RNA synthesized by vaccinia virus in vitro. J Virol 33:208-219

Parry HH (1960) Scrapie: a transmissible hereditary disease of sheep. Nature 185:441-443

Pasek M, Goto T, Gilbert W et al. (1979) Hepatitis B virus genes and their expression in E. coli. Nature 282:575-579

Pattison IH, Hoan WN, Jebbet JN, Watson WA (1977) Spread of scrapie to sheep and goats by oral dosing with fetal membranes from scrapie-affected sheep. Vet Rec 90:465-468

Payne L (1979) Identification of the vaccinia hemagglutinin polypeptide from a cell system yielding large amounts of extracellular enveloped virus. J Virol 31:147-155

Payne L, Kristensson K (1979) Mechanism of vaccinia virus release and its specific inhibition by $\mathrm{N}_{1}$-Isoicotinoyl- $\mathrm{N}_{2}$-3-Methyl-4-chlorobenzoylhydrazine. J Virol 32:614-622

Pearson GR, Orr TW (1976) Antibody-dependent lymphocyte cytotoxicity against cells expressing Epstein-Barr virus antigens. J Natl Cancer Inst 56:485-488

Pennington TH, Follett EAC (1974) Vaccinia virus replication in BSC-I cells: particle production and synthesis of viral DNA and proteins. J Virol 13:488-493

Penttinen K, Cantell K, Soner P, Poikolainen A (1968) Mumps vaccine in the Finnish defense forces. Am J Epidemiol 88:234-299

Pereira HG, Wrigley NG (1974) In vitro reconstruction, hexon bonding, and handedeness of incomplete adenovirus capsid. J Mol Biol 85:617-631

Perez-Bercoff R (1979) Molecular biology of the picornaviruses. Plenum, New York

Perrault J, Leavitt RW (1977) Inverted complementary terminal sequences in singlestranded RNAs and snap-back RNAs from vesicular stomatitis defective interferring particles. J Gen Virol 38:35-50

Petri T, Meier-Ewert T, Crumpton T, Dimmock NJ (1979) RNA of influenza C virus strains. Arch Virol 61:239-243

Pettersson RF, Hewlett MJ, Baltimore D, Coffin JM (1977) The genome of Uukuniemi virus consists of three unique RNA segments. Cell 11:51-63

Pfefferkorn ER (1977) Genetics of togaviruses. In: Fraenkel-Conrat H, Wagner R (eds) Comprehensive virology, vol 9. Plenum, New York, pp 209-238

Pfefferkorn ER, Shapiro D (1974) Reproduction of togaviruses. In: Fraenkel-Conrat H, Wagner RR (eds) Comprehensive virology, vol 2. Plenum, New York, pp 171-230

Philip RN, Reinhard KR, Lackman DB (1959) Observations on a mumps epidemic in a "virgin" population. Am J Hyg 69:91-111

Pierce WE, Rosenbaum MJ, Edwards EA, Perkinpaugh RO, Jackson GG (1968) Outbreak of febrile pharyngitis and conjunctivitis associated with type 3 adenoidal-pharyngealconjunctival virus infection. Am J Epidemiol 87:237-246

Pons MW (1976) A re-examination of influenza single- and double-stranded RNAs by gel electrophoresis. Virology 69:789-792

Pons MW, Rochovansky OM (1979) Ultraviolet inactivation of influenza virus RNA in vitro and in vivo. Virology 97:183-189

Porter DD, Porter HG, Cox NA (1973) Failure to demonstrate a humoral immune response to scrapie infection in mice. J Immunol 111:1407-1410

Porter A, Marx PA, Kingsbury DW (1974) Isolation and characterization of Sendai virus temperature sensitive mutants. J Virol 13:298-304 
Porterfield JS, Casals J, Chumakov MP et al. (1976) Bunyaviruses and Bunyaviridae. Intervirology 6:12-24

Powell KL, Purifoy DJM, Courtney RJ (1975) The synthesis of herpes simplex virus proteins in the absence of virus DNA synthesis. Biochem Biophys Res Commun 66:262-271

Purifoy DJM, Powell KL (1977) Non-structural proteins of herpes simplex virus 1. Purification of the induced DNA polymerase. J Virol 24:618-626

Preston CM (1979) Abnormal properties of an immediate early polypeptide in cells infected with herpes simplex virus type 1 mutant $t s \mathrm{~K}$. J Virol 32:357-369

Preston VG, Davison AJ, Marsden HS, Timbury MC, Subak-Sharpe JH, Wilkie NM (1978) Recombinants between herpes simplex virus types $1 \& 2$ : analyses of genome structures and expression of immediate early polypeptides. J Virol 28:499-517

Prince AM, Szmuness W, Mann MK et al. (1978) Hepatitis B immune globulin: final report of a controlled multicenter trial of efficacy in prevention of dialysis-associated hepatitis. J Infect Dis 137:131-144

Pringle CR (1977) Genetics of rhabdoviruses. In: Fraenkel-Conrat H, Wagner RR (eds) Comprehensive virology, vol 9. Plenum, New York, p 239

Pritchett RF, Hayward SD, Kieff ED (1975) DNA of Epstein-Barr virus. I. Comparative studies of the DNA of Epstein-Barr virus from HR-1 and B95-8 cells: size, structure, and relatedness. J Virol 15:556-569

Purifoy DJM, Purifoy JA, Sagik BP (1968) A mathematical analysis of concomitant virus replication and heat inactivation. J Virol 2:275-280

Purtilo DT (1976) Pathogenesis and phenotypes of an X-linked recessive proliferative syndrome. Lancet 2:882-885

Purtilo DT, De Florio D, Hutt LM, Bhawan J, Yang JPS, Otto R, Edwards W (1977) Variable phenotypic expression of an X-linked recessive lymphoproliferative syndrome. $\mathrm{N}$ Engl J Med 297:1077-1081

Rabinowitz SG, Dal Canto MC, Johnson TC (1976) Comparison of central nervous system disease produced by wild-type and temperature-sensitive mutants of vesicular stomatitis virus. Infect Immun 13:1242-1249

Racaniello VR, Palese P (1979) Influenza B virus genome: assignment of viral polypeptides to RNA segments. J Virol 29:361

Ramos BA, Courtney RJ, Rawls WE (1972) Structural proteins of Pichinde virus. J Virol 10:661-667

Reed JS, Boyer JL (1979) Viral hepatitis: epidemiologic, serologic, and clinical manifestations. DM 25:1-61

Rekosh DMK, Russell WC, Bellett ADJ, Robinson AJ (1977) Identification of a protein linked to the ends of adenovirus DNA. Cell 11:283-295

Rhodes AJ, Van Rooyen CE (1968) Textbook of virology, 5 th edn, chap 3, sect 6. Williams \& Wilkins, Baltimore

Richards JC, Hyman RW, Rapp F (1979) Analysis of DNAs from seven varicellazoster virus isolates. J Virol 32:812-821

Ritchey MB, Palese P (1977) Identification of the defective gene in three mutant groups of influenza virus. J Virol 21:1196-1204

Roa RC, Bose SK (1974) Inhibition by ethidium bromide of the establishment of infection by murine sarcoma virus. J Gen Virol 25:197-205

Rodger SM, Schnagl RD, Holmes IH (1977) Further biochemical characterization including the detection of surface glycoproteins of human, calf and Simian rota viruses. J Virol 29:91-98

Roizman B (1979) The organization of the herpes simplex virus genomes. Annu Rev Genet $13: 25-57$

Roizman B, Kieff ED (1974) Herpes simplex and Epstein-Barr viruses in human cells and tissues: a study in contrasts. In: Becker FF (ed) Cancer: a comprehensive treatise. Plenum, New York

Roizman B, Hayward G, Jacob R, Wadsworth S, Frenkel N, Honess RW, Kozak M (1975) Human herpesviruses. I. A model for molecular organization and regulation of herpesviruses - a review. IARC Sci Publ 2:3-38

Rosenberg N, Baltimore D (1976) In vitro lymphoid cell transformation by Abelson murine leukemia virus, ICN-UCLA Symp Mol Cell Biol 4:311-320 
Ross J, Tronick SR, Scolnick EM (1972) Polyadenylate-rich RNA in the 7OS RNA of murine leukemia-sarcoma virus. Virology 49:230-235

Rübsamen H, Friis RR, Bauer H (1979) "Src" gene product from different strains of avian sarcoma virus: kinetics and possible mechanisms of heat inactivation of protein kinase activity from cell infected by transformation-defective, temperature-sensitive mutants, and wild-type virus. Proc Natl Acad Sci USA 76:967-971

Reuckert RR (1976) On the structure and morphogenesis of picornaviruses. In: FraenkelConrat H, Wagner RR (eds) Comprehensive virology, vol 6. Plenum, New York, pp 131-213

Reuckert RR, Dunker AK, Stoltzfus CM (1969) The structure of the Maus-Elbertcell virus: a model. Proc Natl Acad Sci USA 62:912-919

Russell PK (1979 a) Alphavirus (Eastern, Western, and Venezuelan equine encephalitis. In: Mandell A, Douglas RA, Bennett JE (eds) Infectious diseases. John Wiley and Sons, New York, pp 1243-1248

Russell PK (1979 b) California encephalitis and other Bunyaviruses. In: Principles and practice of infectious disease, vol 2. John Wiley and Sons, New York, pp 1239-1241

Russell WC, Skehel JJ, Marchado R, Pereira HG (1972) Phosphorylated polypeptides in adenovirus-infected cells. Virology 50:931-934

Rymo L, Forsblum S (1978) Cleavage of Epstein-Barr virus DNA by restriction endonucleases Eco R1, Hind III, Bam. 1. Nucleic Acid Res 5:1387-1402

Sambrook J (1977) The molecular biology of the papovaviruses. In: Nayak P (ed) The molecular biology of animal viruses, vol 2, chap II. Dekker, New York

Sangar DV (1979) Replication of picornaviruses. J Gen Virol 45:1-13

Sangar DV, Rowlands DJ, Cavanagh D, Brown F (1976) Characteristics of the minor polypeptides of foot and mouth disease virus particles. J Gen Virol 31:3 546

Sattler F, Robinson WS (1979) Hepatitis B viral DNA molecules have cohesive ends. J Virol 32:226-233

Sawyer RN, Evans AS, Niederman JC, McCollum RW (1971) Prospective studies of a group of Yale University freshmen. I. Occurrence of infectious mononucleosis. J Infect Dis 123:263-269

Scheid A, Choppin PW (1977) Two disulfide-linked polypeptide chains constitute the active F protein of paramyxoviruses. Virology 80:56-66

Schlesinger MJ, Schlesinger S, Burge BW (1972) Identification of a second glycoprotein in Sindbis virus. Virology 47:539-541

Schlesinger S, Schlesinger MJ, Burge BW (1972) Defective virus particles from Sindbis virus. Virology 48:615-617

Schochetman G, Stevens RH, Simpson RW (1977) Presence of infectious polyadenylated RNA in the coronavirus avian infectious bronchitis virus. Virology 77:771-782

Schooley RT, Dolin R (1979) Epstein-Barr virus (infectious mononucleosis). In: Mandell G, Douglas RG, Bennet JE (eds) Principles and practice of infectious diseases. John Wiley and Sons, New York

Scolnick EM, Rands E, Williams D, Parks WP (1973) Studies on the nucleic acid sequences of Kirsten sarcoma virus: A model for formation of a mammalian RNA-containing sarcoma virus. J Virol 12:458-463

Seeff CB, Wright EZ, Zimmerman HK et al. (1980) Type B hepatitis after needle stick exposure. Prevention with hepatitis B immune globulin. Ann Intern Med 88:220-229

Sefton BM, Hunter T, Beemon K (1980) Temperature-sensitive transformation by Rous sarcoma virus and temperature-sensitive protein kinase activity. J Virol 33:220-229

Spencer DJ, Hull HB, Longview AD (1967) Epidemiological basis for eradication of measles in 1967. Public Health Rep 82:1253-1256

Sharp PA, Moore C, Havarty JL (1976) The infectivity of adenovirus 5 DNA-protein complex. Virology 75:442-456

Shatkin AJ (1974) Methylated messenger RNA synthesis in vitro by purified reovirus. Proc Natl Acad Sci USA 71:3204-3207

Shatkin AJ (1976) Capping of eukaryotic mRNAs. Cell 9:645-653

Shatkin AJ, Banerjee AK, Both GW (1977) Translation of animal virus mRNAs in vitro. In: Comprehensive virology, vol 10, chap 1. Plenum, New York 
Sheldon PJ, Papamichail M, Hemsted EH, Holborrow EJ (1973) Thymic origin of atypical lymphoid cells in infectious mononucleosis. Lancet 1:1153-1155

Sheldrick P, Berthelot N (1974) Inverted repititions in the chromosome of herpes simplex virus. Cold Spring Harbor Symp Quant Biol 39:667-678

Shenk TE, Stollar V (1973 a) Defective interfering particles of Sindbis virus. I. Isolation and some chemical and biological properties. Virology 53:162-173

Shenk TE, Stollar V (1973 b) Defective interfering particles of Sindbis virus. II. Homologous interference. Virology 55:530-534

Shi JWK, Gerin JL (1977) Proteins of hepatitis B surface antigen. J Virol 21:347

Shimotohno K, Mizutani S, Temin H (1980) Sequence of retrovirus provirus resembles that of bacterial transposable elements. Nature 285:550-554

Shiroki K, Shimojo H (1974) Analysis of adenovirus 12 temperature-sensitive mutants defective in viral DNA replication. Virology 61:474-479

Siakotos AN, Gadjusek DC, Gibbs CJ Jr, Traub RD, Bucana C (1976) Partial purification of the scrapie agent from mouse brain by pressure disruption and zonal centrifugation in sucrose-sodium chloride gradients. Virology 70:230-237

Siddiqui A, Sattler F, Robinson WS (1979) Restriction endonuclease cleavage map and location of unique features of the DNA of hepatitis B virus, subtype adw 2 . Proc Natl Acad Sci USA 76:4664-4668

Siegl G, Frosner GG (1978) Characterization and classification of virus particles associated with hepatitis A 11. Type and configuration of nucleic acid. J Virol 26:48-53

Silverstein SC, Dale S (1968) The penetration of reovirus RNA and initiation of its genetic function in L-strain fibroblasts. J Cell Biol 36:197-230

Silverstein SC, Schonberg M, Levin DH, Acs G (1970) The reovirus replicative cycle: conservation of parental RNA and protein. Proc Natl Acad Sci USA 67:275-281

Simons K, Keranen S, Kaariainen L (1973) Identification of a precursor for one of the Semliki Forest virus membrane proteins. FEBS Lett 29:87-91

Simpson RW, Houser RE, Dales S (1969) Viropexis of vesicular stomatitis virus by L cells. Virology 37:285-290

Skehel JJ, Hay AJ (1978) Review article: influenza virus transcription. J Gen Virol 39:1-8

Skehel JJ, Joklik WK (1969) Studies on in vitro transcription of reovirus RNA catalyzed by reovirus cores. Virology 39:822-831

Skup D, Millward M (1980) mRNA capping enzymes are masked in reovirus progeny subviral particles. J Virol 34:490-496

Spear PG (1976) Membrane proteins specified by herpes simplex viruses. 1. Identification of four. J Virol 17:991-1008

Spooner LLR, Barry RD (1977) Participation of DNA-dependent RNA polymerase II in replication of influenza viruses. Nature 268:650-652

Stair EL, Rhodes MB, White RG, Mebus CA (1972) Neonatal calf diarrhea: purification and electron microscopy of a coronavirus-like agent. Am J Vet Res 33:1147-1156

Stallcup K, Wechsler S, Fields B (1979) Purification of measles virus and characterization of subviral components. J Virol 30:166-176

Stanley ED, Jackson GG (1969) Spread of enteric live adenovirus type 4 vaccine in married couples. J Infect Dis 119:51-59

Stannard LM, Schoub BD (1977) Observations on the morphology of two rotaviruses. J Gen Virol 37:435-439

Stanners CP, Goldberg VJ (1975) On the mechanism of neurotropism of vesicular stomatitis virus in newborn hamsters. Studies with temperature sensitive mutants. J Gen Virol 29:281-296

Starr JG, Bart RD, Gold E (1970) Inapparent congenital cytomegalovirus infection: clinical and epidemiological characteristics in early infancy. N Engl J Med 202:1075-1077

Stehelin D, Varmus HE, Bishop JM, Vogt PK (1976) DNA related to transforming genes of avian sarcoma viruses is present in normal avian DNA. Nature 250:170-173

Stern DF, Kennedy SIT (1980) Coronavirus multiplication strategy. I. Identification and characterization of virus-specified RNA. J Virol 34:665-674

Stern H, Tucker SM (1973) Prospective study of cytomegalovirus infection in pregnancy. Br Med J 2:268-270 
Sternbergh PH, Moat J, Van Ormandt H, Sussenbach J (1977) The nucleotide sequence at the termini of adenovirus type 5 DNA. Nucleic Acid Res 4:4371-4389

Stevens JG (1972) Latent herpes simplex virus in sensory ganglia. Perspect Virol 8:171-188

Stevens JG, Cook ML (1971) Latent herpes simplex virus in spinal ganglia of mice. Science 173:843-845

Stinski MF (1977) Synthesis of protein and glycoproteins in cells infected with human cytomegalovirus. J Virol 23:751-767

Stinski MF (1978) Sequence of protein synthesis in cells infected by human cytomegalovirus: early and late virus-induced polypeptides. J Virol 26:686-701

Stinski MF, Mocarski ES, Thomsen DR (1979) DNA of human cytomegalovirus: size heterogeneity and defectiveness resulting from serial undiluted passage. J Virol 31:231239

Stoltzfus CM, Banerjee AK (1972) Two oligonucleotide classes of single-stranded ribopolymers in reovirus A-rich RNA. Arch Biochem Biophys 152:733-743

Stoltzfus CM, Shatkin AJ, Banerjee AK (1973) Absence of polyadenylic acid from reovirus messenger ribonuclei acid. J Biol Chem 248:7993-7998

Straus SE, Aulakh SA, Ruyechan WT, Hay J, Vande Woude GF, Owens J, Smith HA (1981) Structural studies of varicella zoster virus DNA. J Virol

Strode GK (ed) (1951) Yellow fever. McGraw-Hill, New York

Stuart-Harris CH (1965) Influenza and other virus infections of the upper respiratory tract. Williams \& Wilkins, Baltimore, pp 8-21

Stuart-Harris CH (1979) The influenza viruses and the human respiratory tract. Rev Infect Dis 1:592-599

Sturman LS (1977) Characterization of a coronavirus. I. Structural protein: effect of preparative conditions on the migration of protein in polyacrylamide gels. Virology 77:637649

Sturman LS, Holmes KV (1977) Characterization of a coronavirus II. Glycoproteins of the viral envelope: tryptic peptide analysis. Virology 77:650-660

Sturman LS, Holmes KV, Behnke J (1980) Isolation of coronavirus envelope glycoproteins and interaction with the viral nucleocapsid. J Virol 33:449-462

Summers D, Maizel J (1971) Determination of the gene sequence of poliovirus with pactamycin. Proc Natl Acad Sci USA 59:966-971

Summers J, Smolec JM, Snyder R (1978) A virus similar to human hepatitis B virus associated with hepatitis and hepatoma in woodchucks. Proc Natl Acad Sci USA 75:45334537

Surina DWR, Bank JL, Ackerman A (1970) Role of measles in skin lesions and koplik spots. N Engl J Med 283:1139-1142

Sussenbach JS (1967) Early events in the infectious process of adenovirus type 5 in Hela cells. Virology 33:567-576

Swanstrom RI, Wagner EK (1974) Regulation of synthesis of herpes simplex type 1 virus mRNA during productive infection. Virology 60:522-533

Sweet C, Smith H (1980) Pathogenicity of influenza virus. Microbiol Rev 44:303-330

Szmuness W (1978) Hepatocellular carcinoma and the hepatitis B virus: evidence for a casual association. Prog Med Virol 29:40-65

Takahaski K, Akahane T, Gotarda T, Mishiro M, Imai Y, Mitakawa Y, Mayumi M (1979) Demonstration of hepatitis $B_{e}$ antigen in the core of dane particles. J Immunol 122:272279

Takano T, Hatanaka M (1975) Fate of viral RNA of murine leukemia virus after infection. Proc Natl Acad Sci USA 72:343-347

Tanaka S, Ihara S, Watanabe Y (1978) Human cytomegalovirus induces DNA-dependent RNA polymerases in human diploid cells. Virology 89:179-185

Tannock GA (1973) The nucleic acid of infectious bronchitis virus. Arch Gesamte Virusforsch 43:259-271

Temin HM (1964) The participation of DNA in Rous sarcoma virus production. Virology 20:577-582

Temin HM, Mizutani S (1970) RNA-dependent DNA polymerase in virions of Rous sarcoma virus. Nature 226:1211-1213 
Theil WK, Boli EH, Agnes AG (1977) Cell culture propagation of porcine rotavirus (reovirus-like agent). Am J Vet Res 38:1765-1768

Thomas-Powell AL, King W, Kieff E (1979) Epstein-Barr virus specific RNA. III. Mapping of DNA encoding viral RNA in restringent infection. J Virol 29:261-274

Thouless ME, Bryden AS, Flewett TH (1978) Serotypes of human rotavirus. Lancet 1:39

Tibbetts C, Giam C-Z (1979) In vitro association of empty adenovirus capsids with doublestranded DNA. J Virol 32:995-1005

Tighor GH, Shope RE, Gershon RK, Waksman BH (1974) Immunopathologic aspects of infection with Lagos bat virus of the rabies serogroup. J Immunol 112:260-265

Tsipis JE, Bratt MA (1976) Isolation and characterization of temperature sensitive mutants of Newcastle disease virus. J Virol 18:848-855

Thyrrell DAJ, Bynoe ML (1965) Cultivation of a novel type of common cold virus in organ cultures. Br Med J 1:1467-1470

Thyrrell DAJ, Almeida JD, Berry DM et al. (1968 a) Coronaviruses. Nature 220:650

Tyrrell DAJ, Bynoe ML, Hoorn B (1968 b) Cultivation of "difficult" viruses from patients with common colds. Br Med J 1:606-610

Tyrrell DLJ, Norby E (1978) Structural polypeptides of measles virus. J Gen Virol 39:219 229

Van der Vliet PC, Levine AJ (1973) DNA-binding proteins specific for cells infected with adenovirus. Nature New Biol 246:170-174

Ventura AK, Scherer WF (1970) Different effects of deoxycholate, ether, chloroform, hydrocarbons, acid alcohols on Venezuelan encephalitis viral infection, hemagglutination, and complement fixation. Proc Soc Exp Biol Med 133:711-717

Vezza AC, Bishop DHL (1977) Recombination between temperature-sensitive mutants of the arenavirus pichinde. J Virol 24:712-715

Vezza AC, Clewley JP, Gard GP, Abraham NZ, Compans RW, Bishop DHL (1978) Virion RNA species of the arenaviruses Pichinde, Tacaribe, and Tamiami. J Virol 26:485-497

Von Magnus P (1954) Incomplete forms of influenza virus. Adv Virus Res 2:59-78

Wagner EK, Roizman B (1969 a) RNA synthesis in cells infected with herpes simplex virus 11. Evidence that a class of viral mRNA is derived from a high molecular weight precursor synthesized in the nucleus. Proc Natl Acad Sci USA 64:626-633

Wagner EK, Roizman B (1969 b) Ribonucleic acid synthesis in cells infected with herpes simplex virus. J Virol 4:36-46

Wagner MJ, Summers WC (1978) Structure of the joint region of termini of the DNA of herpes simplex virus. J Virol 27:379-387

Walker DL, Padgett BL, Zu Rhein GM, Albert AE, Marsh RF (1973) Human papovavirus (JC): induction of brain tumors in hamsters. Science 181:674-676

Wechsler SL, Rustigian R, Stallcup KC, Byers KB, Winston SH, Fields BN (1979) Measles virus - specified polypeptide synthesis in two persistently infected Hela cell lines. J Virol 31:677-684

Wege H, Müller A, Ter Meulen V (1978) Genomic RNA of murine coronavirus JHM. J Gen Virol 41:217-227

Weiner HL, Drayna D, Averill DR Jr, Fields BN (1977) Molecular basis of reovirus virulence: role of the S1 gene. Proc Natl Acad Sci USA 74:5744-5748

Weiner HL, Ramig RF, Mustoe TA, Fields BN (1978) Identification of the gene coding for the hemagglutinin of reovirus. Virology 86:581-584

Weiner HL, Powers ML, Fields BN (1980) Absolute linkage of virulence and central nervous system cell tropism of reoviruses to viral hemagglutinin. J Infect Dis 141:609-616

Welsh RM, Pfau CJ (1972) Determinants of lymphocytic chiriomeningitis interference. J Gen Virol 14:177-187

Welsh RM, O’Connell CM, Pfau CJ (1972) Properties of defective lymphocytic choriomeningitis virus. J Gen Virol 17:355-359

Wetz K, Habermehl K-O (1979) Topographical studies on poliovirus capsid proteins by chemical modification and non-linking with bifunctional agents. J Gen Virol 44:525534

Wiktor TJ, Koprowski H (1974) Rhabdovirus replication in enucleated host cells. J Virol $14: 300-306$ 
Wiktor TJ, Gyorgy E, Schlumberger DH, Sokol F, Koprowski H (1973) Antigenic properties of rabies virus components. J Immunol 110:269-276

Wilcox WC, Ginsberg H (1963) Production of specific neutralizing antibody with soluble antigens of type 5 adenovirus. Proc Soc Exp Biol Med 114:37-42

Wildy P (1967) The progression of herpes simplex virus to the central nervous system of the mouse. J Hyg (Lond) 65:173-192

Wilhelm J, Brison O, Kedinger C, Chambon P (1976) Characterization of adenovirus type 2 transcription complexes isolated from infected Hela cells nuclei. J Virol 19:61-82

Wilkie NM (1973) The synthesis and substructure of herpesvirus DNA: the distribution of alkali-labile single-strand interruptions in HSV-1 DNA. J Gen Virol 21:453-467

Williams JF, Young CSH, Austin P (1974) Genetic analysis of human adenovirus type 5 in permissive and non-permissive cells. Cold Spring Harbor Symp Quant Biol 39:427

Winnaker EL (1978) Adenovirus DNA: structure and function of a novel replicon. Cell 14:761-773

Wolf H, Zur Hausen H, Becker V (1973) Epstein-Barr viral genomes in epithelial nasopharyngeal carcinoma cells. Nature New Biol 244:245-247

Woodward CG, Smith H (1975) Production of defective interfering virus in the brains of mice by an avirulent, in contrast with a virulent, strain of Semliki Forest virus. Br J Exp Pathol 56:363-372

Woode GN, Bridges JC, Jones JM, Flewett TH, Bryden AS, Davies HA, White GBB (1976) Morphological and antigenic relationships between viruses (rotaviruses) from acute gastroenteritis of children, calves, piglets, mice, and foals. Infect Immun 14:804-810

Wright DH (1972) The pathology of Burkitt's lymphoma. IARC Sci Publ 2

Yamanishi K, Rapp F (1979) Induction of host DNA synthesis and DNA polymerase by DNA negative temperature-sensitive mutants of human cytomegalovirus. Virology 94:237-241

Yanagi K, Talavera A, Nishimoto T, Rush MG (1978) Inhibition of herpes simplex virus type 1 replication in temperature-sensitive cell cycle mutants. J Virol 25:42-50

Yogo Y, Wimmer E (1973) Poly A and poly U in poliovirus double stranded RNA. Nature New Biol 242:171-174

Youngner JS, Dubovi EJ, Quagliana DO, Kelly M, Preble OT (1976) Role of temperaturesensitive mutants in persistent infections initiated with vesicular stomatitis virus. J Virol 19:90-101

Zarbl H, Skup D, Millward S (1980) Reovirus progeny subviral particles synthesize uncapped mRNA. J Virol 34:497-505

Zif EB, Evans RM (1978) Coincidence of the promoter and capped 5'-terminus of RNA from the adenovirus type 2 major late transcription unit. Cell 15:1463-1475

Ziola BR, Scraba DG (1974) Structure of the mengovirion 1. Polypeptide and ribonucleotide component of the virus particle. Virology 57:531-542

Zuckerman AJ (1976) Twenty-five centuries of viral hepatitis. Rush Presbyt St Lukes Med Bull 15:57

Zur Hausen H, Schulte-Holthausen H, Klein G, Henle W, Henle G, Clifford P, Santesson L (1970) Epstein-Barr viral DNA in biopsies of Burkitts tumors and anaplastic carcinomas of the nasopharynx. Nature 228:1056-1058

Zur Hausen H, Gissman L, Pfister H, Steiner W, Ojwang S (1978) Papilloma virus and squamous-cell carcinomas in man. Perspect Virol 10

Zu Rhein GM (1969) Association of papova virions with a human demyelinating disease (Progressive multifocal leukoencephalopathy). Prog Med Virol 11:185-247

Zweerink HJ, McDowell MJ, Joklik WK (1971) Essential and non-essential noncapsid reovirus proteins. Virology 45:716-723

Zweerink HJ, Ito Y, Matsuhisa T (1972) Synthesis of reovirus double-stranded RNA within virus-like particles. Virology 50:349-358 